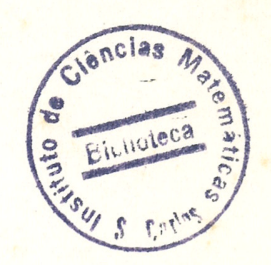

\title{
Subsídios para o Teste de Software Orientado a Objetos: Definição e Mapeamento de Programas C++ para a LI++
}

\author{
Marcelo Morandini
}

Orientador: Prof. Dr. José Carlos Maldonado

Dissertação apresentada ao Instituto de Ciências Matemáticás de São Carlos - USP, como parte dos requisitos para a obtenção do título de Mestre em Ciências - Área de Ciências de Computação e Matemática Computacional.

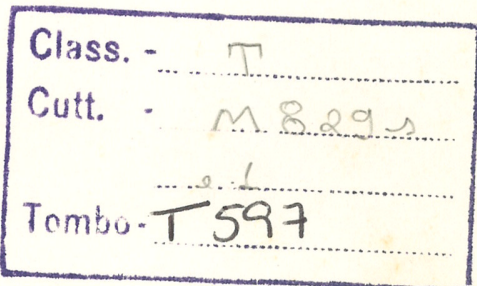




\section{Dedicatória}

À minha mãe Ivete, ao meu pai Arcênio e à Luciana. 


\section{Agradecimentos}

Ao meu orientador, Prof. Dr. José Carlos Maldonado, pela sua dedicação, amizade, bom-senso e profissionalismo demonstrados durante todo este período de convivência, que muito contribuiu para a minha formação acadêmica e que mesmo durante o período em que esteve distante nunca deixou de participar de forma efetiva deste trabalho.

Ao Chaim, que muito por toda ajuda dada, principalmente na definição da LI++e na implementação do mapeamento $\mathrm{C}++$ / LI++, sempre sendo o mais prestativo possível nas mais diversas horas.

Ao Delamaro que muito me ajudou na redação dessa dissertação e ao Plínio pelas contribuições dadas, principalmente em algumas definições da LI++.

Em especial ao Prof. Dr. Mário Jino, pelas relevantes sugestões, que muito contribuiram para a realização desse trabalho.

Ao Prof. Dr. Paulo César Masiero por todo auxílio prestado.

À Profa. Dra. Rosely Sanches pelo valioso incentivo e pelos conselhos oferecidos durante todo esse tempo em que convivemos.

Às demais amigas do Grupo de Testes do ICMSC : Simone (e quem está chegando...), Sandra e Elisa que também me ajudaram com sugestões e dicas bastante aportunas. Ainda, ao pessoal do Grupo de Testes do DCA - FEEC - UNICAMP: Sílvia, Inês, Dino, Adalberto, Paulo e Letícia pela amizade e pelas contribuições.

Às demais amigas do Grupo de Testes do ICMSC, Simone (e quem está chegando...), Sandra e Elisa que também me ajudaram bastante com sugestões e dicas bastante aportunas. Ainda, ao pessoal do Grupo de Testes do DCA - FEEC - UNICAMP: Sílvia, Inês, Dino, Adalberto, Paulo e Letícia pela amizade e pelas contribuições.

À Beth, Laura e Marília pela atenção e dedicação sempre demonstradas.

Ao Jacques e ao pessoal do LDCC, Sônia, Ângelo, Luciano e Rogério pela atenção e colaboração sempre presentes. Ainda, às bibliotecárias: Rose, Silvana, Giselda, Gislene, Sandra e Maria, pela simpatia com que sempre me atenderam. por mim.

Aos amigos de Campinas: Márcio, Dri, Dani e Sílvia que sempre torceram muito 
Ao Jacques e ao pessoal do LDCC, Sônia, Ângelo, Luciano e Rogério, pela atenção e colaboração sempre presentes. Ainda, às bibliotecárias, Rose, Silvana, Giselda, Gislene, Sandra e Maria, pela simpatia com que sempre me atenderam.

À Luciana, que sempre esteve comigo nos principais momentos da minha vida, sendo o meu principal ponto de apoio nas dificuldades e sempre comemorando comigo as nossas conquistas.

Aos meus pais, Arcênio e Ivete, que sempre acreditaram em mim e me deram todo apoio e carinho, principalmente nas horas mais difíceis. Ainda, aos meus irmãos Mateus e Giovana que, mesmo sentindo a minha ausência sempre a entenderam, desde a época da faculdade.

Ao meu sogros, Marcos e Ana, que me acolheram como mais um filho e sempre me incentivaram muito. Também ao Cléber e à Mara que sempre me trataram como um novo irmão, e às tias Tata e Tita, pelo carinho e atenção sempre dispensadas.

Aos amigos da república de São José do Rio Preto, Boy, Ricardo, Davi e Bocaina, pelos bons momentos vividos e pelas conversas que sempre me aguçaram o espírito crítico e científico.

Ao pessoal da república de São Carlos, Coxinha, Betão, Delamaro (de novo!), Mário, Eltão e Pastel (e Elvis), pelo agradável convívio, pelos churrascos, rachas e cervejinhas pós-rachas.

Aos amigos de Rio Preto que também vieram pra São Carlos, Tchelo, Gawa, Prico, Pati, Marcão, Maurão, Marquinhos, Fábio, Rogério e outros, que foram bastante importantes na minha adaptação à nova cidade. Aos novos amigos conquistados em São Carlos, Paulo, Rejane, Lairce, Josmar, Paola, Marisa, Alice, Cláudia, Mineiro, João, Márcio, Flávio, Ana, Fabiano, Shiro, Janaína, Larissa, Sarita, Simone, Auri, Ellen, entre outros, que de algum modo me ajudaram neste trabalho.

Aos amigos de Campinas, Márcio, Dri, Dani e Sílvya, pelos agradáveis momentos vividos.

Ao CNPq pelo apoio financeiro. 


\section{Índice}

CAPÍTULO 1 - INTRODUÇÃ

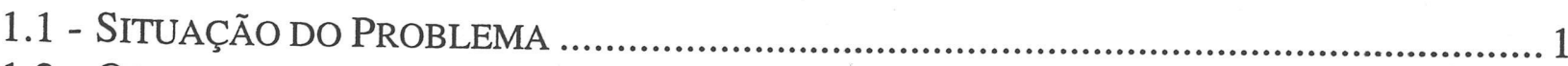

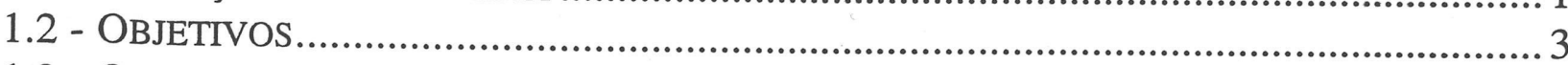

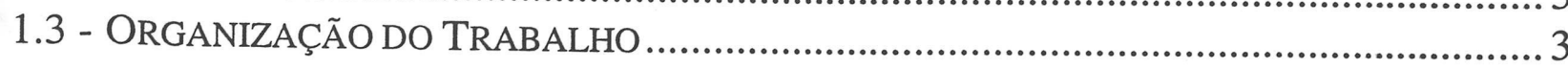

CAPÍTULO 2 - REVISÃO BIBLIOGRÁFICA ............................................................5

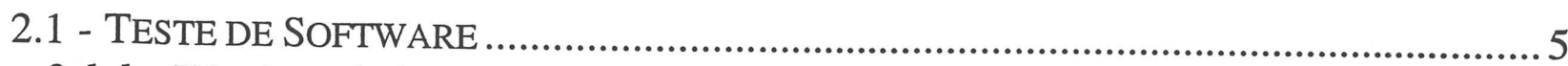

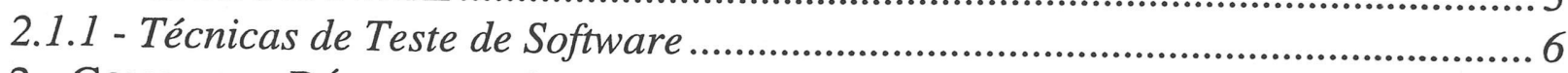

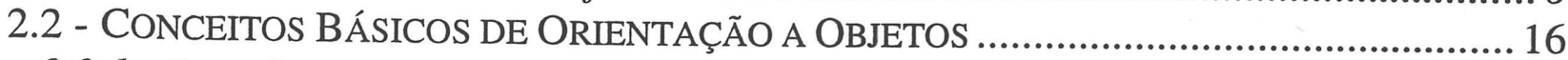

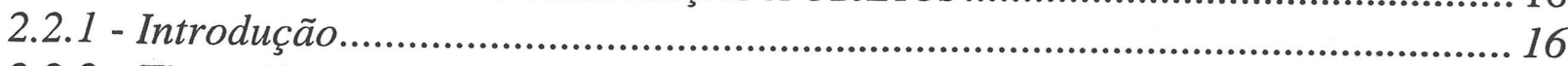

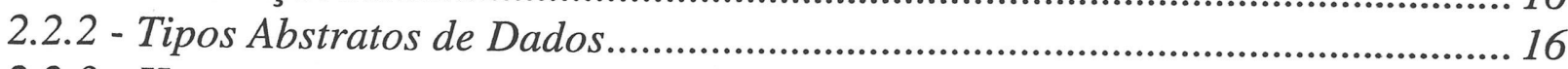

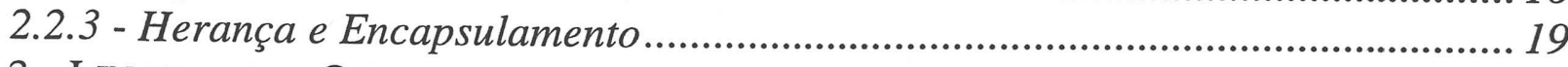

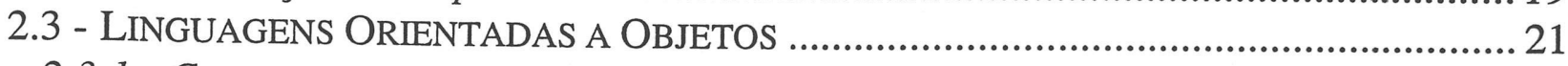

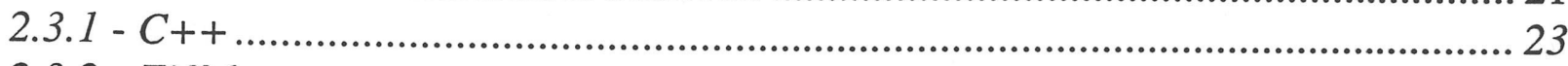

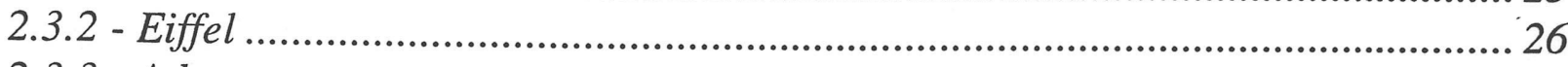

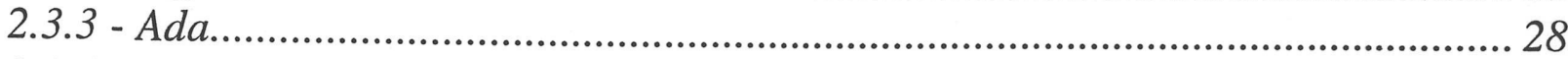

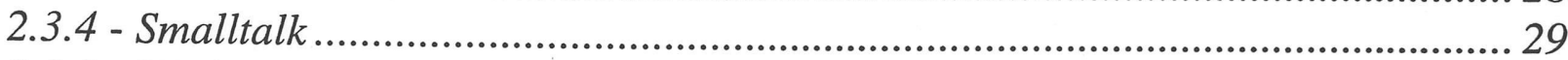

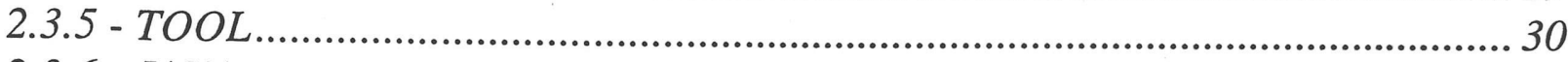

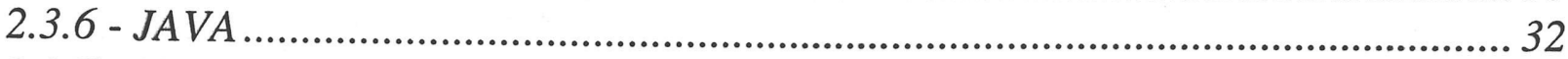

2.3.7 - Uma Comparação entre as Linguagens........................................................... 34

2.4 - OS PROBLEMAS COM O TESTE DE PROGRAMAS ORIENTADOS A OBJETOS ................. 35

2.4.1 - Teste Incremental para Estruturas de Classes ...................................................37

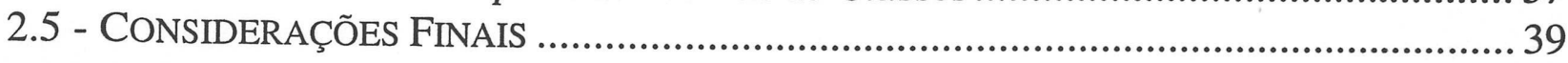

\section{CAPÍTULO 3 - A LINGUAGEM INTERMEDIÁRIA PARA PROGRAMAS}

ORIENTADOS A OBJETOS - LI++......................................................................... 41

3.1 - DEFINIÇÃO DA ESTRUTURAS DA LI++ .................................................................. 42

3.1.1 - O Mapeamento das Definições de Classes..........................................................4 43

3.1.2 - Descrição isolada dos corpos dos métodos...................................................... 45

3.1.3 - Estrutura de um programa LI++....................................................................46

3.2 - COMANDOS C++ E SEUS CORRESPONDENTES NA LI++ .......................................... 47

3.3 - COMANDOS DE OUtRAs LINGUAGENS DE PROGRAMAÇÃo ORIENTADAS A OBJETOS

E SEUS CORRESPONDENTES NA LI++ .......................................................................... 48

3.3 - EXEMPLOS DE MAPEAMENTOS DE TRECHOS DE PROGRAMAS ORIENTADOS A

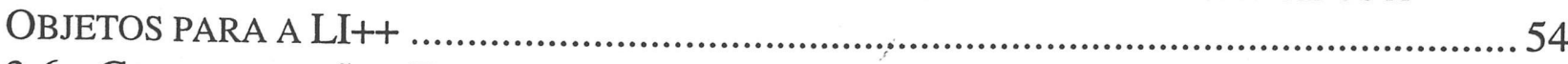

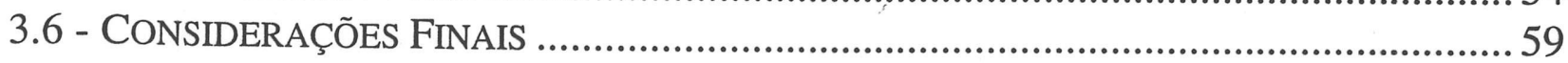

CAPÍTULO 4 - MAPEAMENTO DE LINGUAGENS ORIENTADAS A OBJETOS PARA A LI++ ..........................................................................................................60 60

4.1- Os AlgoritMos UtILIZAdos PARA AS ANÁLISES LÉXICA E SiNTÁTICA....................61 61

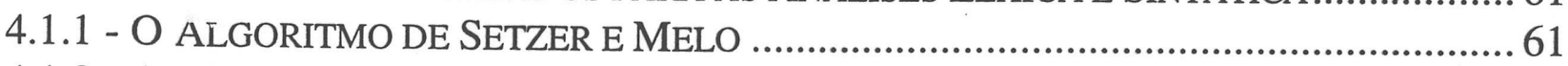

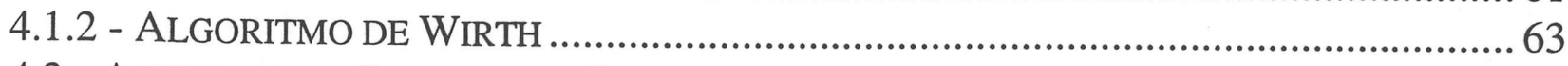

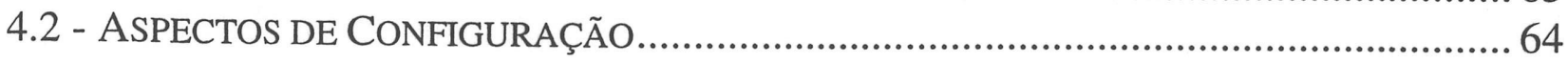


4.3 - ETAPAS DE CONFIGURAÇÃO 64

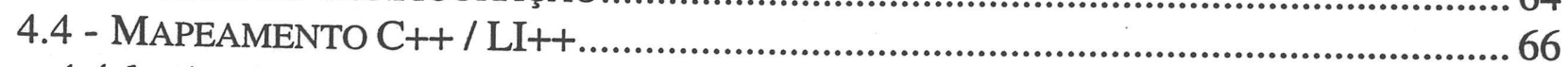

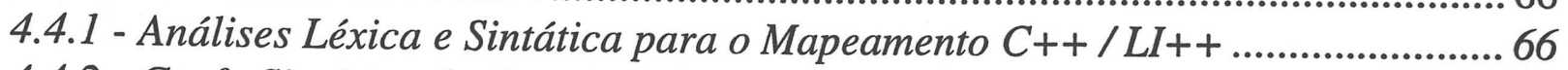

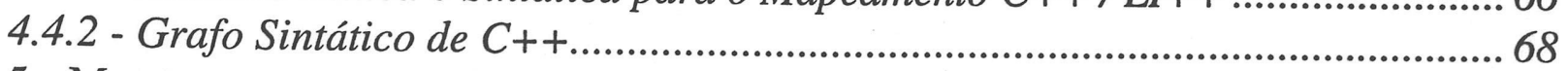

4.5 - MAPEAMENTO DE UM PROGRAMA EXEMPLO …................................................... 71

4.6 - AVALIAÇÃO DE DESEMPENHO DO MAPEAMENTO C++ / LI++ ................................. 74

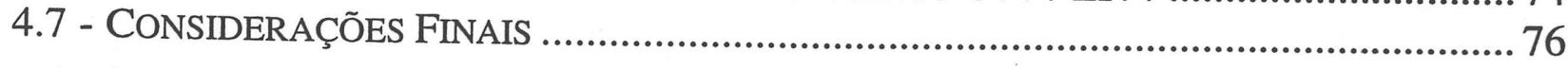

CAPÍTULO 5 - CONCLUSÕES E TRABALHOS FUTUROS................................. 78

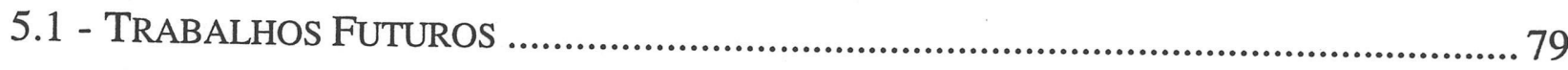

REFERÊNCIAS BIBLIOGRÁFICAS .................................................................... 80

APÊNDICE A - A LINGUAGEM INTERMEDIÁRIA $L I$..................................... 85

A.1 - TIPOS DE COMANDOS E ESTRUTURA DOS ÁTOMOS DA LI.......................................8 85

A.1.1 - Comandos Seqüenciais .................................................................................. 86

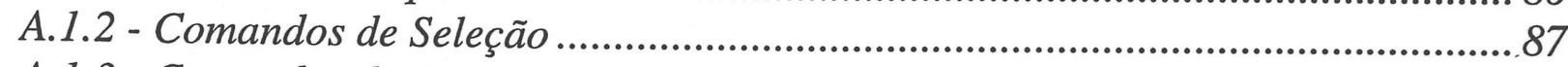

A.1.3 - Comandos de Seleção Múltipla ................................................................... 88

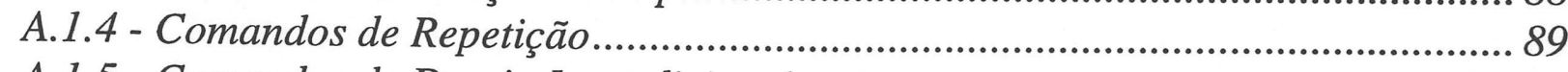

A.1.5 - Comandos de Desvio Incondicional ................................................................ 91

A.1.6 - Comandos Compostos e Programas.................................................................. 91

APÊNDICE B - CÓDIGOS-FONTES DO MAPEAMENTO C++ / LI++.............. 94

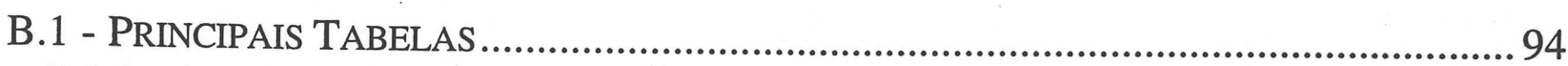

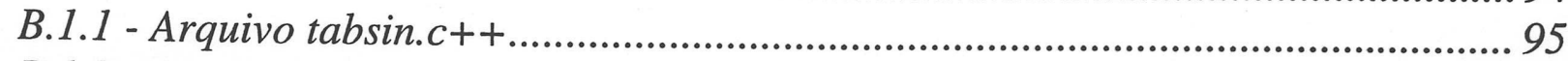

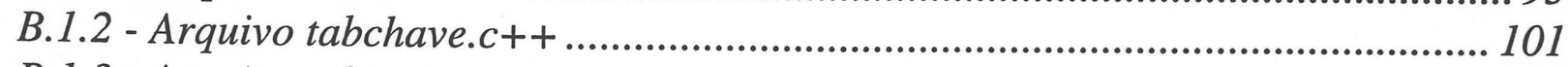

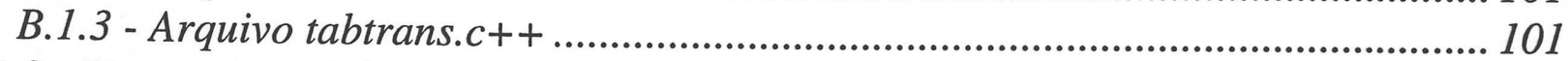

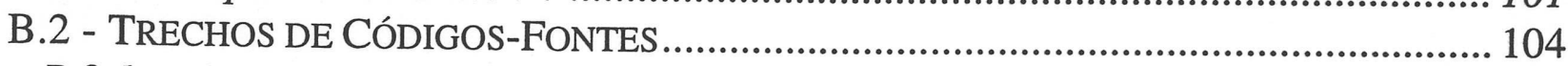

B.2.1 - Algumas Rotinas Semânticas do Arquivo rotsem.c ......................................... 104

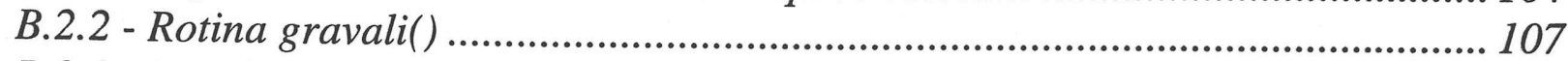

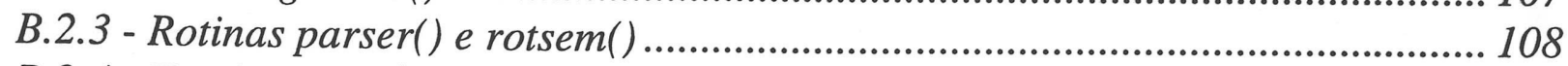

B.2.4 - Trecho do Arquivo li.c .............................................................................. 110 


\section{Lista de Figuras}

FIGURA 2.1 - EXEMPLO DE VARIÁVEIS DE INSTANCIAÇÃo ............................................ 18

FIGURA 2.2 - EXEMPLO DAS RELAÇÕES DE HERANÇA E HERANÇA MÚLTIPLA ................. 20

Figura 2.3 - GENEALOGIA DAS LINGUAGENS DE PROGRAMAÇÃo [BER92] ...................... 22

FIGURA 2.4 - EXEMPLO DE DEFINIÇÃO DE CLASSE EM C++ ............................................2 24

Figura 2.5 - ESCOPO DE DEFINIÇÃo DE SUBCLASSE [ECK91] .................................... 24

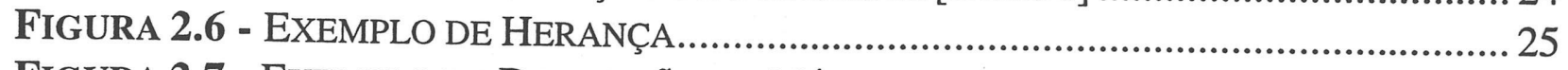

FiguRA 2.7 - EXEMPLO DE DESCRIÇÃo DE MÉTODO …............................................... 25

FIGURA 3.1 - NOME DE MÉTODOS E RESPECTIVOS PARÂMETROS E SEUS CORRESPONDENTES NA LI++ 46

FIGURA 3.2 - (A) TRECHO DE PROGRAMA ESCRITO EM JAVA [NIE96]; (B) RESPECTIVO MAPEAMENTO PARA A LI++

FIGURA 3.3 - (A) TRECHO DE PROGRAMA ESCRITO EM ADA [BAR84]; (B) RESPECTIVO MAPEAMENTO PARA A LI++

FIGURA 3.4 - (A) TRECHO DE PROGRAMA ESCRITO EM EIFFEL [MEY88]; (B) RESPECTIVO MAPEAMENTO PARA A LI++

FIGURA 3.5 - (A) TRECHO DE PROGRAMA ESCRITO EM TOOL [SPA94]; (B) RESPECTIVO MAPEAMENTO PARA A LI++

FigURA 3.6 - (A) TRECHO DE PROGRAMA ESCRITO EM SMALLTALK [GOL84]; (B) RESPECTIVO MAPEAMENTO PARA A LI++

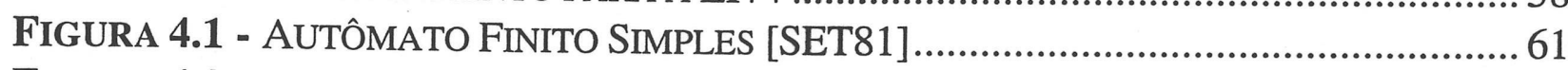

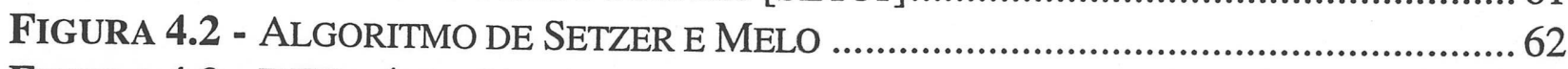

FiguRA 4.3 - DFD NÍVEl 01 Do MAPEAMENTO DE LINGUAGENS DE PROGRAMAÇÃo ORIENTADAS A OBJETOS PARA A LI++ [CAR91] 64

Figura 4.5 - ETAPAS PARA CONFIGURAÇÃO DE UMA LiNGUAGEM DE PROGRAMAÇÃo ORIENTADA A OBJETOS PARA A LI++.

FIGURA 4.4 - TRECHO DO ARQUIVO TABTRANS.C++ 67

FIGURA 4.5 - TRECHO DO GRÁFICO SINTÁTICO DE C++ DESCREVENDO A DEFINIÇÃo DE CLASSE 69

FIGURA 4.6 - TRECHO DO GRÁFICO SINTÁTICO DE C++ DESCREVENDO A DEFINIÇÃo DO CORPO DE UMA CLASSE 70

FIGURA B.1 - EXEMPLO DE CONSTRUÇÃo DE ESTRUTURA DO ARQUIVO TABSIN.C++ .... 95 FIGURA B.2 - ROTINA SEMÂNTICA 48. 104 


\section{Lista de Tabelas}

TABEla 2.1 - ComparaÇÕES ENTRE FERRAMENTAS DE TESTE DE SOFTWARE ............... 15

TABELA 2.2 - CARACTERÍSTICAS DA LingUAGEM C++ ................................................. 26

TABELA 2.3 - CARACTERÍSTICAS DA LINGUAGEM EIFFEL ............................................. 27

TABELA 2.4 - CARACTERÍSTICAS DA LINGUAGEM ADA................................................. 29

TABELA 2.5 - CARACTERÍSTICAS DA LiNGUAGEM SMALLTALK....................................... 30

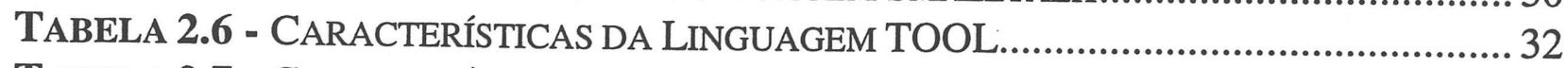

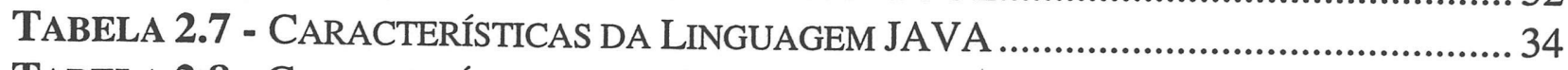

TABELA 2.8 - CARACTERÍSTICAS DAS PRINCIPAIS LINGUAGENS ORIENTADAS A OBJETOS34

TABELA 2.9 - NÚMERO DE CASOS DE TESTE A SEREM UTILIZADOS ................................ 39

TABELA 3.1 - COMANDOS C++ E SEUS CORRESPONDENTES NA LI++ ....................................... 47

TABELA 3.2 - COMANDOS ADA E SEUS CORRESPONDENTES NA LI++ ............................... 49

TABELA 3.3 - COMANDOS EIFFEL E SEUS CORRESPONDENTES NA LI++............................ 50

TABELA 3.4 - COMANDOS SMALLTALK E SEUS CORRESPONDENTES NA LI ++ ....................5 51

TABELA 3.5 - COMANDOS TOOL E SEUS CORRESPONDENTES NA LI++............................ 52

TABELA 3.6 - COMANDOS JAVA E SEUS CORRESPONDENTES NA LI++ ...............................5. 53

TABELA 4.1 - TABELA DE TRANSIÇÕES E Lista DE ESTADOS FinAIS DO AUTÔMATO DA

FIGURA 4.1 62

TABELA 4.1 - EXEMPLO DE MAPEAMENTO DE PROGRAMA C++ PARA A LI++ ................ 72

TABELA 4.2 - PROGRAMAS C++, SUAS CARACTERÍSTICAS E RESPECTIVOS TEMPOS DE MAPEAMENTO PARA A LI++ 


\section{RESUMO}

O paradigma de Orientação a Objetos vem recebendo grande aceitação tanto no meio acadêmico quanto na indústria de produção de software, demandando esforços para o estabelecimento de estratégias de teste e validação nesse contexto.

A atividade de teste é de grande importância para a eliminação dos defeitos que possam persistir no software após a sua conclusão. São encontrados na literatura estudos propondo estratégias de teste de softwares Orientados a Objetos que se baseiam na experiência já adquirida no teste de programas procedimentais, principalmente na utilização de critérios baseados em fluxo de dados; entretanto não foram encontradas, ainda, ferramentas específicas para o teste de softwares Orientados a Objetos. Deve-se observar que qualquer estratégia de teste sem o suporte de ferramentas automatizadas tende a ser trabalhosa e propensa a erros na sua condução.

Os Grupos de Teste de Software do ICMSC - USP - São Carlos e DCA - FEEC UNICAMP especificaram e implementaram duas ferramentas multilinguagens de teste de programas procedimentais baseadas em uma Linguagem Intermediária (LI). Na mesma direção, este trabalho apresenta a definição de uma Linguagem Intermediária para Programas Orientados a Objetos (denominada LI++) com a finalidade de viabilizar o desenvolvimento de ferramentas multilinguagens que apóiem esse paradigma, dada a diversidade de linguagens de programação Orientadas a Objetos existentes, tais como C++, Smalltalk, Eiffel, etc. A LI++ é uma extensão da LI, visto que os corpos dos métodos que compõem um ambiente Orientado a Objetos é basicamente composto por comandos procedimentais (mapeados na LI). Ainda, foi definido e implementado o mapeamento de programas $\mathrm{C}++$ para a $\mathrm{LI}++$, baseando-se fortemente na implementação do mapeamento $\mathrm{C} / \mathrm{LI}$, pois a linguagem $\mathrm{C}++$ é um superconjunto da linguagem $\mathrm{C}$. 


\section{ABSTRACT}

The Object-Oriented paradigm has been widely accepted by the academy as well as by the software production industry, requiring efforts for the establishment of testing validation strategies in this context.

The testing activity is important to eliminate software defects that would persist after software development. In the literature there are several initiatives proposing Object-Oriented testing strategies based on "traditional testing" experiences, some of them based on data flow testing criteria. In the other hand, no specific tools for testing Object-Oriented programs were identified that would support these criteria in this context. It should be observed that any strategy without the support of a tool is errorprone and expensive.

The ICMSC - USP - São Carlos and DCA - FEEC - UNICAMP testing groups have specified and implemented two procedimental multilanguage testing tools based on an Intermediate Language (LI). Following this framework, considering the diversity of Object-Oriented languages, such as $\mathrm{C}++$, Eiffel, Smalltalk, etc, this work presents the definition of an Intermediate Language (named LI++) to represent Object-Oriented programs making feasible the development of multilanguage Object-Oriented testing tools. The LI++ is an extension of LI, given that methods that compose an Object Oriented program are basically composed by procedimental commands (that are mapped to $\mathrm{LI}$ ). The mapping of $\mathrm{C}++$ programs to $\mathrm{LI}++$ based on the $\mathrm{C} / \mathrm{LI}$ implementation, since the language $\mathrm{C}++$ is a superset of $\mathrm{C}$ language, is also defined and implemented. 


\section{CAPÍTULO 1 - INTRODUÇÃO}

\section{1 - Situação do Problema}

Os sistemas de software têm crescido bastante em tamanho e complexidade, exigindo um esforço cada vez maior para testá-los. Particularmente, podemos nos referir a programas que são implementados segundo o Paradigma de Orientação a Objetos. Khoshafian aponta que a década de 90 será indubitavelmente conhecida como a década da Programação Orientada a Objetos [KHO90]. A necessidade dessa nova abordagem de programação é bastante simples: os usuários estão desejando mais funcionalidade de seus sistemas computacionais e pedindo ambientes simples e fáceis de serem usados. Essa perspectiva colocada por Khoshafian é um fato nos dias de hoje, dada a diversidade de linguagens de programação, tais como C++, Eiffel, Smalltalk, Java, entre outras, e de métodos de análise e de desenvolvimento de software Orientados a Objetos (Fusion [COL94], Booch [BOO86], [COA90], entre outros) que apóiam esse paradigma. Entre as linguagens de programação citadas, algumas como C++ têm recebido crescente aceitação na comunidade científica e industrial.

Durante todo o ciclo de vida do software, paralelamente à sua construção, um conjunto de atividades denominadas de Garantia de Qualidade de Software é conduzido com o objetivo de assegurar que tanto o processo de desenvolvimento quanto o produto final atinjam níveis de qualidade conforme o especificado. A Garantia de Qualidade de Software engloba: (1) métodos de análise, projeto, codificação e teste; (2) revisões técnicas formais que são aplicadas durante cada passo do ciclo de vida de um software; (3) estratégias de teste de software abrangentes; (4) controle de documentação do software e das mudanças feitas nele; (5) um procedimento para garantir adequação aos padrões de desenvolvimento do software; e (6) facilidade para realização de medições e produção de relatórios [PRE92].

Dentre as atividades de Garantia de Qualidade de Software, a atividade de teste é sem dúvida uma das técnicas de validação mais utilizadas. A atividade de teste pode ser descrita como a observação do comportamento do programa através de sua execução sobre um conjunto de dados [ADR82] e tem por objetivo revelar a presença de defeitos no software.

Apesar das várias técnicas, métodos e ferramentas empregados durante todo o processo de desenvolvimento do software que procuram evitar a introdução de defeitos no produto, ainda assim, a etapa de teste continua sendo de grande importância para a eliminação dos defeitos que persistem [MAL91]. 
Qualquer estratégia de teste sem o suporte de ferramentas tende a ser trabalhosa e propensa a enganos. Para se aplicar efetivamente um critério de teste, que pode ser definido como um procedimento usado para elaborar ou avaliar um conjunto de casos de teste, é necessário o uso de ferramentas automatizadas que apóiem essa aplicação, pois se isso não ocorrer, a aplicação desse critério ficará limitada a programas muito simples [HOR92]. Basicamente, um critério de teste pode ser classificado em uma das três técnicas: estrutural, funcional e baseada em erros. O que diferencia basicamente essas três técnicas é a origem da informação utilizada para avaliar ou para construir os conjuntos de casos de teste [MAL91].

Atualmente, encontram-se na literatura alguns estudos realizados propondo estratégias de teste de softwares Orientados a Objetos, onde podem ser destacados [SMI90], [HAR92], [JOR94], [MUR94], [POS94], entre outros. Tais estudos baseiamse na experiência já adquirida no teste de programas procedimentais, principalmente na utilização de critérios baseados em fluxo de dados; entretanto não foram encontradas ferramentas automatizadas de teste de software Orientado a Objetos.

Os Grupos de Engenharia de Software do ICMSC - USP - São Carlos e do DCA - FEEC - UNICAMP desenvolvem pesquisas em teste de software desde meados da década de 80, com ênfase nas técnicas de teste estrutural baseado em análise de fluxo de dados [MAL89][CHA91] e no critério análise de mutantes [DEL93]. Nesse contexto, especificaram e implementaram duas ferramentas de teste de software de grande significância: POKE-TOOL [CHA91] e Proteum [DEL93]. A POKE-TOOL e a Proteum são ferramentas de teste multilinguagem, ou seja, suas implementações são baseadas em uma linguagem intermediária denominada LI [CAR91]. Essa abordagem possibilita a caracterização de módulos dependentes e independentes da linguagem alvo, e a configuração dessas ferramentas para uma particular linguagem (na qual esteja implementado o programa que se deseja testar) consiste basicamente na definição do mapeamento para a LI e de ajustes em alguns módulos dependentes da linguagem. Atualmente, por exemplo, a POKE-TOOL encontra-se configurada para as linguagens C, COBOL, FORTRAN e CLIPPER. A Proteum está configurada somente para C. A POKE-TOOL e a Proteum apóiam, respectivamente, a aplicação de critérios estruturais, com ênfase em critérios baseados em fluxo de dados [MAL91], e a aplicação do critério Análise de Mutantes [DEM80]. 


\section{2 - Objetivos}

A diversa gama de linguagens de programação Orientadas a Objetos [STR94] [GOL84][ROS92][KHO90] motiva que abordagens semelhantes à adotada no desenvolvimento das ferramentas POKE-TOOL e Proteum para teste de programas procedimentais, sejam utilizadas com a finalidade de se desenvolver ferramentas de software dentro da abordagem de Orientação a Objetos. Ainda, observa-se na literatura uma tendência de se empregar os conceitos, experiências e ferramentas utilizados no teste "tradicional" no estabelecimento de estratégias de teste dentro da Orientação a Objetos [BER92][HAR92][PER90][SMI90], entre outros. Seguindo o mesmo princípio adotado no desenvolvimento da POKE-TOOL para as linguagens citadas acima, é objetivo deste trabalho definir uma Linguagem Intermediária para Programas Orientados a Objetos (denominada LI++) com a finalidade de viabilizar o desenvolvimento de ferramentas multilinguagens para Orientação a Objetos. A LI++ irá estender a Linguagem Intermediária original (LI), desenvolvida para programas procedimentais, com as características de linguagens Orientadas a Objetos. Ainda, propõe-se definir e implementar o mapeamento de $\mathrm{C}++$ para LI++. Observa-se que a experiência de mapeamento de C para LI será utilizada no contexto do trabalho proposto, pois a implementação dos métodos na linguagem $\mathrm{C}++$ é basicamente realizada utilizando-se comandos da linguagem C [STR86]. Essa definição poderá ser bastante útil para a definição de ferramentas multilinguagens automatizadas de Teste de Softwares Orientados a Objetos, do mesmo modo que a LI foi importante para a definição e implementação das ferramentas de teste POKE-TOOL [CHA91] e Proteum [DEL93].

Esse trabalho fornecerá subsídios para viabilizar a aplicação da Análise de Mutantes e dos Critérios Baseados em Fluxo de Dados para o Teste de Softwares Orientados a Objetos.

\section{3 - Organização do Trabalho}

Esse Capítulo apresentou de forma sucinta o contexto do trabalho, procurando caracterizar o objetivo e a relevância da presente dissertação de mestrado.

O Capítulo 2 fornece uma visão geral de Teste de Software, das técnicas e das ferramentas existentes para a automatização dessa atividade. São apresentadas também algumas características básicas de Orientação a Objetos, onde podemos destacar Tipos Abstratos de Dados, Classes, Polimorfismo, Herança, etc. Será dada ênfase à linguagem $\mathrm{C}++$, uma vez que se trata de uma linguagem de ampla utilização tanto no meio acadêmico quanto no industrial [KHO90]. Ainda, no Capítulo 2 são sintetizadas algumas estratégias de Teste de Softwares Orientados a Objetos. 
No Capítulo 3 é feita a definição da Linguagem Intermediária para programas Orientados a Objetos (LI++) utilizando-se a notação de Backus-Naur [SET81]. A LI++ será um super-conjunto da Linguagem Intermediária para programas procedimentais (LI) [CAR91] e é uma forma de se escolher uma representação comum para os programas codificados nas principais linguagens de Programação Orientadas a Objetos. Nesse Capítulo também são mostrados os comandos das principais Linguagens de Programação Orientadas a Objetos e seus correspondentes na LI++, além de trechos de programas escritos nessas linguagens e seus respectivos mapeamentos para a LI+t. É dado um enfoque especial para a linguagem $\mathrm{C}++$ por ser a linguagem escolhida para realização de seu mapeamento para a LI++ nesse trabalho.

No Capítulo 4 é mostrado o processo para se realizar o mapeamento de um programa Orientado a Objetos para a LI++. A implementação do mapeamento de programas Orientados a Objetos para a LI++ está baseada em dois passos básicos: a Análise Léxica e a Análise Sintática. A forma escolhida para ser realizada a Análise Léxica foi a implementação de um algoritmo bastante parecido com o de Setzer e Melo [SET81], enquanto que a Análise Sintática está baseada no algoritmo de Wirth [WIR76]. Ainda, no Capítulo 4 são sumarizadas as tarefas a serem realizadas por um usuário configurador para realizar o mapeamento de uma linguagem Orientada a Objetos para a LI++.

O Capítulo 5 apresenta a conclusão do trabalho, mostrando a importância da realização do mapeamento de Linguagens de Programação Orientadas a Objetos para a LI++ dentro do contexto de definições e implementações de ferramentas de teste de softwares multilinguagens Orientadas a Objetos, além de discutir perspectivas de trabalhos futuros.

O Apêndice A apresenta a definição da LI segundo a notação de Backus-Naur, e alguns exemplos simples de mapeamentos de trechos de programas escritos em $\mathrm{C}$ para a LI.

O Apêndice B (inclui disquete anexo) apresenta trechos de alguns códigos-fonte utilizados para a realização do mapeamento de programas $\mathrm{C}++$ para a $\mathrm{LI}++$ e das tabelas sintática, de transições léxicas e de palavras-chaves da linguagem $\mathrm{C}++$, por serem de maior importância na realização do mapeamento de programas $\mathrm{C}++$ para a LI++. No disquete anexo encontram-se os códigos-fontes completos (em linguagem C) utilizados para a implementação desse mapeamento e todas tabelas utilizadas. Ainda, diversos programas e trechos de programas $\mathrm{C}++\mathrm{e}$ seus respectivos mapeamentos para a LI++ encontram-se nesse disquete. 


\section{CAPÍTULO 2 - REVISÃO BIBLIOGRÁFICA}

Em função dos objetivos deste trabalho, nesse capítulo apresenta-se essencialmente uma revisão bibliográfica dos aspectos técnicos e teóricos fundamentais para o desenvolvimento do trabalho proposto. Primeiramente, é feita uma revisão dos conceitos, das técnicas e dos critérios de teste de software, bem como uma síntese das características das principais ferramentas empregadas para automatizar o teste de software, em seguida são apresentados os conceitos básicos da abordagem e as principais linguagens de desenvolvimento de softwares Orientados a Objetos, objetivando a definição de uma Linguagem Intermediária que incorpore as características essenciais dessas linguagens. Ainda, são discutidas as abordagens e os aspectos teóricos do teste de software dentro do Paradigma Orientado a Objetos, além de serem analisados os diversos problemas que podem ser encontrados na atividade de teste nesse contexto.

\section{1 - Teste de Software}

Define-se teste de software como o processo de executar um programa com a intenção de revelar a presença de erros [MYE79]. No teste de software é fundamental fazer distinções entre falha, defeito e erro. Uma falha (failure em inglês) consiste essencialmente de um evento observável onde o sistema viola sua especificação; erro consiste de um item de informação que pode levar a uma falha, ou de um estado inconsistente do sistema, e defeito (fault em inglês) uma deficiência mecância ou algorítmica que produz um erro [MYE79]. No escopo deste trabalho será usado o termo defeito para referenciar os dois últimos; ou seja, falha é consequiência, defeito e/ou erro são causas.

No processo de teste, o ideal seria que o programa fosse exercitado para todos os valores do domínio de entrada, porém, sabe-se que na prática o teste exaustivo é, em geral, impraticável devido a restrições de custo e tempo. Testar um programa geralmente não prova a sua corretude, pode apenas aumentar a confiança de que o software desempenhe as funções dele esperadas, quando não forem revelados erros.

Analisando-se esses fatores, torna-se necessária a utilização de alguma técnica que dê indicações de como testar o software; quando parar o teste; e quando possível, fornecer medidas de confiança e qualidade alcançadas com os testes realizados [DEM80].

Nesse contexto, um importante fator consiste em se determinar quais casos de teste utilizar de modo que a maioria dos defeitos existentes possam ser revelados e que o número de casos de teste utilizados não seja tão grande a ponto de ser impraticável. 
Um dado de teste pode ser definido como um conjunto de valores de entrada para o programa que se deseja testar; e um caso de teste é composto por esse conjunto de entrada e a respectiva saída esperada. Não serão feitas diferenciações entre esses dois termos nesse trabalho. No contexto da atividade de teste duas questões são relevantes [FRA87]:

\section{Como os casos de teste devem ser selecionados?}

\section{Como dizer se um programa foi suficientemente testado?}

Define-se método de seleção de dados de teste como um procedimento para escolher casos de teste; e critério de adequação dos dados de teste (do conjunto de dados de teste) como um procedimento usado para avaliar um conjunto de casos de teste. Existe uma correspondência entre um método de seleção de dados de teste e os critérios de adequação de dados de teste. Dado um critério de adequação $\mathbf{C}$, existe um método $\mathbf{M}$ de seleção de dados de teste que estabelece: "Selecione um conjunto de dados de teste que satisfaça o critério C". De forma análoga, dado um método de seleção, existe um critério de adequação $\mathbf{C}_{\mathbf{m}}$ que determina: "Um conjunto de dados de teste é adequado se ele foi gerado pelo método M". Desse modo, costuma-se utilizar o nome de critério de teste para designar as duas atividades [FRA85]. O critério de teste auxilia o testador a decidir se o programa em teste está pronto para ser liberado, como também para decidir como criar novos casos de teste [MAL91].

Vários critérios de teste têm sido elaborados com o objetivo de fornecer uma forma sistemática e rigorosa para selecionar um conjunto de casos de teste $\mathbf{T}$ que seja efetivo em evidenciar a presença de erros. É importante observar que a existência desses critérios sem o apoio de uma ferramenta automatizada é ineficaz, pois fica-se sujeito a erros na própria condução das atividades de teste, além da ineficiência da aplicação manual com relação a custo e tempo [MAL91].

\subsection{1 - Técnicas de Teste de Software}

Um critério de teste pode ser categorizado em uma das três técnicas de teste de software: a funcional, a estrutural e a baseada em erros. A diferença entre essas três técnicas é a origem da informação usada para avaliar ou para construir conjuntos de casos de teste.

Deve-se notar que nenhuma das técnicas de teste é completa isoladamente, pois a aplicação isolada de uma delas não é, em geral, suficiente para garantir a qualidade da atividade de teste. Na verdade, essas diferentes técnicas se complementam e devem ser aplicadas em conjunto para tentar assegurar um teste de boa qualidade [PRE92]. 
A técnica funcional baseia-se na especificação do programa para derivar requisitos de teste, sem se preocupar com detalhes de implementação. Exemplos de critérios da técnica funcional são os critérios de particionamento de equivalência e de análise de valor-limite, entre outros. O teste estrutural considera a estrutura interna da implementação para derivar requisitos de teste, o que normalmente é feito a partir de sua representação por um grafo de fluxo de controle. Entre os exemplos podem ser destacados o teste de caminhos básicos (de McCabe) e o teste de fluxo de dados [WEY85]. No caso da técnica baseada em erros, o foco está nos erros que o programador ou o projetista podem cometer durante o processo de desenvolvimento e nas abordagens que podem ser usadas para detectar a sua ocorrência [HOW89]; a Análise de Mutantes é um critério típico da técnica baseada em erros.

\subsubsection{1 - Técnica Funcional}

O teste funcional também é chamado de teste caixa preta [MYE79], pois a estrutura e o comportamento interno do programa não são considerados na derivação de requisitos de teste. O objetivo é revelar situações em que o comportamento de Entrada/Saída do programa não ocorre como o especificado; com isso o conjunto dos casos de teste é construído a partir da especificação do programa [DEM87].

Coward [COW88] distingüe dois passos principais dessa técnica: primeiro, identificar as funções esperadas do software e segundo, criar casos de teste que chequem de maneira completa a realização das funções determinadas. As funções que o software possui são identificadas a partir de sua especificação, sendo essencial para o teste funcional uma especificação correta e de acordo com os requisitos do usuário [DEM87].

O critério particionamento de classes de equivalência, ou teste de partição, divide o domínio de entrada em classes de equivalência que possuam as mesmas características. Ou seja, se um caso de teste em uma determinada classe de equivalência revelar a presença de um defeito, espera-se que todos os outros casos de teste dessa classe de equivalência também revelem o mesmo defeito. Se um caso de teste em uma classe de equivalência não detectar a presença de um defeito, espera-se que nenhum outro caso de teste dessa classe de equivalência revele esse defeito [MYE79]. A identificação das classes de equivalência normalmente requer uma abordagem heurística [DEM87].

O critério Análise de Valor Limite determina que os casos de teste que estão nos limites das classes de equivalência sejam analisados, pois nesses limites a possibilidade de ocorrência de erros é maior [MYE79][HOW87]. Ao invés de se selecionar qualquer elemento em uma classe de equivalência, a Análise de Valor Limite requer que um ou mais elementos em uma classe de equivalência sejam escolhidos de modo que os limites das classes de equivalência sejam os alvos de teste. 
O Teste Aleatório também é um critério funcional e é uma maneira de, sem referência ao código, utilizando informações sobre o domínio de entrada, gerar os dados de teste aleatoriamente. Duran e Ntafos [DUR81] apontam que a geração aleatória pode ser eficiente e de baixo custo para muitos tipos de programas. Neste critério o programa é testado selecionando-se aleatoriamente dados de teste do conjunto de todos os valores de entrada possíveis para o programa em questão, necessitando-se de um oráculo ${ }^{1}$ para decidir se as saídas obtidas são corretas ou não.

Hamlet e Taylor [HAM92] e Duran e Ntafos [DUR84] desenvolveram comparações entre teste aleatório e teste de particão, sendo que o teste aleatório apresentou custo para detectar defeitos menor que o teste de partição. Weyuker [WEY91] desenvolveu trabalho semelhante onde mostrou que a eficiência do teste de partição é dependente de como as entradas que produzem uma saída incorreta estão concentradas dentro das classes definidas pela partição. Entretanto, o teste aleatório possui a vantagem de ser facilmente automatizado, como também de se apresentar eficiente nos testes finais de um programa [BEI90][WEY91]. Além disso, elimina qualquer influência possível do testador em conduzir a geração dos casos de teste e o particionamento das classes de equivalência. Apresenta como desvantagem a não garantia de que um critério de teste seja satisfeito com o seu uso, sendo visto por alguns autores como um critério "pobre" [BEI90].

Em geral, o teste funcional é uma técnica de validação de programas onde os casos de teste são gerados a partir da especificação tornando-se uma técnica sujeita às inconsistências que podem ocorrer nessa especificação. Outro problema com essa técnica é a dificuldade de quantificar a atividade de teste, visto que não se pode garantir que partes essenciais e/ou críticas do programa foram ou sejam executadas [DEM87].

\subsubsection{2 - Técnica Estrutural de Teste}

A Técnica Estrutural de Teste é provavelmente uma das técnicas de teste mais utilizadas durante o teste de unidade [DEM87]. Essa técnica também é conhecida como teste de caixa branca pois os requisitos de teste são fortemente baseados nos aspectos de implementação do software.

Quase todos os critérios dessa técnica utilizam uma representação de programa conhecida como grafo de fluxo de controle ou grafo de programa. Um grafo de fluxo de controle é um grafo orientado onde cada nó representa um bloco indivisível de comandos e cada aresta representa um desvio de um bloco para outro. Um bloco desse tipo tem as seguintes características: não existem desvios para o meio do bloco e uma

\footnotetext{
${ }^{1}$ Oráculo: Mecanismo pelo qual decide-se se a saída obtida quando da execução de um programa com um dado valor de entrada corresponde à saída esperada.
} 
vez que o primeiro comando do bloco seja executado, todos os demais comandos do bloco são executados seqüencialmente.

Os critérios estruturais baseiam-se em tipos de estruturas diferentes para determinar quais partes do programa são requeridas na execução e podem ser classificados em: Critérios Baseados em Fluxo de Controle, Baseados em Fluxo de Dados e Baseados na Complexidade.

Os Critérios Baseados em Fluxos de Controle usam características de controle da execução do programa, tais como comandos ou desvios, para determinar quais estruturas são necessárias; desses, os critérios mais conhecidos são: Todos-Nós, TodosArcos e Todos-Caminhos. No Critério Todos-Nós exige-se que a execução do programa passe pelo menos uma vez em cada nó do grafo de fluxo, isto é, que cada comando do programa seja executado pelo menos uma vez. No Critério Todos-Arcos exige-se que cada aresta do grafo (cada desvio do programa) seja exercitada pelo menos uma vez. O Critério Todos-Caminhos requer que todos os caminhos possíveis do programa sejam executados [PRE92].

Os Critérios Baseados em Fluxo de Dados fornecem uma hierarquia de critérios entre o critério Todos-Caminhos e o critério Todos-Arcos, tornando o teste estrutural mais rigoroso [RAP85]. No grafo são associadas informações sobre o fluxo de dados do programa, caracterizando o Grafo Def-Uso (Definição-Uso de variável) definido por Weyuker [WEY88] . Esse grafo explora associações entre pontos do programa onde é atribuído um valor a uma variável (definição da variável) e pontos onde esse valor é utilizado (referência ou uso da variável). $\mathrm{O}$ uso da variável pode ser uso computacional (c-uso), quando a variável é usada em uma computação, e uso predicativo (p-uso), quando usada em uma condição. Com base nessas associações são determinados os caminhos a serem exercitados. Os critérios baseados em Fluxo de Dados mais difundidos são:

.Todas-Definições : Requer que cada definição de variável seja exercitada pelo menos por um c-uso ou por um p-uso.

.Todos-Usos : Requer que cada associação entre uma definição da variável $\mathbf{v}$ e c-usos ou p-usos seja exercitada por pelo menos um caminho livre de definição com relação à variável $\mathbf{v}$.

.Todos-Du-Caminhos : Requer que toda associação entre uma definição da variável v e c-usos ou p-usos dessa variável seja exercitada por todos os caminhos livres de definição (caminhos onde não ocorre redefinição da variável v) e livres de laço. 
Os Critérios Baseados na Complexidade utilizam informações sobre a complexidade do programa para poder determinar os requisitos de teste. Um critério muito conhecido dessa classe é o critério de McCabe que utiliza a complexidade ciclomática para derivar os requisitos de teste. Esse critério requer que um conjunto linearmente independente de caminhos do grafo de programa seja executado [PRE92].

Apesar da técnica estrutural possuir vários critérios para gerar os dados de teste, o principal problema dessa técnica é a impossibilidade de se determinar quando um caminho é executável ou não, ou seja, não existe algoritmo que dado um caminho completo qualquer, indique se existe um conjunto de valores que causem a execução desse caminho [MYE79].

Um caminho é executável se existe um conjunto de valores que possa ser atribuído às variáveis de entrada do programa e que cause a execução desse caminho; caso contrário, esse caminho é dito não executável [FRA87].

Os casos de teste definidos pelos critérios funcionais podem corresponder ao conjunto inicial dos testes estruturais. Com esses casos de teste, o programa é executado e analisam-se os resultados obtidos. Normalmente, esse conjunto não é suficiente para satisfazer totalmente um critério estrutural, então novos casos de teste devem ser gerados e adicionados ao conjunto até que se consiga o grau de satisfação desejado, evidenciando-se, desta forma, os aspectos complementares das duas técnicas.

\subsubsection{3 - Técnica de Teste Baseada em Erros}

Os critérios de teste que estão nessa categoria utilizam informações sobre os erros mais freqüentes no processo de desenvolvimento de software e sobre os tipos específicos de erros que se desejam localizar [DEM91]. A Análise de Mutantes e a Semeadura de Erros são critérios dessa técnica de teste [BUD81].

Pelo fato de serem encontrados, na prática, longos trechos de programas com código simples e pouco propensos a erros, e trechos pequenos, porém complexos, onde os erros tendem a acumular-se (a distribuição dos erros no programa dificilmente estará uniforme), a técnica de teste baseada em erros consiste em se incluir propositalmente algum erro no programa e observar o comportamento do programa que contenha esse erro, comparando-o com o comportamento do programa original.

No Critério Semeadura de Erros, alguns erros são inseridos "artificialmente" no programa. Então, dos erros encontrados durante o teste verificam-se quais são naturais e quais são artificiais. Dado que um conjunto de casos de teste descobre um certo número de erros, a relação entre o número de erros naturais e artificiais descobertos deve, pelo menos em teoria, dar alguma indicação do número de erros que ainda restam no programa. Com isso, esse critério visa estimar o número de defeitos naturais 
remanescentes e o critério leva em conta o nível de confiabilidade que se espera do software, isto é, qual probabilidade de defeitos naturais remanescentes pode ser considerada como aceitável. Um problema com esse critério está no fato de alguns erros artificiais poderem interagir com os naturais fazendo com que os erros naturais sejam mascarados pelos erros semeados; além disso, dificilmente encontram-se programas suficientemente grandes que contenham uma quantidade de erros que dê aos valores calculados um significado não questionável [BUD81].

A Análise de Mutantes é um critério de teste baseado em erros que, para avaliar o quanto um conjunto de casos de teste $T$ é adequado para testar um dado programa $P$, utiliza um conjunto de programas, ligeiramente diferentes de $\mathrm{P}$, chamados de mutantes. O objetivo é obter casos de teste que consigam revelar as diferenças de comportamento existentes entre $\mathrm{P}$ e seus mutantes [DEM80].

A Análise de Mutantes é um critério que mede a adequação ${ }^{2}$ dos casos de teste. De Millo apresenta a filosofia básica para a aplicação desse critério, conhecida como hipótese do programador competente: "Programadores possuem uma grande vantagem que é pouco explorada: eles costumam criar programas muito próximos do correto" [DEM80]. Essa hipótese afirma que todo programa criado por um programador competente ou está correto, ou está próximo do correto. Assumindo a validade dessa hipótese, pode-se afirmar que erros são introduzidos nos programas através de desvios sintáticos que alteram a semântica do programa e portanto conduzem o programa a um comportamento incorreto. Para revelar tais erros, a Análise de Mutantes identifica os desvios sintáticos mais comuns e, aplicando pequenas transformações sobre o programa em teste, encoraja o testador a construir casos de teste que mostrem que tais transformações conduzem a programas incorretos.

Ainda, estudos empíricos mostram que os conjuntos de casos de teste que revelam erros simples como os descritos acima conseguem, em geral, revelar outros tipos de erros mais complexos, o que é conhecido como efeito de acoplamento (coupling effect) [DEM80].

Partindo-se da hipótese do programador competente e do efeito de acoplamento, conclui-se que pequenas mudanças em um programa em teste são eficientes para revelar a presença de defeitos nesse programa [DEM78]. Inicialmente, o objetivo é verificar a adequação de um conjunto de casós de teste $\mathrm{T}$, onde para isso um programa $P$ é testado com o conjunto T. Se o programa funciona corretamente, então este sofre pequenas perturbações, gerando seus mutantes que são executados com o mesmo conjunto de casos de teste. Caso o comportamento de $\mathrm{Pi}$ (um mutante de P) seja

\footnotetext{
${ }^{2}$ Um conjunto de casos de teste é adequado a um determinado programa se o programa funciona corretamente quando executado com os casos de teste e se todos os programas mutantes têm um comportamento diferente do programa original com alguns desses casos de teste.
} 
diferente do de $\mathrm{P}$, então esse mutante é dito "morto". Caso contrário, esse mutante está vivo . Isso ocorre ou devido ao fato do conjunto $\mathrm{T}$ não ser suficiente (adequado) para distinguir os comportamentos de $\mathrm{P}$ e de $\mathrm{Pi}$ e, com isso, novos casos de teste devem ser incluídos no conjunto; ou devido a $\mathrm{Pi}$ ser equivalente a $\mathrm{P}$, ou seja, o comportamento dos dois programas não difere para qualquer dado do domínio de entrada.

Com isso, obter-se casos de teste que distingüem o comportamento de todos os mutantes não equivalentes significa que este conjunto de casos de teste é adequado ao programa em teste e que esse programa possui erros pouco prováveis de ocorrerem, de acordo com o efeito de acoplamento, o que é fortemente dependente do tipo de mutante gerado para esse programa [DEM80].

DeMillo destaca um ponto importante que é o fato da Análise de Mutantes fornecer uma medida objetiva do nível de confiança na adequação dos casos de teste analisados[DEM80]. Através do escore de mutação que relaciona o número de mutantes gerados com o número de mutantes mortos, pode-se avaliar a adequação dos casos de testes usados, e como conseqüência, a confiabilidade do programa testado. $\mathrm{O}$ escore de mutação pode ser calculado da seguinte maneira:

$$
\mathrm{ms}=\mathrm{DM}(\mathbf{P}, \mathbf{T}) /\{\mathbf{M}(\mathbf{P})-\mathbf{E M}(\mathbf{P})\}
$$

onde:

$\operatorname{DM}(\mathrm{P}, \mathrm{T})=$ número de mutantes mortos pelos casos de teste em $\mathrm{T}$.

$\mathrm{M}(\mathrm{P})$ = número total de mutantes gerados.

$\operatorname{EM}(\mathrm{P})=$ número de mutantes gerados equivalentes a $\mathrm{P}$.

O ideal é que se obtenha ms igual a 1 , entretanto o que ocorre na prática é que nem sempre é possível anlisar-se todos os mutantes e determinar-se quais são os equivalentes. Dessa maneira, o que se faz na prática é procurar por um ms que se aproxime de 1 .

Para ser avaliada a qualidade de um conjunto de casos de testes $\mathrm{T}$ para um programa $\mathrm{P}$, devem ser seguidos os seguintes passos para aplicar-se o critério Análise de Mutantes:

1) Geração dos mutantes

Constrói-se uma vizinhança de $\mathrm{P}$, denominada $(\mathrm{P})$, que é constituída por programas que possuam pequenas mudanças em relação ao programa $\mathrm{P}$. Cada programa gerado é um mutante de P. 
2) Execução de $P$

O programa P é executado sobre o conjunto de casos de teste T. Se P apresenta algum resultado incorreto, então um erro foi encontrado e o processo termina.

3) Execução dos mutantes

Cada um dos mutantes é executado usando os casos de teste do conjunto T. Caso a execução do mutante apresente resultado diferente do de $\mathrm{P}$, o mutante é considerado morto, caso contrário, $\mathrm{M}$ continua vivo e deve ser analisado.

4) Análise dos mutantes vivos

Examinando-se cada um dos mutantes que permaneceram vivos, duas conclusões são possíveis: ou o mutante é equivalente a $\mathrm{P}$, ou o mutante "não morreu" porque o conjunto de casos de testes $\mathrm{T}$ não possui um caso de teste que consiga diferenciar o mutante do programa $\mathrm{P}$; nesse caso, novos casos de testes devem ser adicionados ao conjunto $\mathrm{T}$ e o processo deve retornar ao passo 2 . O processo termina quando todos os mutantes não equivalentes estiverem mortos.

\subsubsection{4 - Ferramentas de Automatização}

A atividade de teste deve ser presente em qualquer esforço responsável para se desenvolver um sistema de software [HOW87], e ainda assim um grande número de defeitos permanecem sem serem detectados na maioria dos softwares liberados, apesar dessa atividade, em geral, gastar até $50 \%$ do orçamento da fase de desenvolvimento do software [PRE92]. Um dos motivos disso é o fato da atividade de teste ser propensa a erros, principalmente pela interferência humana na sua condução.

A aplicação de técnicas que indiquem como testar o software e de critérios que respondam quando os testes podem parar são cruciais para que a atividade de teste possa ser conduzida de forma planejada e sistematizada [DEM80].

Devido à crescente complexidade dos softwares atuais, qualquer estratégia de teste sem suporte de ferramentas automatizadas tende a ser trabalhosa e propensa a enganos. Para aplicação efetiva de um critério de teste, é necessário o uso de ferramentas automatizadas que apóiem a aplicação desse critério, porque do contrário, a aplicação do critério será limitada a programas muito simples [HOR92].

As ferramentas de teste procuram automatizar a atividade de teste, reduzindo a intervenção humana nos resultados obtidos. Uma ferramenta de teste ideal seria aquela que fosse capaz de pronduzir um conjunto de casos de teste sem nenhuma interferência humana. Caso fossem encontrados erros, a ferramenta deveria produzir casos de teste que mostrem o comportamento errado do programa, além de uma lista dos erros e de 
suas localizações. Apesar desta ferramenta ideal não ser alcançável devido à indecibilidade na análise dos resultados obtidos na execução dos casos de teste, uma ferramenta de teste que esteja próxima desse objetivo pode melhorar significativamente a atividade de teste [DEM91].

A utilização de ferramentas aumenta a qualidade da atividade de teste, através da redução de falhas produzidas pela intervenção humana, além de aumentar consideravelmente a sua produtividade. $\mathrm{O}$ aumento da qualidade e da produtividade influenciam diretamente a confiabilidade do software testado.

A seguir, apresenta-se uma breve descrição de algumas ferramentas de teste de softwares tradicionais extraída de [DEL93]. Pode-se notar a ausência de ferramentas de teste específicas para softwares Orientados a Objetos.

-Xray/DX: ferramenta de teste de software que tem como objetivo verificar a conformidade do programa às restrições de desempenho, fornecendo informações detalhadas sobre a operação do programa, e identificando "gargalos" de desempenho [LUT90].

-ASSET (A System to Select and Evaluate Tests): apóia testes de programas escritos em Pascal, analisando a qualidade dos dados de teste, usando uma família de critérios de adequação baseados na Análise de Fluxo de Dados [RAP85].

-PROTESTE: desenvolvida na UFRS (Universidade Federal do Rio Grande do Sul) realiza testes de programas escritos em Pascal, na mesma filosofia da ferramenta ASSET [PRI90].

-POKE-TOOL (POtential Uses CRiteria TOOL for program testing): desenvolvida no DCA-FEEC-UNICAMP, auxilia a atividade de teste analisando a cobertura de um conjunto de casos de teste e fornecendo ao testador quais caminhos são necessários para satisfazer os critérios Potenciais-Usos [MAL89][CHA91].

-FMS-1 e FMS-2 (FORTRAN Mutation System): trata de programas escritos em FORTRAN, onde a versão 1 apenas pode ser aplicada a programas compostos de apenas uma subrotina com artitmética de inteiros, e a versão 2 pode ser aplicadas a programas com várias subrotinas, exceto para comandos de E/S. Apóiam o critério Analise de Mutantes.

-Mothra : também apóia o critério Análise de Mutantes, e quando comparada com as ferramentas FMS-1 e FMS-2 possui a vantagem de permitir ao sistema apoiar outras linguagens além da FORTRAN. O tamanho máximo dos programas é limitado apenas pela velocidade e capacidade de armazenamento da máquina onde o teste está 
sendo realizado. Além disso, é fácil a incorporação de ferramentas tais como gerador randômico de casos de teste e verificador de equivalência [DEM88][CHO89].

-Proteum (PROgram TEsting Using Mutants): ferramenta que apóia a aplicação do critério Análise de Mutantes para programas escritos em linguagem C. Esta ferramenta possui a característica de ser multilinguagem. Foi desenvolvida no grupo de Engenharia de Software do ICMSC - USP - São Carlos [DEL93]. A Tabela 2.1 mostra uma comparação entre as ferramentas POKE-TOOL, Mothra e Proteum, adaptada de [DEL93].

Tabela 2.1 - Comparações entre Ferramentas de Teste de Software

\begin{tabular}{|c|c|c|c|}
\hline & $\begin{array}{l}\text { POKE-TOOL } \\
\text { (versão PC) }\end{array}$ & Mothra & Proteum \\
\hline Linguagem & C, COBOL, FORTRAN & FORTRAN & $\mathrm{C}$ \\
\hline Geração automática de Casos de Teste & Não & Sim & Não \\
\hline Edição de Casos de Teste & Sim & Sim & Sim \\
\hline $\begin{array}{l}\text { Registro sobre caminhos não executáveis } \\
\text { ou mutantes equivalentes }\end{array}$ & Sim & Sim & Sim \\
\hline Interface & $\begin{array}{c}\text { Linha de Comando e } \\
\text { Menu/Janelas } \\
\end{array}$ & Menu/janelas & $\begin{array}{c}\text { Linha de Comando e } \\
\text { Menu/Janelas } \\
\end{array}$ \\
\hline Sessões de Teste & Sim & Sim & Sim \\
\hline Apoio a Experimentos & Sim & Não & Sim \\
\hline $\begin{array}{l}\text { Restrição do tamanho do programa a ser } \\
\text { testado }\end{array}$ & Sim & Não & Não \\
\hline Importação de casos de teste & Sim & Não & Sim \\
\hline Geração seletiva de mutantes & - & Sim & Sim \\
\hline Ambiente Compilado/Interpretado & Compilado & Interpretado & Compilado \\
\hline $\begin{array}{l}\text { Determinação automática de mutantes } \\
\text { equivalentes ou caminhos não- } \\
\text { executáveis }\end{array}$ & Não & Não & Não \\
\hline
\end{tabular}

A importância de uma ferramenta automatizada de teste de software multilinguagem está no fato dessa ferramenta poder ser facilmente utilizara para testar softwares de diversas áreas de aplicação, tais como Sistemas de Informação, Sistemas Gráficos, Sistemas Distribuídos, entre outras. 


\section{2 - Conceitos Básicos de Orientação a Objetos}

\subsection{1 - Introdução}

O Paradigma de Orientação a Objetos pode ser descrito como uma coleção de disciplinas de modelagem e desenvolvimento (engenharia) que visam a facilitar a construção de sistemas complexos a partir de componentes individuais de software que podem ser utilizados quando necessários [KHO90].

A necessidade desse novo paradigma de desenvolvimento/programação é bastante simples: os usuários estão desejando melhor funcionabilidade e desempenho de seus sistemas computacionais, além de ambientes mais simples e fáceis de serem utilizados.

A Orientação a Objetos proporciona melhores paradigmas e ferramentas para [KHO90]: usuário;

a) Modelar o "mundo real" da melhor forma possível segundo a perspectiva do

b) Ocorrer fácil interação do usuário com o ambiente computacional;

c) Contruir-se bibliotecas de módulos de software extensíveis.

Na programação Orientada a Objetos as entidades centrais são os dados, em vez de serem os procedimentos e as subrotinas, como ocorre no paradigma de programação procedimental. Essa é uma característica de a maioria das Linguagens de Programação Orientadas a Objetos [PRE92].

Os aspectos fundamentais que definem programas escritos em linguagens Orientadas a Objetos são:

1) Tipos Abstratos de Dados

2) Herança e Encapsulamento

Cada um desses aspectos será descrito nas seções seguintes.

\subsection{2 - Tipos Abstratos de Dados}

Os Tipos Abstratos de Dados (TADs) descrevem um conjunto de objetos com a mesma representação. Os objetos são as entidades básicas em tempo de execução de um sistema Orientado a Objetos compostos por um espaço interno, isto é, uma posição de memória em que valores podem ser armazenados e modificados ao longo ào tempo de vida útil do objeto, pois possuem um endereço associado, tal como um registro em 
Pascal ou uma estrutura em C [KOR90]. Ainda, um objeto é composto pelo seu possível comportamento, que é um conjunto de ações pré-definidas, denominadas métodos ou mensagens, através dos quais o objeto responderá à demanda de processamento por parte de outros objetos [TAK90].

Existe um número de operações associadas a cada conjunto de Tipo de Dados, e logo, a cada objeto pertencente a cada elemento desse conjunto. Os TADs estendem a noção de um Tipo de Dados através da atividade de esconder a implementação das operações definidas pelo usuário. Uma classe define um conjunto de objetos que possuem as mesmas características, que tenham comportamentos bastantes semelhantes, e é uma implementação de um TAD; isso significa que os detalhes de implementação da classe são privados à ela. Com os TADs há uma clara separação entre a interface externa para um tipo de dados e sua implementação. Devido ao fato da implementação estar separada da interface de um TAD, implemetações alternativas podem ser utilizadas, sem que seja necessária a alteração da interface. As classes são as construções lógicas utilizadas para a definição de TADs em linguagens Orientadas a Objetos, onde os TADs são implementados através delas.

O fato de uma classe ser uma implementação de um TAD implica que os detalhes de implementação da classe são disponíveis somente a ela. A interface que pode ser designada como pública dessa classe é composta por dois tipos de métodos: o primeiro consiste das funções de acesso que retornam abstrações sobre o estado dos objetos dessa classe (o estado de um objeto também pode ser designado por instanciação); o outro tipo de método é o procedimento de transformação utilizado para mover uma instância de um estado válido para outro [KOR90].

Uma definição de classe inclui:

1) O nome da classe;

2) As operações externas (denominadas de métodos ou mensagens) para manipular as instâncias da classe;

3) A representação interna; e

4) A implementação interna da interface.

Uma definição de classe também deve incluir o código necessário para implementar seus operadores de interface, álém das descrições das representações internas dos objetos (estados dos objetos). Os estados dos objetos são descritos por variáveis de instanciação. A Figura 2.1 mostra um exemplo de variáveis de instanciação definidas na linguagem $\mathrm{C}++[$ STR86]. 


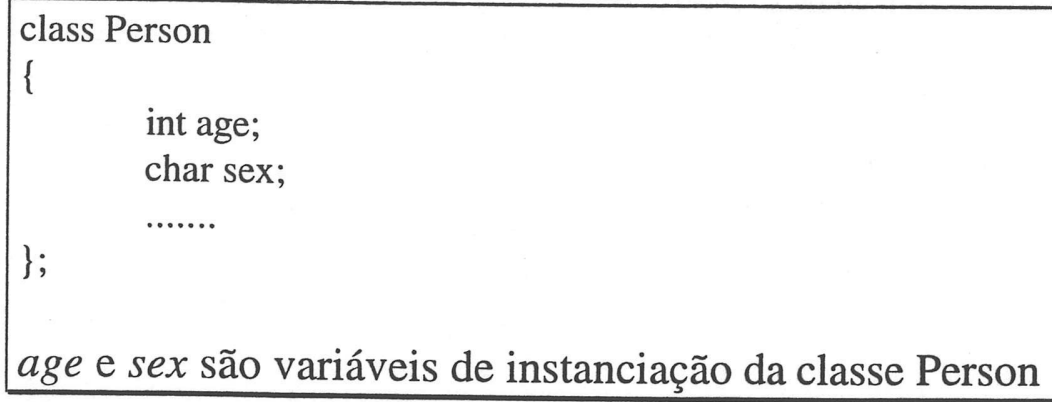

As classes declaram a estrutura (isto é, as variáveis de instanciação) de um conjunto de objetos, ou seja, as instâncias da classe. Uma definição de classe também especifica os métodos que definem o comportamento de suas instâncias e dos obtêm e atualizam as variáveis de instanciação. Um método pode, por exemplo, ser uma operação que aumente o salário de um vendedor dentro de uma empresa. Os métodos podem também retornar valores de variáveis de instanciação e valores calculados a partir dessas variáveis de instanciação.

Na maioria das Linguagens de Programação que apóiam esse paradigma, os objetos são criados pedindo-se à "fábrica" - a classe - "estampar" uma instância de sua produção - um objeto. Com isso, esse novo objeto poderá receber e enviar mensagens próprias de sua classe a outros objetos, além de seus valores internos poderem ser consultados ou atualizados. Com a finalidade de ser liberado o espaço em memória utilizado por um objeto que já não precise ser utilizado, esse objeto pode ser destruído para que as posições de memória onde eram armazenadas suas informações sejam utilizadas com outras finalidades.

O paradigma de Orientação a Objetos apresenta características de “Amarração Dinâmica" e Polimorfismo fundamentais para que seja facilitado o trabalho de codificação de uma aplicação.

"Amarração Dinâmica" (Dynamic Binding) é uma das vantagens mais freqüentemente utilizadas no estilo de programação Orientado a Objetos. Devido ao fato do sistema "amarrar" os seletores de mensagens aos métodos que os implementam em tempo de execução (ao invés disso ser feito em tempo de compilação como ocorre nas linguagens procedimentais), podem ser tiradas vantagens práticas, principalmente para a reutilização de métodos por diversas classes [MEY88]. Os métodos particulares utilizados na amarração dinâmica dependem da classe do objeto recipiente [KHO90]. O mesmo nome de método pode ser sobrecarregado com diferentes semânticas e implementações; por exemplo, um método print pode ser aplicado a inteiros, matrizes ou cadeias de caracteres. Para esse exemplo, podem existir três diferentes implementações do método print. Com isso, podem-se ter três métodos diferentes que 
possuem o mesmo nome, sendo que para cada um deles são passados parâmetros diferentes.

Além desse fator de sobrecarga de nome de método, a Amarração Dinâmica é necessária pois um valor de variável de instanciação pode somente ser conhecido em tempo de execução. Isso acontece em linguagens como Smalltalk que não possuem tipos de variáveis definidos [GOL84].

O Polimorfismo geralmente representa a qualidade ou estado de um objeto ser capaz de assumir diferentes formas [KHO90]. Quando aplicado às linguagens de programação indica que a mesma construção da linguagem pode assumir diferentes tipos, ou manipular objetos de diferentes tipos [WEB89]. Por exemplo, o operador + pode ser usado com inteiros, pontos-flutuantes, ou até mesmo strings.

\subsection{3 - Herança e Encapsulamento}

Herança é a relação entre classes que permite a definição e implementação de uma classe ser baseada nas definições de outras classes já existentes [KOR90]. Através da utilização da herança, os programadores podem construir novos módulos de software (tais como classes) sobre uma hierarquia de módulos existentes. Isso evita o reprojeto e a recodificação desses módulos. As novas classes podem herdar o comportamento, tais como operações e métodos, além da representação (variáveis de instanciação, atributos, etc.) das classes existentes. Esse comportamento de herança permite o compartilhamento de código, e com isso, a reusabilidade, entre dois módulos do software [KHO90].

Através da herança, os projetistas podem construir novos módulos de software (tais como classes) em cima de uma hierarquia de módulos. Isso evita que sejam reprojetados e recodificados módulos já existentes que se apliquem em casos um pouco diferentes para os quais eles foram definidos. Usando-se a relação de herança, todos objetos são membros de uma classe e herdam a estrutura de dados privados e as operações que foram definidas para essa classe.

As classes são inseridas em uma hierarquia de especialização, de tal forma que uma classe mais especializada herde todas as propriedades da classe mais geral a que ela imediatamente se subordine na hierarquia. A classe mais geral é denominada de superclasse, classe-pai ou classe-base e a classe mais especializada é denominada classe-filho ou subclasse. A herança é o mecanismo no qual uma classe-filho herda características de sua classe-pai e as estende ou restringe de algum modo. Essa relação pode ser pensada como a relação "é uma", onde a classe-filho é uma especialização da classe-pai. 
A herança de classes é estabelecida através da declaração explícita da relação de herança. A estrutura da definição de uma classe que herda características de outras classes pode ser a seguinte:

\section{classe vendedor "é-uma" subclasse da classe empregado}

Cada classe é declarada como uma subclasse de uma ou mais superclasses. Quando existe mais de uma superclasse, a relação de herança é denominada de herança múltipla. Podem existir problemas de conflito entre informações herdadas por uma subclasse provenientes de diferentes superclasses, como por exemplo, serem herdadas variáveis com mesmo nome, porém com tipos diferentes. A maioria das linguagens de programação Orientadas a Objetos proporciona mecanismos para se lidar com tais conflitos.

$\mathrm{Na}$ Figura 2.2 encontra-se um exemplo ilustrativo das relações de herança e de herança múltipla. A classe vendedor herda características da classe empregado e da classe pessoa, o que caracteriza Herança Múltipla; o mesmo ocorre com a classe secretário. Já as classes estudante e empregado herdam características apenas da classe pessoa, o que determina o mecanismo de herança simples. Nem todas as linguagens de programação Orientadas a Objetos possuem o mecanismo de herança múltipla.

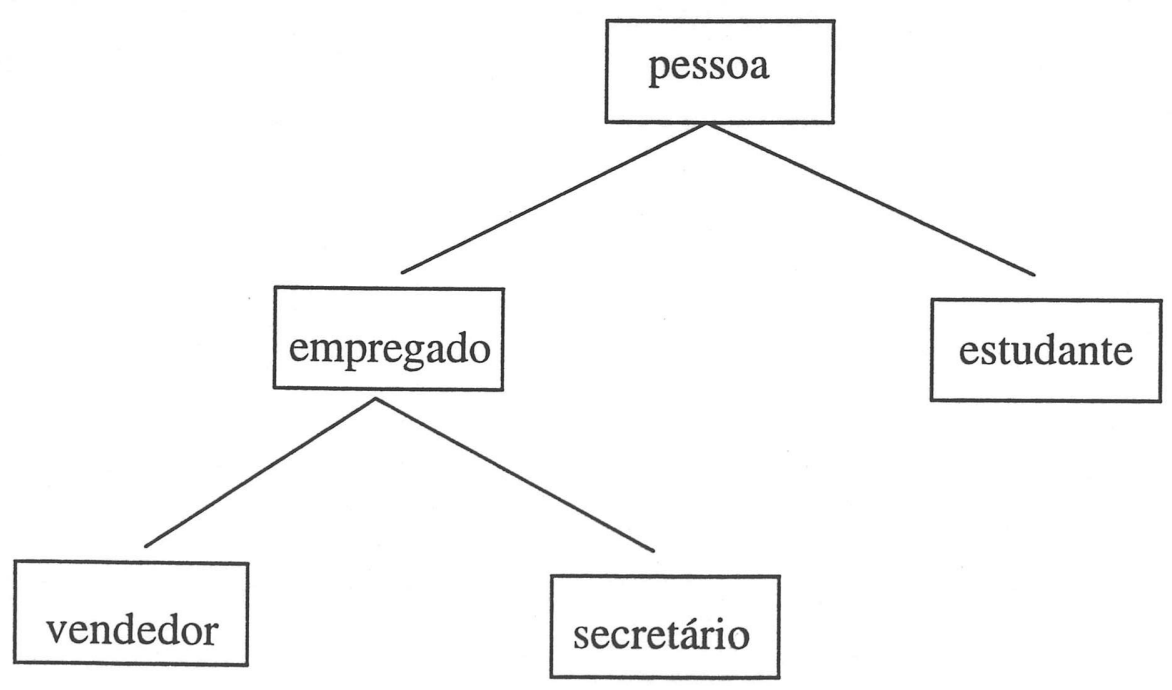

FIGURA 2.2 - EXEMPLO DAS RELAÇÕES DE HERANÇA E HERANÇA MÚLTIPLA

A herança não apenas facilita a reutilização entre sistemas, como também facilita diretamente a extensibilidade dentro de um dado sistema [KOR90]. 
O comportamento de uma classe é especificado e utilizado nos métodos associados às instâncias dessa classe. Os métodos são operações que podem utilizar e/ou atualizar o estado de um objeto. Em uma hierarquia de herança, um método definido por uma classe é herdado por suas subclasses; o que implica que os métodos herdados são parte da interface que manipulam as instâncias da subclasse e podem ser invocados por elas. Com a finalidade de se manter separado a interface e a implementação dos métodos pode ser utilizada a técnica de encapsulamento de dados.

Encapsulamento de dados é uma técnica empregada para garantir o ocultamento de informações, onde a interface e a implementação de uma unidade são sintaticamente separadas. Isso permite ao programador esconder as decisões de projeto dentro da implementação, e apontar as possíveis interdependências com outros componentes através da interface. $\mathrm{O}$ encapsulamento encoraja a modularidade do programa, isola as unidades desenvolvidas, e restringe as implicações de possíveis mudanças. Em particular, se um programador mudar a implementação de um unidade, mantendo a interface da mesma, as outras unidades não devem ser afetadas por essa mudança.

\section{3 - Linguagens Orientadas a Objetos}

Serão descritas nessa seção as características básicas das principais linguagens Orientadas a Objetos. A natureza das linguagens de programação Orientadas a Objetos está na sua habilidade de construir quatro importantes conceitos de software: abstração, modularidade, ocultamento de informações e segurança [PRE87]. Essas características motivaram a utilização cada vez maior das linguagens Orientadas a Objetos como uma forma de se desenvolver softwares de forma mais rápida e eficiente. Durante os anos 80 , a rápida evolução de linguagens como Ada e Smalltalk causou aumento cada vez maior da popularidade e da utilização da Orientação a Objetos, que vem sendo utilizada em softwares que variam desde animações de computação gráfica [LOR86] até telecomunicações [LOV85].

A primeira linguagem Orientada a Objetos lançada no mercado foi SIMULA, baseada em linguagens estilo ALGOL (do final da década de 60) e foi a linguagem que norteou as definições das linguagens Ada, Object Pascal e Smalltalk (em suas várias versões posteriores). Ao final da década de 70 houve o aparecimento da linguagem $\mathrm{C}$ da qual se originaram duas novas e importantes linguagens Orientadas a Objetos: Eiffel e $\mathrm{C}++$.

A Figura 2.3 mostra uma visão da genealogia das principais linguagens de programação Orientadas a Objetos, tais como Smalltalk, C++, Simula, Ada e Eiffel.

O ambiente TOOL [SPA94] foi desenvolvido como um esforço da indústria brasileira de produção de software SPA - Sistemas Planejamento e Análise S. A. - para 
propiciar um ambiente gráfico e interativo que se utilize dos conceitos de Orientação a Objetos.

A linguagem C++ [STR86] será descrita com maiores detalhes na Seção seguinte por ter sido a linguagem escolhida neste trabalho para que seja realizado o seu mapeamento automatizado para a LI++.

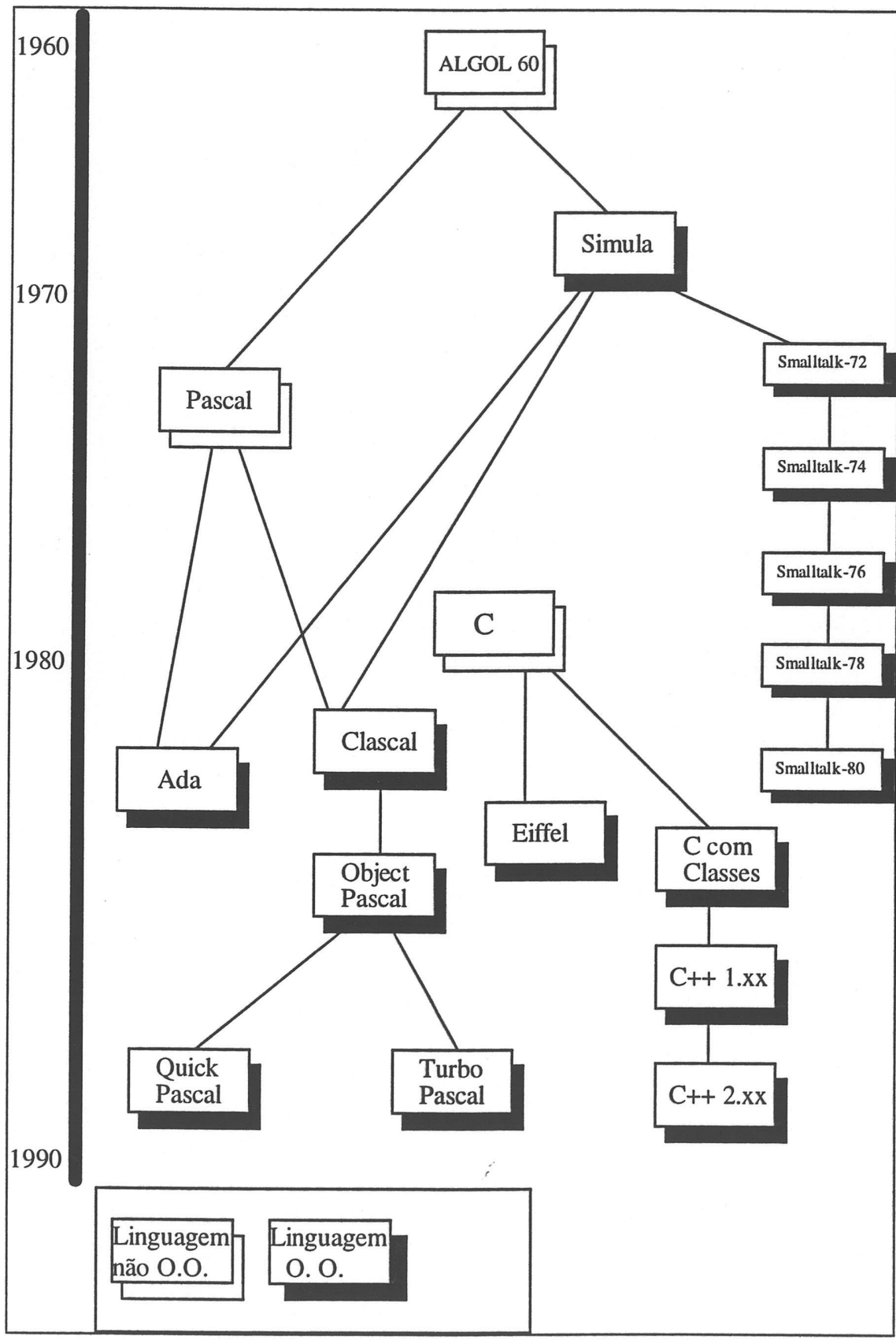

Figura 2.3 - GENEALOGIA DAS Linguagens DE PROGRAMAÇÃo [BER92] 


\subsection{1 - C++}

C++ é uma linguagem de programação Orientada a Objetos, de propósito geral com o intuito de tornar a tarefa de programação mais agradável [STR86]. C++ é um superconjunto da linguagem $\mathrm{C}$ e fornece facilidades para definição de novos tipos, que englobam objetos que contenham mesmo relacionamento de tipos.

$\mathrm{O}$ conceito chave da linguagem $\mathrm{C}++$ é a classe. As classes fornecem encapsulamento de dados, garantem a inicialização dos dados, tipagem dinâmica, gerenciamento de memória controlado pelo usuário e mecanismos de sobrecarga de operadores [ECK91].

C++ contém também melhorias não diretamente relacionadas às classes, tais como a inclusão de constantes simbólicas, substituição direta de funções, argumento de funções padrão (default), entre outras.

Todas essas características proporcionam garantias aos programadores, para que sejam implementados os Tipos Abstratos de Dados com um alto grau de eficiência. Ainda, C++ permite a utilização de hierarquia de classes para que sejam herdados métodos e variáveis de instanciação de classes definidas anteriomente. A partir da versão 2.0 dessa linguagem, foi incluída a possibilidade de emprego de Herança Múltipla [STR86].

\subsubsection{2 - Definição de Classes}

O objetivo do conceito de classe em $\mathrm{C}++$ é fornecer ao programador uma ferramenta para a criação de novos tipos que podem ser utilizados convenientemente para a construção de Tipos Abstratos de Dados.

Considere o exemplo descrito na Figura 2.4, extraído de [STR86]. O rótulo public separa o corpo da classe em duas partes. Os nomes na primeira parte (private por default) somente podem ser utilizados pelos métodos pertencentes à esta classe, e portanto possuem as características de terem suas utilizações privadas aos métodos da classe. A segunda parte, que é a parte pública, constitui a interface da classe com os seus objetos. 


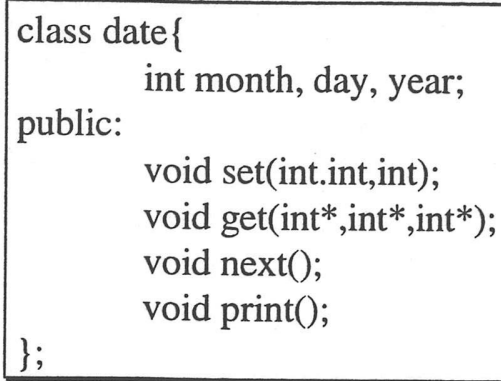

FIGURA 2.4 - EXEMPLO DE DEFINIÇÃO DE ClASSE EM C++

Um construtor de uma classe em C++ é definido como um método público, possui o mesmo nome da classe, e tem como objetivo criar uma nova instância (objeto) dessa classe. Opcionalmente, um construtor pode aceitar parâmetros para serem utilizados na inicialização do objeto, sendo que uma classe pode possuir mais de um construtor. O que determina a variação entre qual objeto "chama" qual tipo de construtor é a quantidade e o tipo dos parâmetros utilizados.

Um destrutor de uma classe C++ não aceita argumentos como parâmetros e tem a função de liberar espaço de memória utilizados para o armazenamento de objetos instanciados, e que não serão mais utilizados. Para uma classe de nome N_CLASS, o seu construtor deve ser definido como N_CLASS(parâmetros) e seu destrutor como $\sim \mathrm{N} \_$CLASS(). Os parâmetros do construtor são opcionais.

\subsubsection{3 - Herança e Sobrecarga}

Em $\mathrm{C}++$, as características de um TAD definido pelo usuário (uma classe) podem ser herdadas por outro. Quando se herda, sabe-se que esta nova classe é uma classe antiga com algumas modificações (adições ou restrições) [ECK91].

A definição de uma subclasse que herde as características de uma superclasse utilizando a linguagem $\mathrm{C}++$ deve seguir o escopo definido na Figura 2.5.

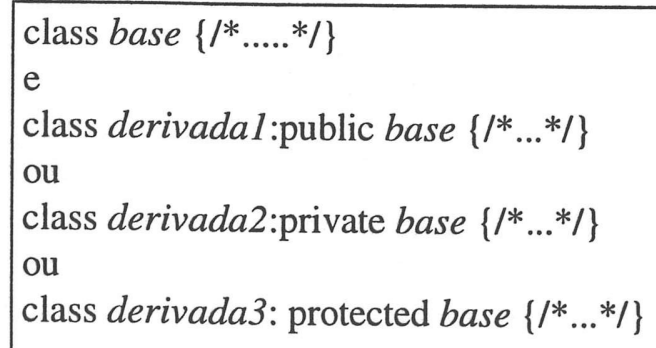

FiguRA 2.5 - ESCOPO DE DEFINIÇÃo DE SUBCLASSE [ECK91]

Um exemplo dessa utilização se encontra na Figura 2.6, e foi extraído de [STR86]. 


\begin{tabular}{|l|l|}
\hline class employee \{ & class manager:public employee \{ \\
$\quad$ char *name; & //....... \\
I/....... & public: \\
public: & void print(); \\
$\quad$ employee* next; & \\
$\quad$ void print(); & \\
\hline ; & \\
\hline
\end{tabular}

FIGURA 2.6 - EXEMPLO DE HERANÇA

Nesse exemplo, a classe manager herda algumas características da classe employee (nesse caso o campo name) e redefine a impressão (o método print) proporcionando modificações na subclasse. Para que seja determinado corretamente qual método print deve ser chamado em um certo momento, é preciso que se tenha sido definido um objeto que pertença a uma das duas classes (manager ou employee) e efetuar a sua chamada. Desse modo é tratado o problema de sobrecarga de métodos que possuam o mesmo nome em $\mathrm{C}++$. Como exemplo tem-se:

\section{employee E; manager $M$; \\ /*...........*/ \\ E.print(); \\ M.print();}

A descrição do corpo de cada um desses métodos print pode seguir o mesmo tipo de estrutura definida na Figura 2.7.

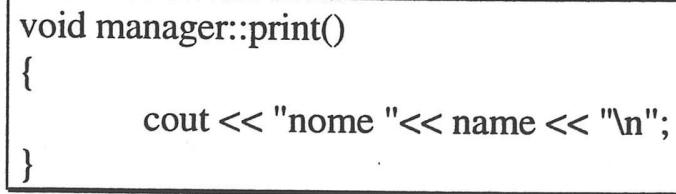

FIGURA 2.7 - EXEMPLO DE DESCRIÇÃO DE MÉTODO

A linguagem $\mathrm{C}++$ permite sobrecarga de métodos e de operadores. Os métodos podem ser sobrecarregados e podem possuir o mesmo nome, porém com parâmetros diferentes em uma mesma classe, ou então podem pertencer a classes diferentes. $\mathrm{C}++$ também permite que operadores tais como $+,-, *, /$, e outros, sejam sobrecarregados para classes definidas pelo usuário. Assim pode-se ter $\mathrm{A}+\mathrm{B}$, onde $\mathrm{A}$ e $\mathrm{B}$ podem ser matrizes, inteiros, strings, ou quaisquer outros tipos de dados que o usuário deseje. 
É possível que se declare alguns membros públicos de uma classe-base em uma subclasse. Um exemplo ilustrativo foi extraído de [STR94]:

class manager:public employee \{

public:

$$
\text { II............. }
$$

employee::name;

\};

employee::department;

A notação nome_da_classe::nome_do_membro; não introduz um novo membro; ela simplesmente cria um membro de uma classe como público para uma subclasse. Desse modo, name e department podem ser utilizados por um objeto da classe manager. Entretanto, os demais métodos da classe employee não são públicos para a classe manager.

Essas características, adicionadas àquelas que se encontram resumidas na Tabela 2.2, fazem da Herança e da Herança Múltipla um dos principais artifícios da linguagem $\mathrm{C}++$ com relação à utilização das características de linguagens Orientadas a Objetos.

Tabela 2.2 - Características da Linguagem C++

\begin{tabular}{|l|l|l|}
\hline Abstração & $\begin{array}{l}\text { Variáaeis } \\
\text { Métodos }\end{array}$ & $\begin{array}{l}\text { Sim } \\
\text { Sim }\end{array}$ \\
\hline Encapsulamento & $\begin{array}{l}\text { De varíaveis } \\
\text { De métodos }\end{array}$ & $\begin{array}{l}\text { public, protected, private } \\
\text { public, protected, private }\end{array}$ \\
\hline Hierarquia & Herança \\
Generic units & $\begin{array}{l}\text { Múltipla } \\
\text { Não }\end{array}$ \\
\hline Tipagem & $\begin{array}{l}\text { Fortemente tipada } \\
\text { Polimorfismo }\end{array}$ & $\begin{array}{l}\text { Sim } \\
\text { Sim }\end{array}$ \\
\hline Concorrência & Multitarefa & Não \\
\hline
\end{tabular}

\subsection{2 - Eiffel}

$\mathrm{O}$ compilador da linguagem Eiffel utiliza a linguagem $\mathrm{C}$ como linguagem intermediária, tornando Eiffel potencialmente portável para qualquer ambiente que suporte a linguagem C. Os princípios gerais de Eiffel seguem as seguintes tendências: reusabilidade, extensibilidade e compatibilidade [MEY88].

Para atingir os aspectos de corretude, robustez, portabilidade e eficiência, a linguagem é baseada nos princípios de Orientação a Objetos e possui as seguintes características: 
- A ênfase está no estruturamento do sistema entre as classes de objetos que a linguagem manipula em vez das funções que ele executa sobre elas, e na reutilização de estruturas abstratas de dados.

- Os objetos são descritos como instâncias dos Tipos Abstratos de Dados.

- A unidade básica - a classe - descreve a implementação de um conjunto de objetos do mesmo Tipo Abstrato de Dados.

- Reflete a existência de relações importantes entre as classes, particularmente a relação de herança múltipla.

Eiffel permite e encoraja os programadores a expressarem as propriedades formais das classes escrevendo assertivas que podem aparecer da seguinte forma:

. "preconditions" da rotina: expressam as condições que devem ser satisfeitas toda vez que uma rotina é chamada;

- "postconditions" da rotina: expressam as condições que devem ser garantidas como verdadeiras no retorno (final) da rotina;

- "class invariants": devem ser satisfeitas pelos objetos da classe a qualquer momento, ou precisamente, após haver sido chamada uma rotina da classe. Representam restrições que podem ser impostas a todas as rotinas da classe.

No mecanismo de herança da linguagem Eiffel, qualquer método herdado que possua nome igual ao da superclasse deve ser renomeado. Meyer apresenta um apanhado de ótima qualidade a respeito da linguagem Eiffel [MEY88], mostrando diversos exemplos ilustrativos das principais características dessa linguagem. Essas características estão sumarizadas na Tabela 2.3.

Tabela 2.3 - Características da Linguagem Eiffel

\begin{tabular}{|l|l|l|}
\hline Abstração & $\begin{array}{l}\text { Variáveis } \\
\text { Métodos }\end{array}$ & $\begin{array}{l}\text { Sim } \\
\text { Sim }\end{array}$ \\
\hline Encapsulamento & De varíveis & (pre/pos)conditions \\
& De métodos & (pre/pos)conditions \\
\hline Hierarquia & Herança & Múltipla \\
& Generic units & São \\
\hline Tipagem & Fortemente tipada & Sim \\
\hline Concorrência & Polimorfismo & Não \\
\hline
\end{tabular}




\subsection{3 - Ada}

Ada é o resultado do esforço do Departamento de Defesa dos Estados Unidos para reduzir o custo do desenvolvimento de software. Ada contém as estruturas normais de controle e a capacidade de definir tipos e subprogramas (rotinas). Proporciona o projeto modular via conceito de pacote (package). Os pacotes permitem que os componentes (contruções, tipos, dados e subprogramas), sejam divididos em pedaços de projeto lógico. A modularidade também é provida ao permitir a compilação separada de várias unidades. Os pacotes correspondem à noção de classes de um ambiente Orientado a Objetos.

Além das características de Orientação a Objetos, Ada proporciona construções para auxiliar no desenvolvimento de aplicações de tempo real. Elas incluem modelos de se manipular a execução de tarefas paralelas. Esse tipo de implementação não será discutido nessa seção por não ser uma característica própria de Orientação a Objetos dessa linguagem, e que portanto, não se encaixa no contexto desse trabalho.

Ada suporta diversos conceitos de Orientação a Objetos, tais como Tipos Abstratos de Dados e Polimorfismo. O único conceito Orientado a Objetos que Ada não suporta é a Herança.

O conceito de Tipos Abstratos de Dados é suportado pela linguagem Ada através da noção de pacotes. Os pacotes permitem ao usuário agrupar entidades lógicas relacionadas como uma única unidade. Os tipos definidos pelo usuário podem ser definidos baseados na especialização de tipos existentes ou de outros tipos definidos pelos usuários.

Os nomes de funções e operadores definidos pelo sistema podem ser sobrecarregados (overloaded) por funções definidas pelos usuários. O Polimorfismo é alcançado via generic units (unidades genéricas). Uma unidade genérica pode ser um subprograma ou uma unidade package. Ada também suporta ponteiros.

Ada é uma linguagem fortemente tipada, o que significa que os únicos operadores permitidos em um objeto são aqueles definidos como válidos pelo tipo do qual o objeto é um membro, e os objetos são tipados estaticamente em tempo de compilação.

Ada suporta três tipos de sobrecarga: de nome, de função e de operadores. A sobrecarga de nome permite um literal enumerado ou caracter ser utilizado em mais de uma definição. A de função permite a reutilização da mesma função ou do mesmo subprograma para duas diferentes implementações, enquanto que a sobrecarga de operadores permite estender a maioria dos operadores da linguagem Ada para tipos definidos pelo usuário. 
Os Tipos Abstratos de Dados são implementados em Ada através de pacotes, que são utilizados para agrupar entidades lógicas relacionadas. Um pacote normalmente é dividido em duas partes: uma especificação do pacote (obrigatória) e o corpo do pacote (opcional). A especificação é a parte declarativa da estrutura do pacote, definindo os componentes do pacote que são visíveis para o usuário. $\mathrm{O}$ corpo do pacote contém definições que são escondidas dos usuários, e essas definições são usadas apenas dentro da estrutura do pacote, de forma bastante semelhante ao que ocorre em uma classe na linguagem $\mathrm{C}++$. Na Tabela 2.4 estão sumarizadas as principais características da linguagem Ada.

Com relação aos conceitos de Orientação a Objetos, Khoshafian apresenta uma excelente explanação sobre a linguagem Ada em [KHO90].

Tabela 2.4 - Características da Linguagem Ada

\begin{tabular}{|l|l|l|}
\hline Abstração & $\begin{array}{l}\text { Variáveis } \\
\text { Métodos }\end{array}$ & $\begin{array}{l}\text { Sim } \\
\text { Sim }\end{array}$ \\
\hline Encapsulamento & $\begin{array}{l}\text { De variáveis } \\
\text { De métodos }\end{array}$ & - \\
\hline Hierarquia & $\begin{array}{l}\text { Herança } \\
\text { Generic units }\end{array}$ & $\begin{array}{l}\text { Não } \\
\text { Sim }\end{array}$ \\
\hline Tipagem & $\begin{array}{l}\text { Fortemente tipada } \\
\text { Polimorfismo }\end{array}$ & $\begin{array}{l}\text { Sim } \\
\text { Não }\end{array}$ \\
\hline Concorrência & Multitarefa & Sim (definida pela linguagem) \\
\hline
\end{tabular}

\subsection{4 - Smalltalk}

Smalltalk é um ambiente de programação gráfico e interativo. Smalltalk é projetada de modo que cada componente no sistema acessível ao usuário possa ser apresentado de modo significativo para observação e manipulação. As regras de interface em Smalltalk propiciam a criação de uma linguagem visual para cada objeto. O sistema Smalltalk-80 utilizado como padrão para essa seção descrito em [GOL83] é formado por vários componentes. Ele inclui objetos que fornecem funções normalmente atribuídas a um Sistema Operacional: gerenciamento de armazenagem automático, sistema de arquivos, controlador de display, edição de textos e figuras, etc. Smalltalk é contruído sobre o modelo de objetos comunicantes [GOL83].

O sistema Smalltalk-80 inclui um conjunto de classes que fornecem a funcionalidade padrão para uma linguagem de programação e seu ambiente: controle aritmético, estruturas de dados e facilidades de entrada e saída desses dados. A maioria dos objetos no sistema Smalltalk funciona como uma estrutura de Tipo Abstrato de Dados, e as classes representam a coleção de estruturas que possuem a mesma caracterísitica. 
Dois modos de apresentação de uma classe são requeridos em Smalltalk: um descreve a funcionalidade das instâncias e o outro descreve a implementação dessa funcionalidade. Cada mensagem desse ambiente é acompanhada por um comentário descrevendo a operação que a instância irá executar quando ela for executada, definindo dessa forma o protocolo de descrição; o protocolo de implementação mostra como a funcionalidade descrita no protocolo de descrição é implementada. Uma descrição de implementação dá a forma das instâncias privadas e o conjunto de métodos que descrevem como as instâncias irão executar suas operações. Uma descrição de implementação possui três partes: um nome de classe, uma declaração de variáveis disponíveis às instâncias e os métodos utilizados pelas instâncias para responderem às mensagens. Uma mensagem (método) é descrita como um procedimento que executa uma das operações de um objeto.

Uma subclasse especifica que suas instâncias irão ser as mesmas instâncias de uma outra classe, chamada de superclass (superclasse), com exceção das diferenças explicitamente colocadas. Uma subclasse pode possuir suas próprias subclasses, constituindo o mecanismo de herança múltipla da linguagem Smalltalk, e cada subclasse herda as declarações de variáveis e os métodos de sua superclasse. $\mathrm{Na}$ Tabela 2.5 estão especificadas as principais características da linguagem Smalltalk.

Tabela 2.5 - Características da Linguagem Smalltalk

\begin{tabular}{|l|l|l|}
\hline Abstração & $\begin{array}{l}\text { Varíveis de instanciação } \\
\text { Métodos de instanciação }\end{array}$ & $\begin{array}{l}\text { Sim } \\
\text { Sim }\end{array}$ \\
\hline Encapsulamento & De variáveis & private \\
& De métodos & public \\
\hline Hierarquia & Herança & Simples \\
& Generic units & Não \\
\hline Tipagem & Fortemente tipada & Não \\
& Polimorismo & Simples) \\
\hline Concorrência & Multitarefa & Não \\
\hline
\end{tabular}

\subsection{5 - TOOL}

O ambiente TOOL [SPA94] é um esforço que vem sendo realizado pela indústria brasileira de produção de software SPA - Sistemas, Planejamento e Análise S.A. com a finalidade de proporcionar um ambiente de programação gráfico, interativo e que se utilize dos conceitos de Orientação a Objetos.

O principal objetivo do ambiente TOOL é facilitar a construção e a execução de programas escritos na linguagem de programação Orientada a Objetos TOOL. Para isso, o ambiente TOOL proporciona várias funções, tais como edição de texto, compilação de código-fonte, entre outras. 
TOOL deve ser executado no ambiente WINDOWS e se utiliza dos recursos gráficos oferecidos por este ambiente. Isso significa que um programador que se utilize do ambiente TOOL conduz o desenvolvimento e a execução de uma aplicação TOOL ativando ícones em sua tela, utilizando o mouse ou o teclado. Logo, os usuários que estão familiarizados com o ambiente WINDOWS não encontram maiores dificuldades para enteder as interfaces do ambiente TOOL. Além disso, o sistema de programação TOOL oferece construtores visuais que permitem a criação e a utilização de bases de dados, de relatórios, etc.

Um programa TOOL é basicamente uma coleção de classes. Por ser proporcionado um mecanismo de herança na linguagem de programação TOOL, uma classe pode ser utilizada na construção de outras classes. A descrição dos métodos de cada classe é feita de forma particular, onde os métodos implementam operações a serem realizadas nos objetos e são declarados dentro da classe que contenha esses objetos. O ambiente TOOL proporciona classes estendidas que contêm características adicionais àquelas das classes tradicionais para que possa ser realizada uma forma assíncrona de passagem de mensagens entre os objetos.

Uma classe na linguagem TOOL é uma unidade de programa com dois propósitos fundamentais: (1) modelar os objetos, definindo basicamente suas estruturas de dados e as operações que podem ser aplicadas a eles; e (2) a criação de classes mais especializadas através do mecanismo de herança, onde uma classe pode ser descrita como uma especialização de uma super-classe [SPA94].

As classes na linguagem TOOL podem ser convencionais ou estendidas. As classes convencionais possuem estruturas praticamente idênticas às das classes encontradas em outras linguagens de programação Orientadas a Objetos, tais como $\mathrm{C}++$, Eiffel, etc. Cada classe estendida (que deve ser descrita como XCLASS) é basicamente criada para que as mensagens possam ser passadas de modo assíncrono. A vantagem da passagem de mensagens de modo assíncrono está no fato de que o método que envia uma mensagem não ter que esperar pelo método que a recebe terminar sua execução: tanto o método que envia quanto o método que recebe a mensagem continuam suas execuções após o envio da mensagem. As mensagens assíncronas são muito utilizadas em aplicações gráficas.

O ambiente TOOL possui mecanismos de definição e controle das mensagens, que podem ser utilizados para separar completamente a parte da interface de uma classe da parte que desceve sua implementação. A linguagem de programação TOOL possui diversas características encontradas na demais linguagens de programação Orientadas a Objetos, e que estão sumarizadas na Tabela 2.6.

Um dos aplicativos do ambiente TOOL é o construtor visual (Visual TOOL), que é totalmente escrito utilizando a linguagem de programação TOOL. A idéia básica 
desse construtor é proporcionar aos usuários do ambiente TOOL diversas facilidades para que sejam criadas contruções visuais com a utilização do mouse ou do teclado, e então, automaticamente construir o código-fonte em TOOL, que quando compilado e executado, gere exatamente os objetos criados visualmente. Utilizando o Visual TOOL podem ser construídos relatórios, bases de dados e "caixas de diálogos". Uma "caixa de diálogo" serve para libertar o programador da especificação e definição das especificações de controle dos objetos, tais como os atributos de posicionamento na tela, lista de procedimentos a serem executados, entre outros. Cada dispositivo do Visual TOOL é colocado como um ícone para o usuário de forma a facilitar suas utilizações.

Tabela 2.6 - Características da Linguagem TOOL

\begin{tabular}{|c|c|c|}
\hline Abstração & $\begin{array}{l}\text { Variáveis de instanciação } \\
\text { Métodos de instanciação }\end{array}$ & $\begin{array}{l}\text { Sim } \\
\text { Sim }\end{array}$ \\
\hline Encapsulamento & $\begin{array}{l}\text { De variáveis } \\
\text { De métodos }\end{array}$ & $\begin{array}{l}\text { shared } \\
\text { public }\end{array}$ \\
\hline Hierarquia & $\begin{array}{l}\text { Herança } \\
\text { Generic units }\end{array}$ & $\begin{array}{l}\text { Simples } \\
\text { Não }\end{array}$ \\
\hline Tipagem & $\begin{array}{l}\text { Fortemente tipada } \\
\text { Polimorfismo }\end{array}$ & $\begin{array}{l}\text { Sim } \\
\text { Sim }\end{array}$ \\
\hline Concorrência & Multitarefa & Não \\
\hline
\end{tabular}

\subsection{6 - JAVA}

JAVA é uma linguagem de programação Orientada a Objetos que apresenta uma característica bastante relevante nas linguagens de programação que apóiam esse paradigma: é simples e fácil de ser empregada em uma grande variedade de aplicações de desenvolvimento de software. JAVA é bastante parecida com C++.. Os programadores que estiverem familiarizados essa linguagem não encontrarão dificuldades com o aprendizado da linguagem JAVA [GOS95].

O código abaixo mostra, em caráter ilustrativo, um trecho de programa JAVA que imprime a frase HelloWorld!.

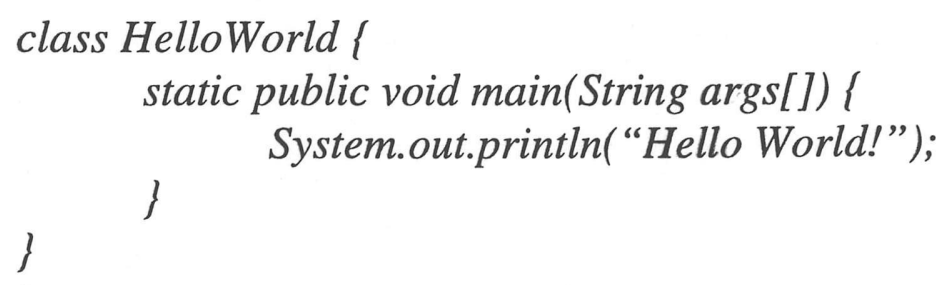

O exemplo acima declara uma classe HelloWorld. A estrutura de classes é idêntica à utilizada na linguagem $\mathrm{C}++$; os métodos, tal como System.out.println(), também são declarados e empregados como na linguagem $\mathrm{C}++$, e os tipos de dados 
também são os mesmos (int, long, short, char, etc.) e são declarados da mesma forma. Ainda, os comandos de desvio de fluxo e de iteração também são os mesmos e possuem a mesma sintaxe.

As principais diferenças entre JAVA e C++ são [GOS95]:

. JAVA não suporta herança múltipla. As facilidades que a herança múltipla proporciona são dadas pelas interfaces da linguagem JAVA. Uma interface é a definição de um conjunto de métodos que um ou mais objetos irá implementar. Uma regra importante de uma interface é que ela declara apenas métodos. Não se pode definir variáveis de instanciação utilizando-se interfaces.

. JAVA não permite a utilização de estruturas (struct em C++), uniões (union em $\mathrm{C}++$ ) ou tipos definidos (typedef em $\mathrm{C}++$ ) para se definir tipos de dados. A definição de classes em JAVA engloba tais características.

. JAVA não aceita a utilização de ponteiros. Qualquer tarefa que possa requisitar ponteiros pode ser facilmente realizada empregando-se apenas objetos e vetores (arrays) de objetos. Tal característica facilita bastante a manutenção e reutilização do código.

. JAVA não possui o comando de desvio incondicional (goto em $\mathrm{C}++$ ).

. JAVA não aceita sobrecarga de operadores.

A habilidade de se criar páginas WWW (Wide World Web) animadas utilizando JAVA é o que basicamente fez com que essa linguagem fosse difundida e sua popularidade tenha sido aumentada. Ainda, JAVA é bastante importante por ser portável: o código-fonte em JAVA pode ser executado em diversos sistemas, tais como Windows 95, Windows NT, Macintosh ou UNIX, o que a torna uma linguagem ideal para ser empregada na definição de softwares que "viajem" na Internet [NIE96]. A grande portabilidade da linguagem JAVA está na característica dela ser "précompilada" antes de ser enviada para outro ambiente em que será executada (via internet ou não). Nesse processo de pré-compilação são gerados bytecodes que são entendíveis por diversos ambientes (o código em bytecodes é que será transmitido). Somente na máquina em que será executada é que os bytecodes são interpretados. Entretanto, essa vantagem de interpretação dos bytecodes diminui bastante a segurança do código sendo enviado, pois não existe mecanismo capaz de fazer com que tal código seja executado apenas para o cliente que se deseja, principalmente se for utilizada a WWW como meio de transmissão. 
Por ser uma linguagem de programação Orientada a Objetos, JAVA possui características comuns às demais linguagens desse paradigma. As principais características dessa linguagem estão sumarizadas na Tabela 2.7.

Tabela 2.7 - Características da Linguagem JAVA

\begin{tabular}{|l|l|l|}
\hline Abstração & $\begin{array}{l}\text { Varíaveis de instanciacão } \\
\text { Métodos de instanciação }\end{array}$ & $\begin{array}{l}\text { Sim } \\
\text { Sim }\end{array}$ \\
\hline Encapsulamento & $\begin{array}{l}\text { De varáveis } \\
\text { De métodos }\end{array}$ & $\begin{array}{l}\text { shared } \\
\text { public }\end{array}$ \\
\hline Hierarquia & Herança & $\begin{array}{l}\text { Simples } \\
\text { Não }\end{array}$ \\
\hline Tipagem & $\begin{array}{l}\text { Goneric units } \\
\text { Polimente tipada }\end{array}$ & $\begin{array}{l}\text { Sim } \\
\text { Sim }\end{array}$ \\
\hline Concorrência & Multitarefa & Não \\
\hline
\end{tabular}

\subsection{7 - Uma Comparação entre as Linguagens}

A Tabela 2.8 sumariza algumas características das principais linguagens Orientadas a Objetos.

Tabela 2.8 - Características das Principais Linguagens Orientadas a Objetos

\begin{tabular}{|l|l|l|l|l|l|l|}
\hline & Ada & C++ & Eiffel & JAVA & Smalltalk & TOOL \\
\hline TAD & packages & class & class & class & class & $\begin{array}{l}\text { class } \\
\text { xclass }\end{array}$ \\
\hline $\begin{array}{l}\text { Overloa } \\
\text { ding / } \\
\text { Polimorfis } \\
\text { mo }\end{array}$ & $\begin{array}{l}\text { nome, } \\
\text { função e e e } \\
\text { operadores } \\
\text { generic } \\
\text { units }\end{array}$ & $\begin{array}{l}\text { nome, } \\
\text { função e e } \\
\text { operadores } \\
\text { amarração } \\
\text { dinâmica }\end{array}$ & $\begin{array}{l}\text { função / } \\
\text { redefinição } \\
\text { de métodos }\end{array}$ & $\begin{array}{l}\text { nome e } \\
\text { função } \\
\text { amarração } \\
\text { dinâmica }\end{array}$ & $\begin{array}{l}\text { nome e } \\
\text { função }\end{array}$ & $\begin{array}{l}\text { nome, } \\
\text { função e } \\
\text { operadores }\end{array}$ \\
\hline $\begin{array}{l}\text { Encapsula } \\
\text { mento }\end{array}$ & sim & sim & sim & sim & sim & sim \\
\hline Herança & não & sim & sim & sim & sim & sim \\
\hline $\begin{array}{l}\text { Herança } \\
\text { Múltipla }\end{array}$ & não & sim & sim & não & não & sim \\
\hline
\end{tabular}




\section{4 - Os problemas com o Teste de Programas Orientados a Objetos}

O teste de programas Orientados a Objetos é uma área bastante incipiente e que está sendo amplamente estudada pela comunidade científica, onde podem ser destacados diversos trabalhos nessa área: [ARN94], [BER92], [DOO94], [HAR92], [JOR94], [MUR94], [POS94], [SMI92], [HAR92], entre outros. Alguns desses trabalhos propõem estratégias de teste com a finalidade de se estender as técnicas e critérios já consolidados do teste de programas procedimentais para programas Orientados a Objetos. Entretanto, encontram-se diversos problemas para que se utilize as mesmas técnicas e critérios, principalmente pelo fato dos sistemas Orientados a Objetos poderem ser considerados, do ponto de vista do testador, em diferentes níveis de abstrações. Esses níveis foram definidos por Smith em [SMI92] da seguinte forma:

(1) o nível algoritmico: considera o código escrito do método. Diz respeito à manipulação de dados dentro do método, o que é basicamente procedimental;

(2) o nível de classe: consiste nas interações entre os métodos e os dados que esses encapsulam;

(3) o nível de cluster: considera as interações entre os grupos de classes que "colaboram" entre si. Também pode ser considerado como o relacionamento entre classes que pertencem a uma mesma hierarquia de herança (simples ou múltipla); e

(4) o nível de sistema: contém o código de todas as classes, das rotinas independentes e do programa principal necessários para que se rode o sistema.

Desses quatro níveis, o algorítmico pode ser facilmente testado usando-se as técnicas procedimentais para o Teste de Unidade (técnica estrutural basicamente) e o nível de sistema se assemelha ao Teste de Sistema.

Nos níveis de classe e de cluster os objetos e as classes contêm métodos e estruturas de dados que fazem acesso e atualizam o estado dos objetos. Os objetos e classes do modelo Orientado a Objetos contêm rotinas e possíveis estruturas de dados que armazenam os estados dos objetos. Nenhum ordenamento da invocação das operações é explicitamente especificado pará um objeto que tenha sido criado. Com isso não se tem um modelo entrada - processo - saída sequiêncial, como se tem em programas estruturais. As técnicas de teste de softwares procedimentais nem sempre podem ser diretamente aplicáveis em programas Orientados a Objetos, pois a análise dos fluxos de dados e de controle pode necessitar ser aplicada em relações de interações inter-classes. 
Dentre os trabalhos citados anteriormente, o autor dessa dissertação considera que merecem destaque os trabalhos de Harrold [HAR92], Berard [BER92] e Perry e Kaiser [PER90]. Harrold propõe uma estratégia de se testar cada classe individualmente, onde os casos de teste projetados para o teste de uma classe-base podem ser aproveitados para o teste das subclasses. Essa estratégia será descrita na Seção 2.4.1. Berard aborda a problemática do teste de integração de classes, enquanto que Perry e Kaiser abordam o impacto do encapsulamento à luz dos axiomas de teste propostos por Weyuker [WEY86], [WEY88].

Segundo Berard a menor unidade a ser testada é a classe (e suas instâncias). Além disso, o conceito de unidade não é o mesmo que em sistemas tradicionais, onde uma unidade pode ser vista como um subprograma (um procedimento ou uma subrotina). Um subprograma em uma classe deve ser considerado como um dos métodos que compõem a classe. Integrar um por vez os métodos em uma classe pode não ser uma boa opção por haver dificuldades para que seja realizada a integração. Como ilustração, sabe-se que existem interações diretas e indiretas entre os componentes que formam uma classe (que são os métodos).

Berard ainda aponta que existem outras implicações para o teste de integração em um ambiente Orientado a Objetos. Por exemplo, em softwares tradicionais, as hierarquias de invocações (módulo A chama o módulo B, que eventualmente retorna o controle para o módulo A) são as normas. Os softwares Orientados a Objetos não são requeridos a suportar uma invocação de hierarquia tão rigorosa, ou seja, o objeto $\mathrm{A}$ pode interagir diretamente com o objeto $\mathrm{B}$, sem necessariamente ter que passar por um objeto intermediário (de controle). Isso leva à frase que softwares Orientados a Objetos não possuem tops (topos), e portanto, pode não haver um módulo de controle-mestre no ápice de alguma hierarquia de invocação. Se forem tratados sistemas que não possuem tops então seria praticamente impossível definir estratégias de teste de integração do tipo top-down ou bottom-up, pois elas assumem que deve haver um top e um bottom (fundo) previamente definidos. Isso significa que novas estratégias de teste deverão ser desenvolvidas.

Do ponto de vista de encapsulamento, Perry e Kaiser entendem que uma classe pode ser analisada como se estivesse encapsulando vários subprogramas (métodos). Além disso, o mesmo subprograma pode se encontrar sendo encapsulado por vários outros subprogramas. Os subprogramas que sấo encapsulados em uma entidade maior uma classe - irão trabalhar em conjunto com os outros subprogramas de um objeto definido como sendo dessa classe. Isso significa que em um ambiente Orientado a Objetos, testar um subprograma isoladamente é virtualmente sem significado. Nesse contexto eles dicutiram os 11 axiomas propostos por Weyuker em [WEY86] e [WEY88] que checam a completude de um esforço de teste. Dentre esses, podemos 
destacar 4 que dizem mais respeito ao impacto do encapsulamento no teste de programas Orientados a Objetos:

- o $5^{\circ}$ axioma - antiextensionabilidade - Diz que se existirem dois algoritmos diferentes que computem a mesma função, um conjunto de teste adequado para um algoritmo não é necessariamente adequado para o outro. Isso mostra que ao se substituir um método herdado por um método definido localmente que realize a mesma função, o conjunto de casos de teste para o método herdado não é necessariamente adequado para o método definido localmente.

- o $6^{0}$ axioma - mudança geral múltipla - Diz que se dois programas possuem o mesmo formato, um conjunto de casos de teste que seja adequado para um não é adequado para o outro. (Dois programas são do mesmo formato se um pode ser transformado no outro através de uma mudança simples de um ou mais operadores relacionais com outros operadores relacionais, constantes com constantes e operadores aritméticos com operadores aritméticos). Esse axioma mostra que quando os mesmos ítens são herdados de ancestrais diferentes (via mudanças na ordem de precedência em um esquema de herança múltipla) então conjuntos de casos de teste diferentes serão necessários.

- o 70 axioma - antidecomposição - Diz que algo que for testado em um contexto deve ser retestado se o contexto mudar. Por exemplo, supõe-se que seja testado completamente um método dentro do contexto de uma dada classe e que seja criada uma especialização (uma subclasse) baseada nessa classe, e que a especialização herde o método testado da generalização (de uma superclasse). Mesmo se for testado o método dentro do contexto da generalização, não pode ser garantida a adequação do mesmo dentro do contexto da especialização, a não ser que seja retestado o método dentro do contexto da especialização.

- o $8^{0}$ axioma - anticomposição - Estipula que testar adequadamente cada unidade isoladamente é normalmente insuficiente para testar adequadamente o programa inteiro (integrado). Supondo que seja mudada a implementação de um objeto, mas que seja mantida a sua interface, devem ser retestadas todas as unidades dependentes desse objeto (especializações e unidades que direta ou indiretamente se referenciem ao objeto modificado).

\subsection{1 - Teste Incremental para Estruturas de Classes}

Essa estratégia de teste de classes proposta por Harrold e outros, e batizada por Técnica Incremental Hierárquica, pode ser utilizada para testar as classes de softwares Orientados a Objetos avaliando-se cada classe individualmente [HAR92]. Entretanto, testar isoladamente cada classe requer completa retestagem das subclasses, apesar de muitos de seus métodos já haverem sido testados, uma vez que eles são herdados das 
classes-bases. Além disso, retestar completamente cada classe não explora oportunidades de reutilizar e compartilhar o projeto, a construção e a execução dos casos de teste. Um outro ponto importante dessa estratégia de teste é a de se utilizar a natureza hierárquica de classes relacionadas por herança para reduzir o overhead de retestar cada subclasse, havendo, portanto, uma melhoria no tempo para projetar casos de teste, para construir um novo conjunto de teste e o tempo atual para executar o conjunto de teste é menor, já que a subclasse toda não é testada.

Essa estratégia propõe que, inicialmente, sejam testadas todas as classes-bases, determinando-se um conjunto de casos de testes para cada método e outro que teste as interações entre os métodos. Para se projetar um conjunto de casos de teste para uma subclasse, o conjunto de casos de teste utilizado para testar a classe-base pode ser aproveitado.

A principal característica dessa estratégia é o fato de que testar completamente uma subclasse é evitado, já que a história de teste da classe-pai será reutilizada para projetar o conjunto de casos de teste para a subclasse. Uma história de teste associa cada caso de teste com os atributos que ele testa.

Essa técnica de teste é hierárquica, pois é guiada pelo ordenamento parcial da relação de herança; e é incremental pois usa todos os resultados de testar um nível de hierarquia anterior para reduzir os esforços necessários nos níveis subseqüentes. Primeiramente, devem ser testadas classes-bases usando-se as técnicas tradicionais de teste de unidade para testar os métodos. Testar adequadamente cada método é particularmente importante uma vez que os eles podem ser herdados pelas subclasses e podem operar em um novo contexto. $\mathrm{O}$ axioma de antidecomposição coloca que o teste adequado de uma classe não implica que os métodos individuais foram adequadamente testados para uso em todos os contextos. Essa técnica testa cada método independentemente de sua classe. $\mathrm{O}$ axioma de anticomposição coloca que testar adequadamente um método isoladamente não é suficiente para assumir que a classe foi testada como uma parte do conjunto de métodos que se interagem. São utilizadas técnicas de teste de integração para testar as interações entre métodos sem retestar suas implementações internas. $\mathrm{O}$ axioma de anticomposição mostra que testar cada método individualmente não significa que a classe foi adequadamente testada. Portanto, além de testar cada método, deve-se testar também as interações entre eles na mesma classe. Essa atividade é conhecida como teste intra-classe. Ainda, os autores propõem que também sejam testadas as interações sobre os métodos que acessam métodos em outras classes, conhecido como teste inter-classe.

Para determinar as vantagens ganhas no teste, os autores utilizaram uma hierarquia de classes em $\mathrm{C}++$ definidas em InterViews[LIN87], onde se encontram 4 classes: a classe-base Interactor e suas subclasses Scene, MonoScene e Dialog (Scene é 
uma subclasse de Interactor, MonoScene é uma subclasse de Scene e Dialog é uma subclasse de MonoScene). A Tabela 2.9 mostra a comparação da execução dessa estratégia de teste e a execução de todos os métodos, incluindo-se os métodos herdados que foram testados mais de uma vez.

Tabela 2.9 - Número de Casos de Teste a Serem Utilizados

\begin{tabular}{|l|c|c|c|}
\hline CLASSE & $\begin{array}{l}\text { UTILIZAR } \\
\text { TODOS }\end{array}$ & $\begin{array}{l}\text { TECNICA } \\
\text { INCREMENTAL }\end{array}$ & $\begin{array}{l}\text { RAZÃO ENTRE AS } \\
\text { DUAS TÉCNICAS }\end{array}$ \\
\hline Interactor & 93 & 93 & $100 \%$ \\
\hline Scene & 96 & 36 & $38 \%$ \\
\hline MonoScene & 99 & 9 & $9 \%$ \\
\hline Dialog & 103 & 6 & $6 \%$ \\
\hline
\end{tabular}

A eficácia dessa técnica é observada pelo número de novos casos de teste que tiveram que ser gerados para as subclasses que compõem o sistema, comparando-os com a reutilização de todos os casos de teste, por se tratar da única comparação possível a ser realizada.

Os resultados mostram que em uma hierarquia de classes, esforço significante para a realização dos testes seria salvo com a utilização dessa técnica. Esse é um resultado razoável para uma hierarquia bem projetada.

Muitos métodos que devem ser retestados irão reutilizar os casos de teste que foram desenvolvidos para suas classes-bases. A reutilização de conjuntos de testes da classe-base resulta em uma melhoria no tempo da realização desse processo de teste.

\section{5 - Considerações Finais}

A falta de ferramentas de teste de softwares Orientados a Objetos indica que devem ser realizados estudos voltados para a solução desse problema. Alguns trabalhos vêm sendo apresentados, onde podem ser destacados [ARN94], [DOO94], [JOR94], [MUR94], [POS94], entre outros.

Para proporcionar facilidades na elaboração de ferramentas de teste de software Orientado a Objetos, é interessante que sejam definidos subsídios que tornem possível a criação desses tipos de ferramentas de teste com características de multilinguagem, dada a diversidade de linguagens de programação Orientadas a Objetos. $\mathrm{O}$ conhecimento técnico das atividades de teste utilizando-se linguagens de programação tradicionais, como C, Pascal, Fortran, Cobol, entre outras, constitui um importante passo para o desenvolvimento de ferramentas de teste de software Orientado a Objeto, pois a maior parte da implementação dos métodos das classes em uma abordagem 
Orientada a Objetos é construída utilizando-se comandos procedimentais tradicionais [KHO90]. Com isso, o teste dos métodos descritos em uma classe deve aproveitar ao máximo essas técnicas, critérios e ferramentas de teste já consolidados.

A definição de uma Linguagem Intermediária para Programas Orientados a Objetos (LI++) é um desses subsídios, e o mapeamento da linguagem $\mathrm{C}++$ (uma das principais linguagens de programação Orientada a Objetos) para a LI++ facilitará bastante a estruturação, definição e implementação desse tipo de ferramenta de teste. No próximo Capítulo é definida a LI++ segundo a notação de Backus-Naur [SET81], onde o estudo sistematizado das diversas linguagens de programação Orientadas a Objetos apresentado nesse capítulo foi fundamental para essa definição. 


\section{CAPÍTULO 3 - A Linguagem Intermediária para Programas Orientados a Objetos - LI++}

A diversidade de linguagens de programação procedimentais motiva a criação de ferramentas automatizadas de teste de software que possuam características de serem multilinguagens e sejam capazes de atender à crescente demanda de ambientes automatizados de teste de software. A definição de uma Linguagem Intermediária para programas procedimentais (LI) [CAR91] é uma forma de se escolher uma representação comum para os programas codificados nas diversas Lingugens de Programação procedimentais abrangidas. A LI tem como função principal identificar o fluxo de execução de um programa, e é constituída basicamente de dois tipos de comandos: seqüenciais e de controle de fluxo. Os comandos seqüenciais indicam comandos das linguagens procedimentais que representam uma declaração de variável ou uma computação, e que não alteram o fluxo de execução. Os comandos de controle de fluxo correspondem aos comandos das linguagens de programação que causam seleção, seleção múltipla, iteração e transferência incondicional, e que portanto, alteram o fluxo de execução.

Partindo-se desse mesmo raciocíonio, propõe-se identificar o fluxo de execução de programas escritos em linguagens de programação Orientadas a Objetos, através da definição de uma Linguagem Intermediária para programas Orientados a Objetos (LI++), onde o mapeamento já realizado para os comandos procedimentais será o mesmo descrito na LI, pois os comandos que formam os corpos dos métodos das diversas classes em um ambiente Orientado a Objetos são constituídos basicamente de comandos procedimentais [KHO90]. Com isso, a definição da LI deve ser aproveitada para a definição da LI++ e a descrição da LI++ será bastante próxima da descrição da LI.

A existência de diversas linguagens de programação Orientadas a Objetos, tais como C++, Eiffel, Simula, Ada, entre outras, motiva a definição da LI++, que deve ser utilizada como subsídio básico para a construção de ferramentas multilinguagens de teste de softwares Orientados a Objetos. Ainda, as principais características da Orientação a Objetos, tais como Herança, Herança Múltipla, Amarração Dinâmica, etc., que a maioria das linguagens de programação Orientadas a Objetos fornece devem estar descritas na LI++, pois são elas que determinam a facilidade de utilização desse paradigma de programação e de todas as vantagens que podem ser obtidas a partir delas.

As características que não são basicamente Orientadas a Objetos, mas que estão presentes em algumas linguagens de programação Orientadas a Objetos, tais como aspectos de programação concorrente / paralela em Ada, tratamento de exceções em 
$\mathrm{C}++$, entre outras, não serão consideradas na definição da LI++ por estarem fora do contexto desse trabalho. Logo, os comandos das linguagens que implementam estas características não poderão ser mapeados para a LI++.

Mais particularmente, pode-se destacar a linguagem $\mathrm{C}++$ que vem recebendo grande aceitação tanto na comunidade científica quando na indústria de produção de software. Essa linguagem engloba esses principais conceitos de programação Orientada a Objetos, e possivelmente por isso, vem sendo cada vez mais empregada. Outra linguagem que tem recebido muita atenção é a linguagem Java, onde os subsídios gerados para a linguagem $\mathrm{C}++$ podem ser facilmente transferidos para o contexto em que deve ser empregada a linguagem Java [NIE96], dado que Java é basicamente extraída de $\mathrm{C}++$.

Primeiramente nesse capítulo será mostrada a definição dos átomos da LI++, em seguida, são mostrados os comandos das linguagens C++, Ada, Eiffel, Java, Simula, Smalltalk e Tool e seus respectivos similares na LI++, além de trechos de programas escritos nessas linguagens de programação e seus respectivos mapeamentos para a LI++.

\section{1 - Definição da Estruturas da LI++}

Utilizando-se a notação de Backus-Naur, onde os átomos contidos entre colchetes ([]) são optativos, um átomo da LI++ (que não foi descrito na LI) pode ser descrito da seguinte forma:

$<$ atm_li++>::=<átomo $><$ início $><$ comprimento $><$ linha $>$

<átomo>::= \$CLASS/ \$PRIVATE/ \$PUBLIC/ \$PROTECTED/ \$FRIEND/ $\{\{/\}\} /$ \$PACKAGE/ \$XCLASS/ \$ENSURE/ \$REQUIRE/ \$TEMPLATE/ \$BASECL

<início $>::=\mathrm{NUM}$

$<$ comprimento $>:=\mathrm{NUM}$

$<$ linha $>:=$ NUM

Uma característica própria da LI++ é que os átomos da linguagem são seguidos por números que identificam, respectivamente, o início do átomo no arquivo fonte da unidade em teste (isto é, a quantos bytes do começo do arquivo se inicia o átomo no arquivo fonte), o comprimento do átomo (quantos bytes possui o átomo) e a linha onde 
o átomo se encontra. Tal notação facilita bastante o acesso ao código fonte sempre que necessário.

Os comandos procedimentais sequienciais e de controle de fluxo, que basicamente definem os corpos dos métodos pertencentes à uma classe [KHO90], não serão detalhados nessa seção por motivos de praticidade. Tais comandos já foram definidos na LI [CAR91] e estão sintetizados no Apêndice A.

\subsection{1 - O Mapeamento das Definições de Classes}

A LI++ possui comandos seqüenciais, de controle de fluxo e de definição de classes e subclasses. Dentre os comandos de controle de fluxo temos os de seleção, de seleção múltipla, de iteração e de desvios incondicionais. Esses comandos, bem como os comandos seqüenciais já foram descritos na LI e serão utilizados na LI++ quando forem descritos os corpos dos métodos, pois os comandos que compõem o corpo de um método são basicamente procedimentais.

As estruturas que não determinam uma classe propriamente dita, como por exemplo a estrutura package da linguagem Ada, ou que determinam uma classe permitindo que os métodos sejam aplicados de modo assíncrono, tal como xclass da linguagem TOOL, mas que se assemelham bastante a uma classe serão descritas nessa seção. Uma estrutura package em Ada é, basicamente, um Tipo Abstrato de Dados, a principal diferença com relação à uma classe (tal qual em $\mathrm{C}++$ ) é que não é possível o emprego de algumas das principais características que compõem um ambiente Orientado a Objetos, tais como herança e polimorfismo [BAR89].

As definições dos nomes dos átomos e comandos da LI++ foram descritas baseando-se fortemente nos termos da linguagem de programação $\mathrm{C}++$, por reportarem mais precisamente os termos que se desejam mapear.

A definição genérica de uma classe é da seguinte forma:

$$
\begin{aligned}
<\text { classe }>::= & <\text { class_rot }>\{<\text { desc_basecl }>\}^{*}<\text { início_classe }> \\
& \{<\text { descrição }>\}^{*}<\text { fim_classe }>
\end{aligned}
$$

onde

$<$ class_rot $>::=<$ class_atm $>/<$ pack_atm $>/<$ xclass_atm $>$

$<$ class_atm $>::=\$ C L A S S<$ início $><$ comprimento $><$ linha $>$

$<$ pack_atm $>:=\$$ PACKAGE $<$ início $><$ comprimento $><$ linha $>$

$<$ xclass_atm $>:=\$$ XCLASS $<$ início $><$ comprimento $><$ linha $>$ 
$<$ desc_basecl $>::=\$ B A S E C L<$ início $><$ comprimento $><$ linha $>$

$<$ início_classe $>::=1\{$

$<$ descrição $>::=[<$ def_public $>] /[<$ def_private $>] /[<$ def_protected $>] /$

$[<$ def_friend $>] /[<$ def_template $>] /[<$ def_método $>] /[<$ dcl $>]$

$<$ def_public $>::=<$ public_atm $>$

$<$ public_atm $>::=\$$ PUBLIC $<$ início $><$ comprimento $><$ linha $>$

$<$ def_private $>::=<$ private_atm $>$

$<$ private_atm>::=\$PRIVATE $<$ início $><$ comprimento $><$ linha $>$

$<$ def_protected $>::=<$ protected_atm $>$

$<$ protected_atm $>::=\$$ PROTECTED $<$ início $><$ comprimento $><$ linha $>$

$<$ def_friend $>::=<$ friend_atm $>$

$<$ friend_atm $>::=\$ F R I E N D<$ início $><$ comprimento $><$ linha $>$

$<$ def_template $>::=<$ template_atm $>$

$<$ template_atm>::=\$TEMPLATE<início $><$ comprimento $><$ linha $>$

$<$ def_método $>::=@$ NOME-ÚNICO<início $><$ comprimento $><$ linha $>$

$$
<\text { dcl }>[<\text { def_precond }>]\{<\text { statement }>\} *[<\text { def_poscond }>]
$$

@NOME-ÚNICO representa um nome que deve ser único para cada método, pois pode ser encontrada sobrecarga (overload) de métodos.

$<$ def_precond $>::=<$ precond_atm $>\{<$ desc_precond $>\}$

$<$ precond_atm $>::=\$$ ENSURE $<$ início $><$ comprimento $><$ linha $>$

$<$ desc_precond $>::=\{<$ statement $>\}$

$<$ def_poscond $>::=<$ poscond_atm $>\{<$ desc_poscond $>\}$

$<$ poscond_atm $>::=\$ R E Q U I R E<$ início $><$ comprimento $><$ linha $>$ 


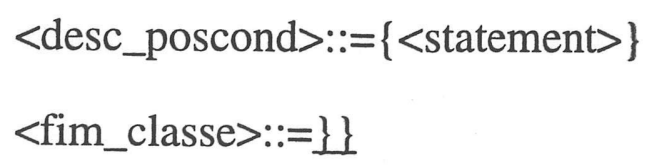

A maioria das linguagens de programação Orientadas a Objetos possui métodos que podem ser considerados especiais por serem métodos construtores ou destrutores de objetos instanciados para uma determinada classe. Esses métodos serão mapeados normalmente como qualquer outro método, sendo que seu nome representa intrinsicamente a sua finalidade. Como ilustração podemos nos ater às linguagens Eiffel e C++. A linguagem Eiffel possui a característica dos métodos construtores serem denominados por create e não possui métodos destrutores. Na linguagem $\mathrm{C}++$ os métodos construtores possuem o mesmo nome pelo qual foi designada a classe na qual o método está sendo descrito, enquanto que os métodos destrutores devem ser definidos apresentando o caracter ' $\sim$ ' antes do nome do método destrutor que também deve ter $o$ mesmo nome que designou a classe.

\subsection{2 - Descrição isolada dos corpos dos métodos}

Todo corpo de método que for descrito deve ser mapeado por <metodo_atm>. Essa descrição pode ocorrer juntamente com a definição do método, ou após esta, sendo feita de forma separada da definição. Ainda, em toda descrição de corpo de método deve haver um @NOME-ÚNICO relacionando-o ao método sendo descrito.

Para evitar problemas com relação à sobrecarga de métodos (overload) propõese a elaboração de uma tabela que mantenha um nome de método único para cada um dos métodos e de seus parâmetros. Esse nome único é que será mapeado para a LI++ em NOME-ÚNICO. Na Figura 3.1 encontra-se um exemplo ilustrativo escrito na linguagem $\mathrm{C}++$, onde os métodos são definidos na ordem em que estão apresentados: 


\begin{tabular}{|l|l|}
\hline nome do método e seus parâmetros & $\begin{array}{l}\text { NOME-METODO na LI++ } \\
\text { (NOME-ÚNICO) }\end{array}$ \\
\hline void tie(int); & @TIE_LI++01 \\
\hline void tie(float); & @TIE_LI++02 \\
\hline void tie(int, int); & @TIE_LI++03 \\
\hline void tie(); & @TIE_LI++04 \\
\hline
\end{tabular}

Figura 3.1 - NOME DE MÉTOdOS E RESPECTIVOS PARÂMETROS E SEUS CORRESPONDENTES NA LI++ forma:

Logo, a descrição separada da definição de um método deverá ser da seguinte $<$ desc_método $>::=$ @NOME-ÚNICO<início $><$ comprimento $><$ linha $>$

$$
\{<\text { statement }>\text { \} }
$$

\subsection{3 - Estrutura de um programa LI++}

Segundo o que foi descrito nas seções anteriores, a estrutura dos programas LI++ pode ser definida da seguinte maneira:

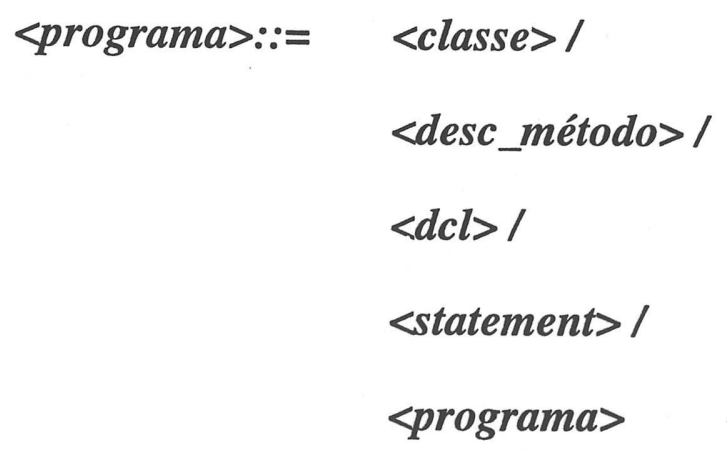




\section{2 - Comandos C++ e seus Correspondentes na LI++}

A Tabela 3.1 mostra os comandos $\mathrm{C}++$ e seus respectivos similares na LI++. O estudo dessa linguagem foi fundamental tanto para a definição da LI++ quanto para a realização do mapeamento $\mathrm{C}++$ / LI++. A gramática dessa linguagem encontra-se em [STR94].

Tabela 3.1 - Comandos C++ e seus correspondentes na LI++

\begin{tabular}{|lll|}
\hline Comando C++ & Correspondente na LI++ \\
\hline\{ & - & $\{$ ou $\{\{$ \\
abort & - & $\{$ ou $\}\}$ \\
break & - & \$Sn \\
case & - & \$ROTC \\
class & - & \$CLASS \\
cin & - & \$Sn \\
continue & - & \$CONTINUE \\
cout & - & \$Sn \\
delete & - & \$Sn \\
default & & \$ROTD \\
do $/$ while & - & \$REPEAT / \$UNTIL \\
else & - & \$ELSE \\
for & - & \$FOR \\
friend & - & \$FRIEND \\
goto & - & \$GOTO \\
if & - & \$IF \\
label & - & \$LABEL \\
new & - & \$Sn \\
private & - & \$PRIVATE ou \$BASECL (1) \\
protected & - & \$PROTECTED ou \$BASECL (1) \\
public & - & \$PUBLIC ou \$BASECL (1) \\
return & - & \$RETURN \\
switch & - & \$CASE \\
template & - & \$TEMPLATE \\
while & - & \$WHILE \\
\hline & & \\
\hline
\end{tabular}

(1) public, private ou protected podem estar definindo métodos e variáveis de instanciação ou classes-bases de uma subclasse 


\section{3 - Comandos de Outras Linguagens de Programação Orientadas a Objetos e seus Correspondentes na LI++}

As Tabelas 3.2 a 3.6 mostram, respectivamente, os comandos das linguagens de Programação Orientada a Objetos Ada, Eiffel, Smalltalk, TOOL e JAVA. O estudo de cada uma dessas linguagens foi fundamental para a definição da LI++, e os comandos dessas referidas linguagens podem ser mapeados para a LI++. Os comandos que fazem parte dessas linguagens e que pertencem a outros paradigmas de programação (comandos concorrentes da linguagem Ada ou de tratamento de exceções da linguagem $\mathrm{C}++$, por exemplo) não estão mapeados por não se situarem dentro dos objetivos deste trabalho. 
Tabela 3.2 - Comandos Ada e seus correspondentes na LI++

\section{Comando Ada Correspondente na LI++}

\begin{tabular}{lll}
\hline access & - & \$DCL \\
begin & - & $\{$ ou $\{\{$ \\
case & - & \$CASE \\
declare & - & \$DCL \\
delay & - & \$Sn \\
delta & - & \$DCL \\
digits & - & \$DCL \\
do & - & \$REPEAT / \$UNTIL \\
else & - & \$ELSE \\
elsif & - & \$ELSE / \$IF \\
end & - & \}ou \}\} \\
exit $($ when) $)$ & - & \$BREAK \\
for & - & \$FOR \\
function & - & \$DCL \\
generic & - & \$DCL \\
goto & - & \$GOTO \\
if & - & \$IF \\
loop & - & \$FOR \\
new & - & \$Sn \\
package & - & \$PACKAGE \\
procedure & - & \$DCL \\
private & & \$PRIVATE \\
range & - & \$DCL \\
record & - & \$DCL \\
return & - & \$RETURN \\
select & - & \$CASE \\
terminate & - & \$BREAK \\
when & - & \$ROTC \\
while & - & \$WHILE \\
\hline
\end{tabular}


Tabela 3.3 - Comandos Eiffel e seus correspondentes na LI++

\section{Comando Eiffel Correspondente na LI++}

\begin{tabular}{lll}
\hline begin & - & $\{$ ou $\{\{$ \\
case & - & \$CASE \\
check & - & \$Sn \\
class & - & \$CLASS \\
create & - & \$DCL \\
clone & - & \$DCL \\
debug & - & \$Sn \\
deferred (class) & \$CLASS \\
deferred (method) & \$DCL \\
else & - & \$ELSE \\
elsif & - & \$ELSE / \$IF \\
end & - & \}ou \}\} \\
ensure & - & \$ENSURE \\
export & - & \$PUBLIC \\
external & - & \$Sn \\
feature & & \$DCL \\
flat & - & \$DCL \\
inherit & - & \$PUBLIC \\
if & - & \$IF \\
like & - & \$Sn \\
local & - & \$DCL \\
loop & - & \$WHILE \\
old & - & \$Sn \\
once & - & \$Sn \\
redefine & - & \$Sn \\
rescue & - & \$Sn \\
require & & \$REQUIRE \\
retry & - & \$Sn \\
\hline
\end{tabular}


Tabela 3.4 - Comandos Smalltalk e seus correspondentes na LI++

\begin{tabular}{lll} 
Comando Smalltalk & & Correspondente na LI++ \\
\hline[ & - & \{ \\
] & - & \} \\
at...put... & - & \$Sn \\
class name & - & \$CLASS \\
class variable names & - & \$DCL \\
class methods & - & \$DCL \\
detect & - & \$Sn \\
display (at) & - & \$Sn \\
ifFalse & - & \$ELSE \\
ifTrue & - & \$IF \\
new & - & \$Sn \\
superclass & - & \$BASECL \\
(n) timesRepeat & - & \$FOR \\
whileFalse & - & \$WHILE \\
whileTrue & - & \$WHILE
\end{tabular}


Tabela 3.5 - Comandos TOOL e seus correspondentes na LI++ Comando TOOL Correspondente na LI++

\begin{tabular}{lll}
\hline begin & - & $\{$ ou $\{\{$ \\
case & - & \$ROTC \\
call & - & \$Sn \\
class & - & \$CLASS \\
clone & - & \$Sn \\
create & - & \$Sn \\
dispose & - & \$Sn \\
else & - & \$ELSE \\
elsif & - & \$ELSE / \$IF \\
end & - & \}ou $\}$ \\
exit & - & \$BREAK \\
for & - & \$FOR \\
generic & - & \$DCL \\
handler & - & \$DCL \\
if & - & \$IF \\
loop & - & \$FOR \\
main & - & \$MAIN \\
method & - & \$DCL \\
message & - & \$Sn \\
private & - & \$PRIVATE \\
public & - & \$PUBLIC \\
repeat & - & \$REPEAT \\
return & - & \$RETURN \\
when & - & \$ROTC \\
xclass & - & \$XCLASS \\
\hline
\end{tabular}


Tabela 3.6 - Comandos JAVA e seus correspondentes na LI++

\section{Comando JAVA Correspondente na LI++}

\begin{tabular}{lll}
\{ & - & $\{$ ou $\{\{$ \\
\} & - & $\{$ ou $\}\}$ \\
abort & - & \$Sn \\
applet & - & \$Sn \\
break & - & \$BREAK \\
case & - & \$ROTC \\
class & - & \$CLASS \\
continue & - & \$CONTINUE \\
delete & - & \$Sn \\
default & & \$ROTD \\
do/while & - & \$REPEAT / \$UNTIL \\
else & - & \$ELSE \\
extends & - & \$BASECL \\
for & - & \$FOR \\
friend & - & \$FRIEND \\
goto & - & \$GOTO \\
if & - & \$IF \\
label & - & \$LABEL \\
new & - & \$Sn \\
package & - & \$PACKAGE \\
public & - & \$PUBLIC \\
private & - & \$PRIVATE \\
protected & - & \$PROTECTED \\
public & - & \$PUBLIC \\
return & - & \$RETURN \\
switch & - & \$CASE \\
template & - & \$TEMPLATE \\
while & - & \$WHILE \\
\hline & &
\end{tabular}




\section{3 - Exemplos de mapeamentos de trechos de programas Orientados a Objetos para a LI++}

As figuras 3.2 a 3.6 mostram trechos de programas escritos em linguagens Orientadas a Objetos e seus respectivos mapeamentos para a LI++.

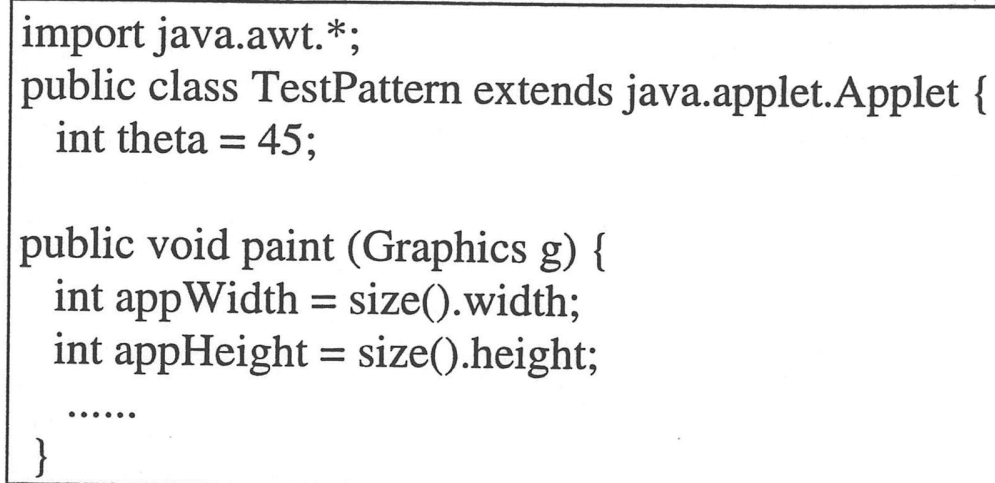

(a)

\begin{tabular}{|llll|}
\hline \$DCL & 1 & 17 & 1 \\
\$CLASS & 19 & 21 & 2 \\
\$BASECL & 41 & 26 & 2 \\
\{ & 68 & 1 & 2 \\
\$DCL & 73 & 15 & 3 \\
\$PUBLIC & 89 & 6 & 6 \\
@paint-LI++01 & 0 & 0 & 0 \\
\$DCL & 96 & 23 & 6 \\
\{ & 120 & 1 & 6 \\
\$DCL & 124 & 28 & 7 \\
\$DCL & 155 & 30 & 8 \\
$\cdots \cdots \cdots$ & & &
\end{tabular}

(b)

FIGURA 3.2 - (A) TRECHO DE PROGRAMA ESCRITO EM JAVA [NIE96]; (B) RESPECTIVO MAPEAMENTO PARA A LI++ 
package STACK is

procedure PUSH(X: INTEGER);

function POP return INTEGER;

end;

procedure $\mathrm{PUSH}(\mathrm{X}$ : INTEGER) is

begin

TOP:=TOP+1;

$\mathrm{S}(\mathrm{TOP}):=\mathrm{X}$;

end PUSH;

(a)

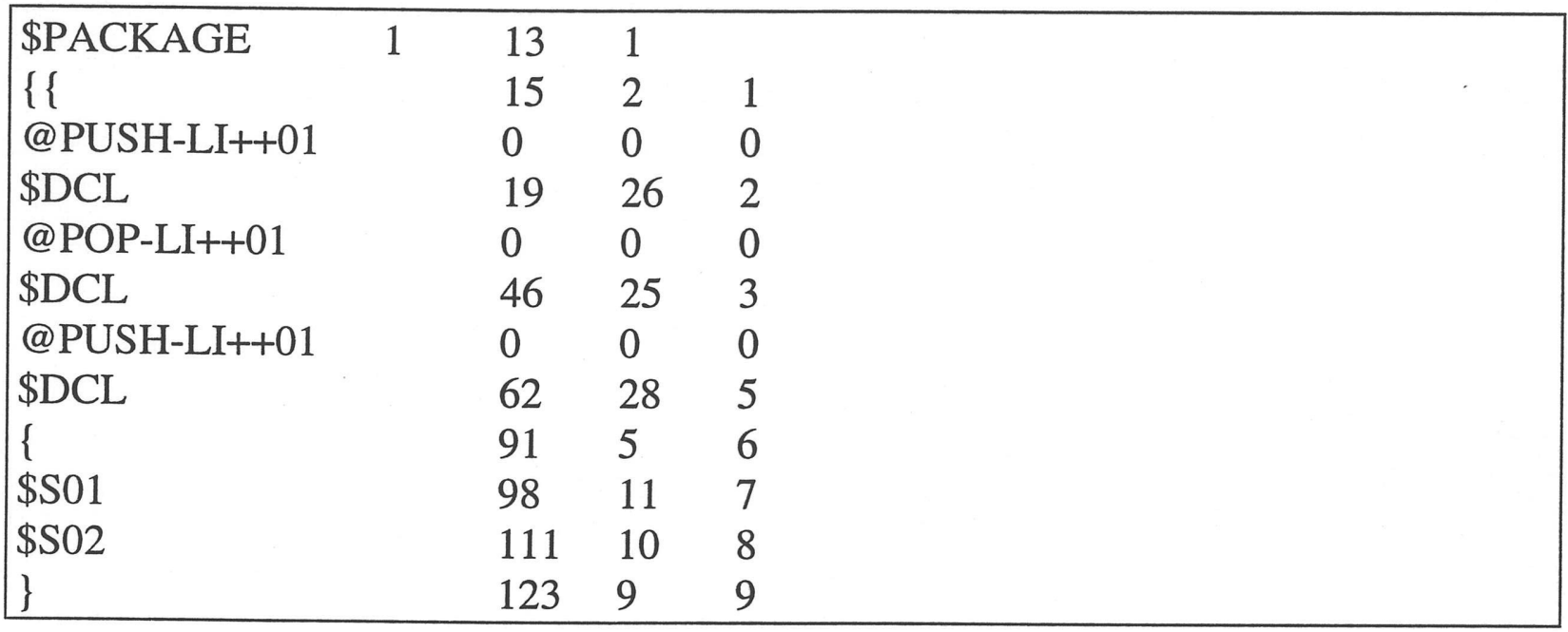

(b)

FIGURA 3.3 - (A) TRECHO DE PROGRAMA ESCRITO EM ADA [BAR84]; (B) RESPECTIVO MAPEAMENTO PARA A LI++ 


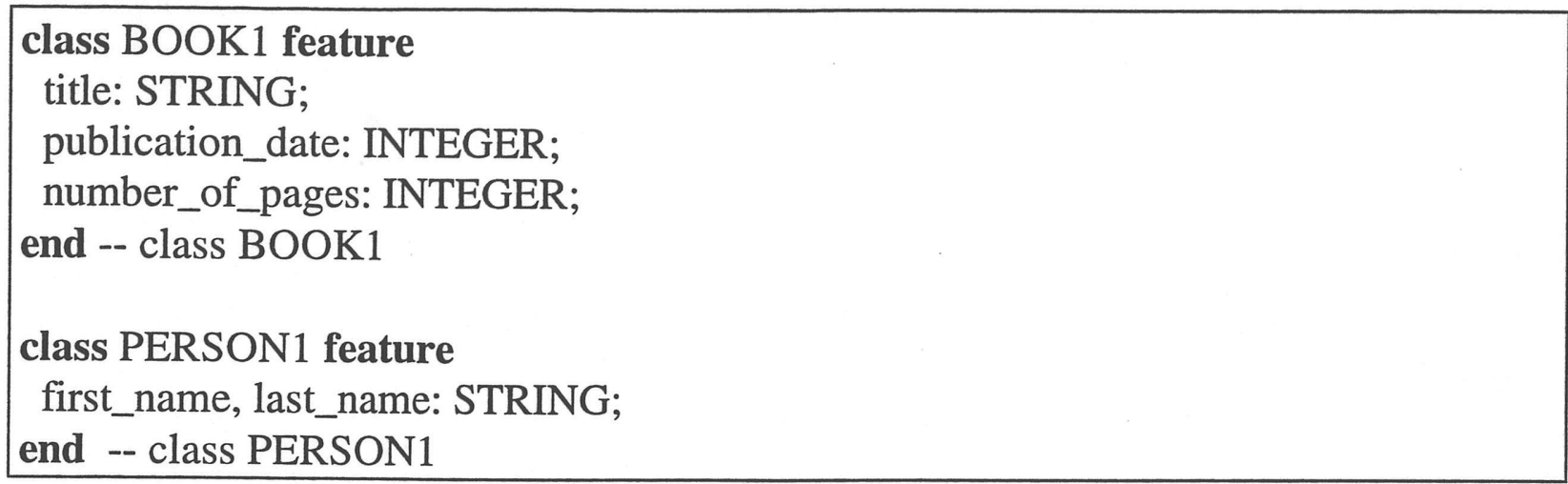

(a)

\begin{tabular}{|llll|}
\hline \$CLASS & 1 & 11 & 1 \\
$\{\{$ & 12 & 7 & 1 \\
\$DCL & 22 & 14 & 2 \\
\$DCL & 39 & 26 & 3 \\
\$DCL & 68 & 25 & 4 \\
\}$\}$ & 94 & 4 & 5 \\
\$CLASS & 100 & 12 & 7 \\
$\{\{$ & 113 & 7 & 7 \\
\$DCL & 124 & 10 & 8 \\
\$DCL & 138 & 21 & 8 \\
\}\} & 160 & 4 & 9 \\
\hline
\end{tabular}

(b)

Figura 3.4 - (A) TRECHO DE PROGRAMA ESCRITO EM EIFFEL [MEY88]; (B) RESPECTIVO MAPEAMENTO PARA A LI++ 
CLASS A;

REPRESENTATION

INTEGER tot;

END REPRESENTATION

METHOD print;

INTEGER i;

END METHOD

METHOD print;

END METHOD

END CLASS

CLASS B FROM A;

REPRESENTATION

CHARACTER b1;

END REPRESENTATION

METHOD print;

END METHOD

END CLASS

(a)

\begin{tabular}{|llll|}
\hline \$CLASS & 1 & 8 & 1 \\
$\{\{$ & 0 & 0 & 0 \\
\$PUBLIC & 10 & 14 & 2 \\
\$DCL & 27 & 12 & 3 \\
@ print-LI++01 & 0 & 0 & 0 \\
\$DCL & 60 & 24 & 5 \\
@ print-LI++02 & 0 & 0 & 0 \\
\$DCL & 97 & 13 & 7 \\
\}\} & 111 & 9 & 9 \\
\$CLASS & 124 & 7 & 11 \\
\$BASECL & 132 & 7 & 11 \\
\{1 & 0 & 0 & 0 \\
\$PUBLIC & 141 & 14 & 12 \\
\$DCL & 144 & 13 & 13 \\
@print-LI++03 & 0 & 0 & 0 \\
\$DCL & 179 & 13 & 15 \\
\}\} & 207 & 9 & 17 \\
\hline
\end{tabular}

(b)

FIGURA 3.5 - (A) TRECHO DE PROGRAMA ESCRITO EM TOOL [SPA94]; (B) RESPECTIVO MAPEAMENTO PARA A LI++ 


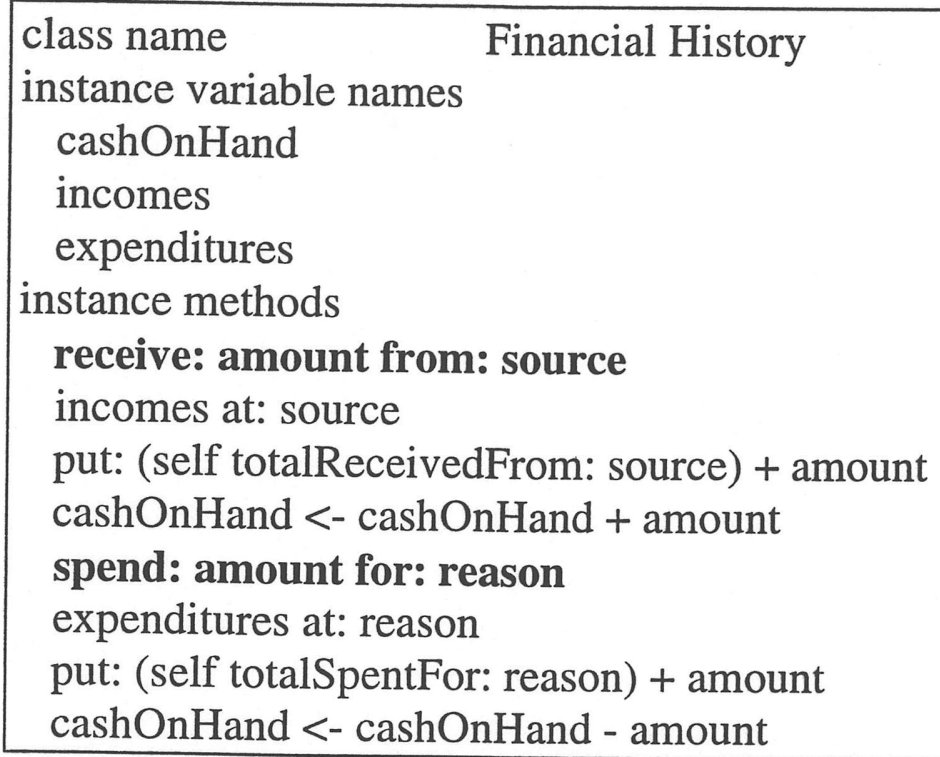

(a)

\begin{tabular}{llll}
\hline \$CLASS & 1 & 40 & 1 \\
\{ & 0 & 0 & 0 \\
\$PRIVATE & 43 & 23 & 2 \\
\$DCL & 71 & 10 & 3 \\
\$DCL & 85 & 7 & 4 \\
\$DCL & 97 & 12 & 5 \\
@ RECEIVE-LI++01 & 0 & 0 & 0 \\
\$DCL & 132 & 50 & 7 \\
\{ & 0 & 0 & 0 \\
\$S01 & 185 & 46 & 8 \\
\$S02 & 236 & 39 & 9 \\
\} & 0 & 0 & 0 \\
@ SPEND-LI++01 & 0 & 0 & 0 \\
\$DCL & 278 & 50 & 10 \\
\$S03 & 332 & 39 & 12 \\
\$S04 & 375 & 36 & 13 \\
\hline
\end{tabular}

(b)

FiguRA 3.6 - (A) TRECHO DE PROGRAMA ESCRITO EM SMALlTALK [GOL84]; (B) RESPECTIVO MAPEAMENTO PARA A LI++ 


\section{6 - Considerações Finais}

O fato das principais características de Orientacão a Objetos, tais como Herança, Herança Múltipla, Amarração Dinâmica, Sobrecarga, que a maioria das linguagens de programação Orientadas a Objetos fornece poderem ser mapeados para a LI++ é mais um indício da facilidade que a utilização dessa Linguagem Intermediária proporcionará às definições e implementações de ferramentas de teste que apóiem esse paradigma. Devido ao fato da LI+ ter que retratar essas características, o estudo dessas linguagens foi de fundamental importância para sua definição.

O próximo Capítulo apresenta a forma como deve ser conduzido o mapeamento das principais Linguagens Orientadas a Objetos para a LI++, destacando-se o modo como o mapeamento da linguagem $\mathrm{C}++$ para a $\mathrm{LI}++$ foi realizado. 


\section{CAPÍTULO 4 - Mapeamento de Linguagens Orientadas a Objetos para a LI++}

A implementação do mapeamento de uma Linguagem de Programação Orientada a Objetos para a LI++ tem como um de seus principais objetivos propiciar facilidades para que sejam distingüidos módulos dependentes e independentes da linguagem alvo na qual está escrito o programa que se deseja testar, com a finalidade de fornecer facilidades para que sejam projetadas e criadas ferramentas automatizadas de teste de softwares Orientados a Objetos segundo a mesma abordagem utilizada para programas procedimentais empregada nas ferramentas POKE-TOOL [CHA91] e Proteum [DEL93]. Essas ferramentas são compostas de vários módulos que implementam funções sensitivas e não-sensitivas à linguagem na qual está escrita a unidade em teste.

A implementação do mapeamento de programas escritos nas principais Linguagens Orientadas a Objetos para a LI++ está baseada em dois passos básicos: a Análise Léxica e a Análise Sintática. A Análise Léxica separa os ítens léxicos constituintes da linguagem e determina suas classes, que tipicamente são identificadores, palavras reservadas da linguagem alvo, símbolos especiais (e.g., +, =, *, etc.) e constantes (números, cadeia de caracteres, etc.), enquanto que a Análise Sintática é o processo de reconhecimento de sentenças válidas da linguagem.

Chaim em [CHA91] aponta que existem diversas maneiras de se realizar as Análises Léxica e Sintática de um programa. Uma delas é criando um algoritmo específico para as características da linguagem em questão; outra é utilizando um algoritmo genérico que se ajuste à linguagem desejada através de uma entrada externa. Como o intuito desse trabalho é definir uma Linguagem Intermediária para Orientação a Objetos capaz de ser mapeada por programas escritos nas principais Linguagens Procedimentais e Orientadas a Objetos escolheu-se como forma de implementação a utilização de autômatos finitos empregados por Setzer e Melo em [SET81] para a implementação da Análise Léxica e a implementação do algoritmo de Wirth [WIR76], capaz de analisar sintaticamente as principais linguagens Orientadas a Objetos sem, no entanto, possuir um custo muito elevado. Wirth propõe um algoritmo de Análise Sintática dirigido por um grafo sintático, construído a partir da gramática da linguagem.

Primeiramente nesse capítulo são apresentas as metodologias e os algoritmos empregados nas Análises Léxicas e Sintáticas, onde são utilizados os algoritmos de Setzer e Melo e de Wirth, respectivamente; depois encontram-se os aspectos de configuração do mapeamento das principais linguagens de Orientação a Objetos para a LI++. Em seguida, é descrita a forma como foi feita a implementação dos algoritmos 
de Análises Léxica e Sintática empregados no mapeamento de programas C++ para a LI++ baseados no mapeamento de programas C para a LI.

\section{1- Os Algoritmos utilizados para as Análises Léxica e Sintática}

Para se realizar a Análise Léxica do código fonte foi implementado o algoritmo de Setzer e Melo, baseado em autômatos finitos, enquanto que para se realizar a Análise Sintática foi implementado o algoritmo de Wirth. A escolha desses dois algoritmos foi feita por se tratar de algoritmos já consagrados, que possuem características que os tornam empregáveis independentemente da linguagem em que está escrito o programa e que se mostraram bastante eficazes no mapeamento de programas escritos em $\mathrm{C}$ para programas $\mathrm{LI}$.

\subsection{1 - O Algoritmo de Setzer e Melo}

O algoritmo genérico proposto por Setzer e Melo [SET81] é dirigido por uma tabela de transições e uma lista de estados finais, que interpreta autômatos finitos. Esse algoritmo lê a cadeia de entrada e realiza as transições através da interpretação de uma tabela. Essa tabela é constituída pelos seguintes campos: estado atual, símbolo lido e próximo estado, que representam as transicões propriamente ditas. Ainda, essa tabela possui os campos transição e próxima transição que indicam, respectivamente, a posição na tabela da transição corrente e a posição da primeira transição do próximo estado. A Tabela 4.1 mostra um exemplo para o autômato finito da Figura 4.1.

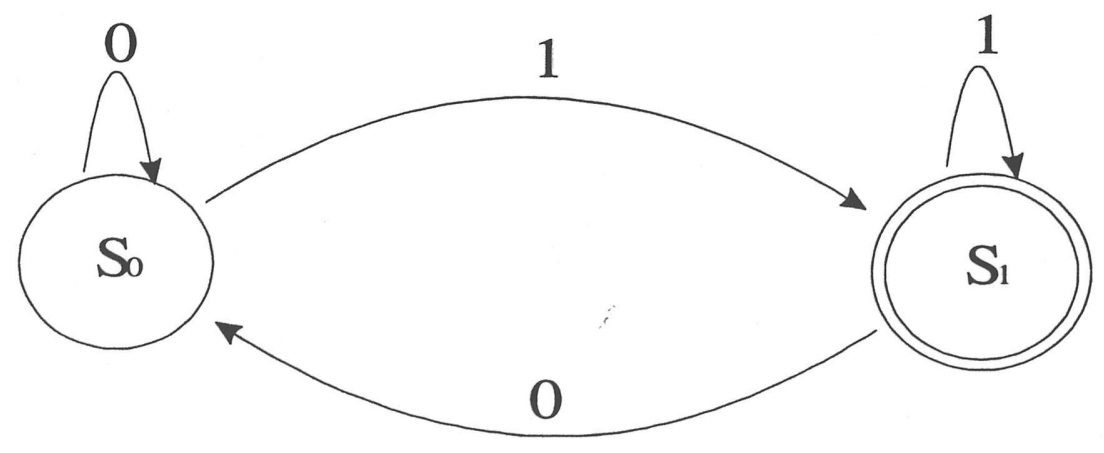

FIGURA 4.1 - AUTÔMATO FINITO SIMPLES [SET81] 
Tabela 4.1 - Tabela de Transições e Lista de Estados Finais do Autômato da Figura 4.1

\begin{tabular}{|c|c|c|c|c|}
\hline Transição & Estado Atual & Símbolo Lido & $\begin{array}{c}\text { Próximo } \\
\text { Estado }\end{array}$ & $\begin{array}{c}\text { Próxima } \\
\text { Transição }\end{array}$ \\
\hline $\mathbf{1}$ & $\mathrm{s}_{0}$ & 0 & $\mathrm{~s}_{0}$ & 1 \\
\hline $\mathbf{2}$ & $\mathrm{s}_{0}$ & 1 & $\mathrm{~s}_{1}$ & 3 \\
\hline $\mathbf{3}$ & $\mathrm{s}_{1}$ & 0 & $\mathrm{~s}_{0}$ & 1 \\
\hline $\mathbf{4}$ & $\mathrm{s}_{1}$ & 1 & $\mathrm{~s}_{1}$ & 3 \\
\hline
\end{tabular}
são:

Na Figura 4.2 encontra-se o algoritmo de Setzer e Melo. As variáveis utilizadas

L: contém o número da linha da tabela de transições. Será utilizada como índice para elementos das colunas da tabela;

E: contém o símbolo de entrada atual (um caracter no exemplo)

S: contém o estado atual do autômato

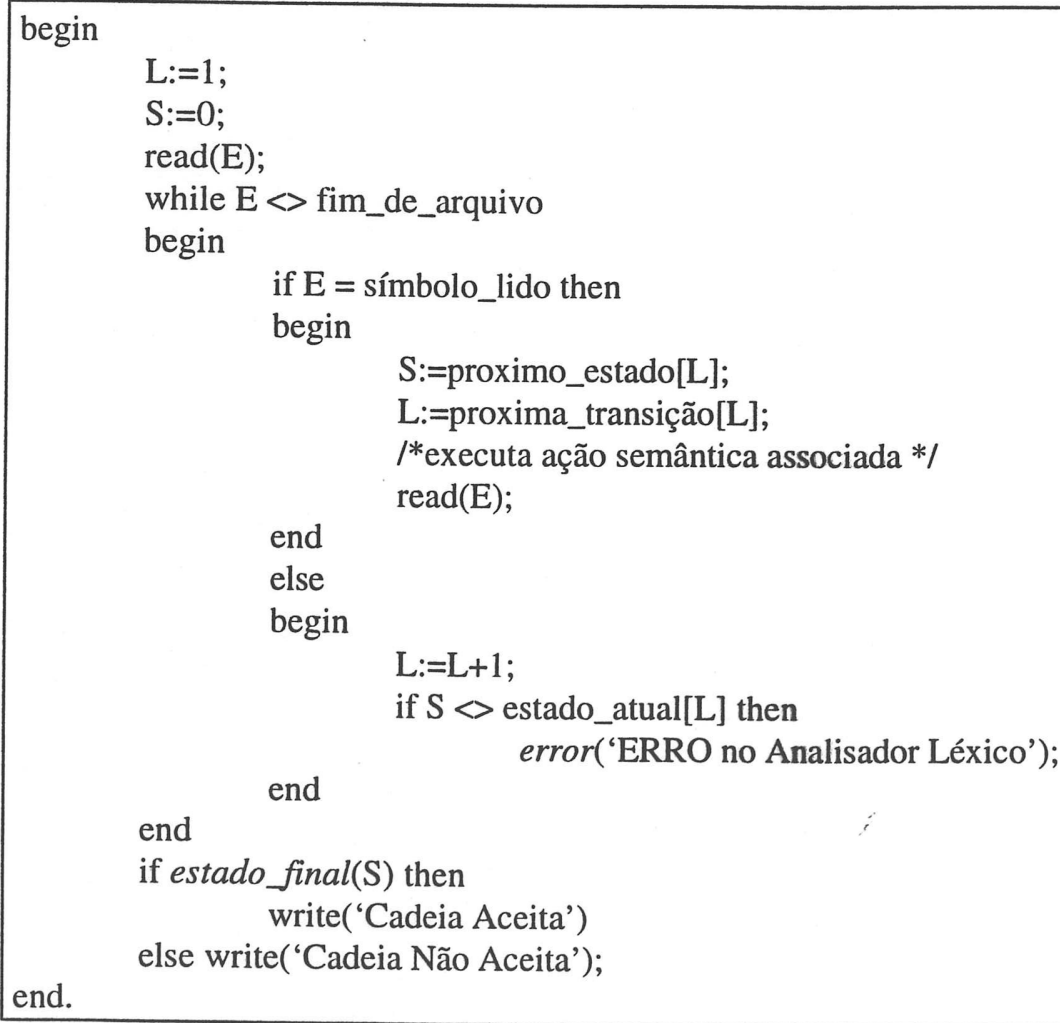

Figura 4.2 - Algoritmo de Sétzer e Melo 
Obs: error é uma função que imprime uma cadeia de caracteres, e estado_final é uma função que retorna se o seu parâmetro é ou não um dos estados finais que possui o autômato (no caso do exemplo utilizado, apenas o estado $\mathrm{s}_{1}$ é final).

Nesse algoritmo, onde é encontrado o comentário /*executa ação semântica associada $\% /$, pode-se ter uma estrutura do tipo case que determine qual é a ação semântica associada e execute tal ação. Para o emprego dessa estrutura basta que na tabela seja inserido um campo adicional que contenha o número da ação semântica que se deve executar.

A Seção 4.3.1 apresenta detalhes da realização da Análise Léxica para o mapeamento de programas $\mathrm{C}++$ para a $\mathrm{LI}++$.

\subsection{2 - Algoritmo de Wirth}

De maneira semelhante ao enfoque adotado para a Análise Léxica, para a realização da Análise Sintática deve-se procurar utilizar um algoritmo da literatura que seja capaz de dirigir esse processo através de uma Estrutura de Dados. O algoritmo de Wirth [WIR76] é dirigido por um grafo sintático que deve ser construído a partir da gramática da linguagem em que está escrito o programa a ser testado.

O método de Análise Sintática utilizada por Wirth utiliza-se do método de Análise Sintática Descendente. Esse método produz um algoritmo genérico e eficiente. Nele, todo passo da Análise Sintática depende unicamente do estado atual da transição e do próximo símbolo a ser lido; além disso, nenhum passo que já tenha sido executado precisa ser recuperado durante o processo de análise. Algoritmos que satisfazem esses requisitos são conhecidos como algoritmos com um lookahead e sem backtracking; a complexidade, para o pior caso é dada pela expressão $n \cdot \log n$, onde $n$ é o comprimento da sentença.

Basicamente, a gramática da maioria das linguagens de programação seguem estruturação de comandos em que após um certo comando se tenha um rol de opções e/ou imposições necessárias. Com isso, devem ser definidas as construções sintáticas da linguagem a serem reconhecidas pelo Analisador Sintático e, após o reconhecimento de cada uma dessas construções, rotinas semânticas associadas podem ser executadas. A execução dessas rotinas semânticas irá definir a forma como foi realizada a Análise Sintática [WIR76].

Detalhes mais significativos sobre o modo como é realizada a Análise Sintática do mapeamento de programas C++ para programas LI++ são dados na Seção 4.3.1. 


\section{2 - Aspectos de Configuração}

Configurar o mapeamento de um programa escrito em uma Linguagem de Programação Orientada a Objetos para a LI++ significa ajustá-lo para aceitar unidades a serem testadas em uma dada linguagem Orientada a Objetos. O objetivo é torná-lo hábil para traduzir unidades em uma linguagem Orientada a Objetos para a LI++.

O modelo de configuração foi discutido na seção anterior, sendo que o emprego de metodologias de Análises Léxica e Sintática para a realização do mapeamento do código fonte para a LI++ torna padrão o mapeamento de programas escritos em uma das principais linguagens de programação Orientadas a Objetos. O que vai ser diferente é o modo como será descrita a gramática da linguagem e do conjunto de palavras reservadas dessa linguagem.

A Figura 4.3 extraída de [CAR91] ilustra o DFD nível 01 do ambiente discutido nas seções anteriores e adotado na configuração.

Figura 4.3 - DFD NíVEl 01 do MAPEAMENTo dE LinguAgENS DE PRogramaÇÃo ORIENTADAS A OBJETOS PARA A LI++ [CAR91]

Os algoritmos de Análise Léxica e Sintática manipulam tabelas que contêm as particularidades da linguagem do programa em questão. Com isso, a configuração do mapeamento da linguagem em que está escrito o programa para a LI++ consiste em definir tabelas descritoras da linguagem e escrever acões e rotinas semânticas que realizem o mapeamento.

\section{3 - Etapas de Configuração}

Nessa seção estão sumarizadas as tarefas a serem realizadas por um usuário configurador para a obtenção do mapeamento da linguagem em que está escrito o programa a ser mapeado para a LI++. Os passos procedimentais estão descritos na Figura 4.5. 
1. Realizar o estudo preliminar da linguagem com o intuito de adquirir conhecimento léxico, sintático e semântico da linguagem

2. Configurar o Analisador Léxico. Essa tarefa demanda que o usário conheça bem os ítens léxicos da linguagem alvo e está dividida em:

2.1. Determinar os ítens léxicos, os quais constituirão os símbolos terminais presentes na gramática da linguagem;

2.2. Construir a tabela de palavras reservadas da linguagem;

2.3. Desenvolver um autômato finito [SET81] que realize a Análise Léxica da linguagem;

2.4. Identificar as ações semânticas associadas às transições do autômato finito; genérico;

2.5. Transcrever esse autômato para a notação aceita pelo Analisador Léxico

2.6. Complementar o Analisador Léxico através de procedimentos, que são as ações semânticas, para realizarem a separação dos átomos da linguagem fonte, colocando-os nas estruturas de dados disponíveis para armazená-los;

2.7. Depurar o Analisador Léxico conjuntamente com as ações semânticas desenvolvidas.

3. Configurar o Analisador Sintático. Essa tarefa demanda que o usuário configurador conheça bem a sintaxe e a semântica da linguahem alvo e está dividida em: [WIR76];

3.1. Descrever a gramática da linguagem fonte na forma de grafos sintáticos

3.2. Identificar as rotinas semânticas associadas ao mapeamento para a LI++;

3.3. Transcrever os grafos sintáticos para a notação aceita pelo mapeamento;

3.4. Complementar o Analisador Sintático com as rotinas semânticas que realizem a gravação dos átomos da LI++;

3.5. Depurar o Analisador Sintático conjuntamente com as rotinas semânticas desenvolvidas.

Figura 4.5 - ETAPAS PARA CONFIGURAÇÃo DE UMA LINGUAGEM DE PROGRAMAÇão ORIENTADA A OBJETOS PARA A LI++

O estudo preliminar da linguagem antecede a configuração propriamente dita, pois o trabalho de configuração do mapeamento para a LI++ pressupõe o conhecimento prévio e amplo da linguagem em questão. A tradução de programas escritos em uma Linguagem Orientada a Objetos para a LI++ consiste basicamente em relacionar construções sintáticas de ambas linguagens; ou seja, é o mapeamento de sentenças entre linguagens. 


\section{4 - Mapeamento $\mathrm{C}++$ / LI++}

Para se realizar o mapeamento de programas escritos em $\mathrm{C}++$ para a $\mathrm{LI}++$ foi feito um estudo preliminar da linguagem $\mathrm{C}++$. Esse estudo, bem como todas as características dessa linguagem se encontram na Seção 2.3.1; a gramática da linguagem C++ está descrita em [STR94]. A partir desse estudo foram definidos os arquivos de tabela sintática e de palavras-chaves para a linguagem $\mathrm{C}++$, respectivamente tabsin.c++ e tabchave.c++. Devido ao fato da linguagem $\mathrm{C}++$ ser um superconjunto da linguagem $\mathrm{C}$, a definição desses novos arquivos foi fortemente baseada nos arquivos tabsin.c e tabchave.c definidos por Chaim [CHA91].

\subsection{1 - Análises Léxica e Sintática para o Mapeamento C++ / LI++}

As Análises Léxica e Sintática encontradas no mapeamento de programas C++ para a LI++ utilizaram-se basicamente dos algoritmos de Setzer e Melo e de Wirth, conforme mostrado nas Seções 4.1.1 e 4.1.2. Para a leitura e o armazenamento em posições de memória dos caracteres do arquivo fonte (código $\mathrm{C}++$ ) o usuário configurador deve fornecer duas tabelas: tabela de transições léxicas e tabela de palavras reservadas.

A primeira tabela define um autômato finito, onde cada estado depende do caracter lido e das regras de transições do autômato. A tabela de palavras reservadas é usada para decidir se um elemento candidato a ser um identificador é ou não uma palavra reservada. Na Figura 4.4 encontra-se um trecho desse arquivo.

Para o relacionamento das demais tabelas utilizadas pelos Analisadores Léxico e Sintático foi utilizada a extensão $. c++$, porém a extensão desses arquivos também fica a cargo do configurador que deve utilizar sempre a mesma extensão, de preferência uma extensão ilustrando qual a linguagem em que está escrito o programa fonte; assim pode-se ter as extensões $. c++$ para programas $\mathrm{C}++$, .eif para programas Eiffel, .ada para programas Ada, etc. 


\begin{tabular}{|llllll|}
\hline linha 6 & "cl" & 5 & 0 & 0 & 6 \\
linha 7 & "ill" & 5 & 6 & 1 & 8 \\
linha 8 & "ild_" & 6 & 6 & 2 & 8 \\
linha 9 & "cld_" & 6 & 1000 & 7 & 1000 \\
\hline
\end{tabular}

FIGURA 4.4 - TRECHO DO ARQUIVO TABTRANS.C++

$\mathrm{Na}$ linha 7, se o caracter lido é uma letra então ocorre a transição do estado 5 para o estado 6, a ação semântica 1 é executada e a primeira transição do estado 6 ocorre na linha 8. Os caracteres do primeiro campo $i$ e $l$ determinam a comparação igual à letra, respectivamente; ou seja a ação semântica associada na linha 7 só será executada se o caracter lido for uma letra. $\mathrm{O}$ caracter $c$ encontrado no primeiro campo das linhas 6 e 8 determinam que a comparação é com o operador diferente de. Então, na linha 9 a transição do estado 6 para o estado 1000 associada à execução da ação semântica 7 só ocorre se o caracter lido for diferente de letra, de dígito ou do caracter caixa-baixa (_).

Qualquer transição para o estado final (1000) resultará na execução de uma ação semântica que gera um item léxico. As transições que são relativas a um mesmo estado devem estar agrupadas consecutivamente no arquivo tabtrans.c++ (que contém a tabela de transições léxicas).

A tabela de palavras reservadas determina os ítens léxicos que formam a classe de palavras reservadas. Geralmente, esses elementos têm uso exclusivo dos comandos da linguagem, não sendo, em hipótese alguma, permitido ao programador usá-los como identificadores (mesmo que a estrutura de algumas linguagens permita esse tipo de construção). O emprego dessa tabela dispensa a inclusão das palavras reservadas no autômato que define as transições léxicas.

As ações semânticas complementam a configuração léxica. Suas funções básicas são a geração dos ítens léxicos. O algoritmo de Análise Léxica lê caracteres que vão sendo concatenados em uma variável. Quando o próximo caracter lido for um símbolo especial ou um espaço em branco (diferente de letra, dígito ou "_"), o conteúdo dessa variável é pesquisado na tabela de palavras reservadas e, caso não seja encontrado nenhum item igual nessa tabela, esse item léxico pode ser classificado como identificador.

No contexto da geração da unidade em LI++, a Análise Sintática reconhece as sentenças da linguagem e as traduz para comandos LI++. O processo é conduzido segundo o algoritmo de Wirth descrito na Seção 4.1.2. Associadas ao reconhecimento das construções sintáticas da linguagem, as rotinas semânticas gravam comandos da LI++ equivalentes àqueles da unidade que se deseja mapear. Ou seja, através das rotinas semânticas será gerado o arquivo que contenha a unidade LI++. O arquivo 
tabsin.c++ contém a estruturação dos comandos, dos identificadores e das rotinas semânticas associadas que devem ser executadas sempre que uma determinada estrutura for reconhecida. A notação empregada para a criação dessa tabela é bastante parecida com a notação de Backus-Naur [SEB81] e está relacionada com a gramática da linguagem em que está escrito o programa a ser mapeado.

Logo, a preparação do Analisador Sintático consiste em se especificar a gramática do programa a ser mapeado na forma de um grafo sintático (obtido a partir da gramática da linguagem), transcrevê-lo para a notação aceita pelo mapeamento, isto é, criar a tabela sintática, e contruir as rotinas semânticas que gravem a versão em LI++ do programa a ser mapeado.

O Apêndice B descreve com mais detalhes as tabelas sintáticas (tabsin.c++), de palavras-chaves (tabchave.c++) e de transições léxicas (tabtrans.c++). Ainda, todas essas tabelas criadas para a realização do mapeamento automatizado de programas escritos em C++ para programas LI++ e os códigos-fontes escritos em C encontram-se no disquete anexo. O mapeamento foi implementado para ser executado sobre a plataforma SUN-OS / UNIX.

\subsection{2 - Grafo Sintático de C++}

A elaboração do grafo sintático de C++ é de significativa importância para a construção do arquivo tabsin.c++ que contém a estruturação dos comandos, dos identificadores e das rotinas semânticas associadas que irão ser as responsáveis pela gravação dos comandos LI++. Esse grafo pode ser criado a partir da gramática da linguagem $\mathrm{C}++$, encontrada em [WIR94].

A Figura 4.5 mostra um trecho desse grafo sintático que descreve a declaração de classes e subclasses. O símbolo não-terminal member_list é praticamente o mesmo que para a linguagem $\mathrm{C}$. A diferença está no fato de para a linguagem $\mathrm{C}++$ poderem ser incluídas definições de métodos e variáveis de instanciação private, protected e public, além de métodos virtuais e friends de outra classe. Pode-se observar que tanto a declaração de subclasses, quanto a declaração do corpo da classe são opcionais. O grafo sintático da linguagem C encontra-se em [CHA91b]. 


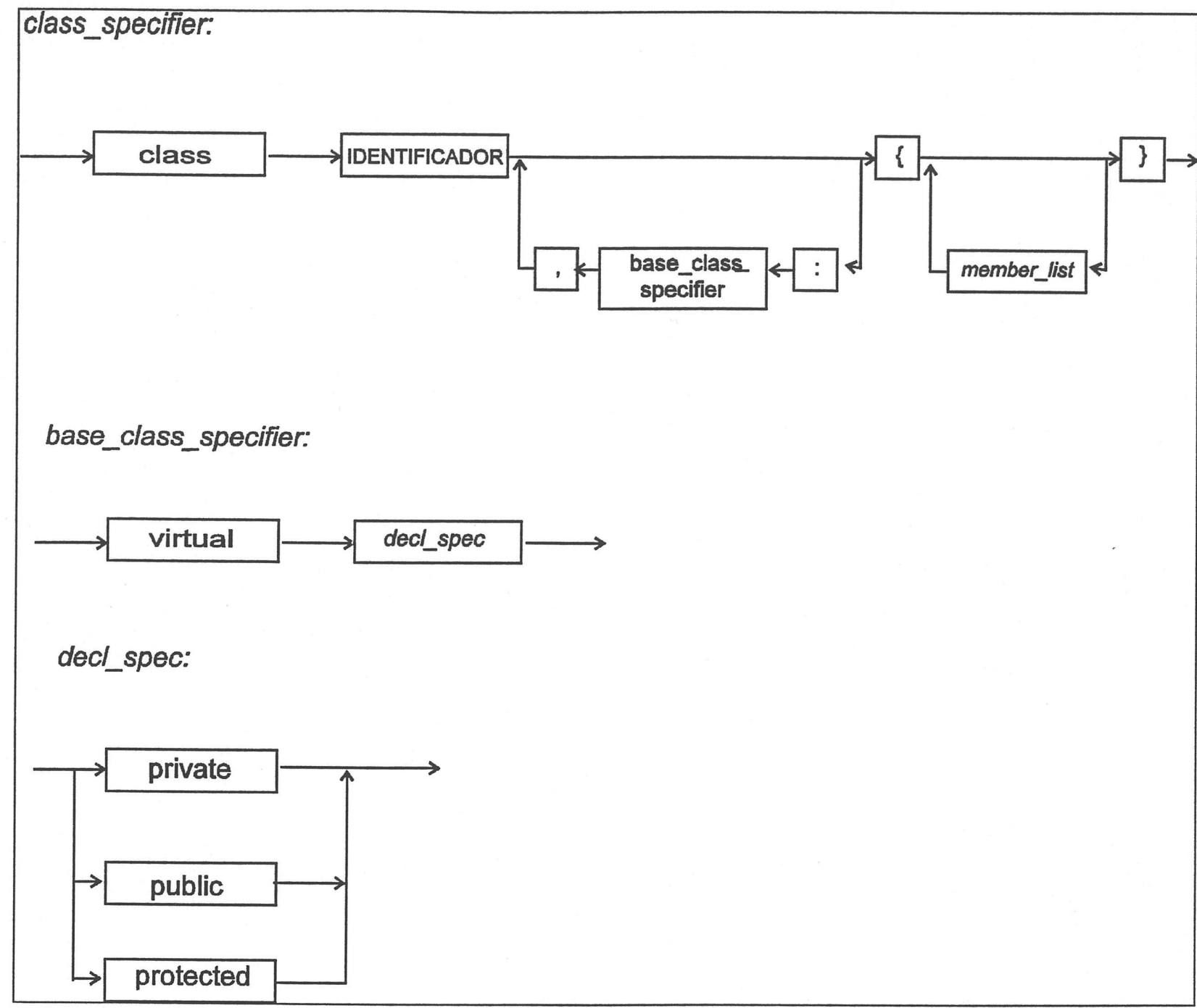

FIGURA 4.5 - TRECHO DO GRÁFICO SINTÁTICO DE C++ DESCREVENDO A DEFINIÇÃO DE CLASSE

Devido ao fato de poderem ser declarados métodos e variáveis de instanciação private, protected, public e friend, a Figura 4.6 pode representar o grafo sintático que descreve member_list. O símbolo não-terminal type_spec é praticamente igual ao definido no grafo sintático da linguagem $\mathrm{C}$ e representa os tipos de dados definidos pelo usuário ou pertencentes à linguagem $\mathrm{C}++$, tais como int, float, void, entre outros, apenas assumindo-se que o nome de uma classe passa a ser um tipo definido pelo usuário. Ao símbolo não-terminal statement serão adicionados símbolos representando as sintaxes de comandos que pertencem à linguagem $\mathrm{C}++$ e não pertencem à linguagem C, tais como os comandos cin e cout. 


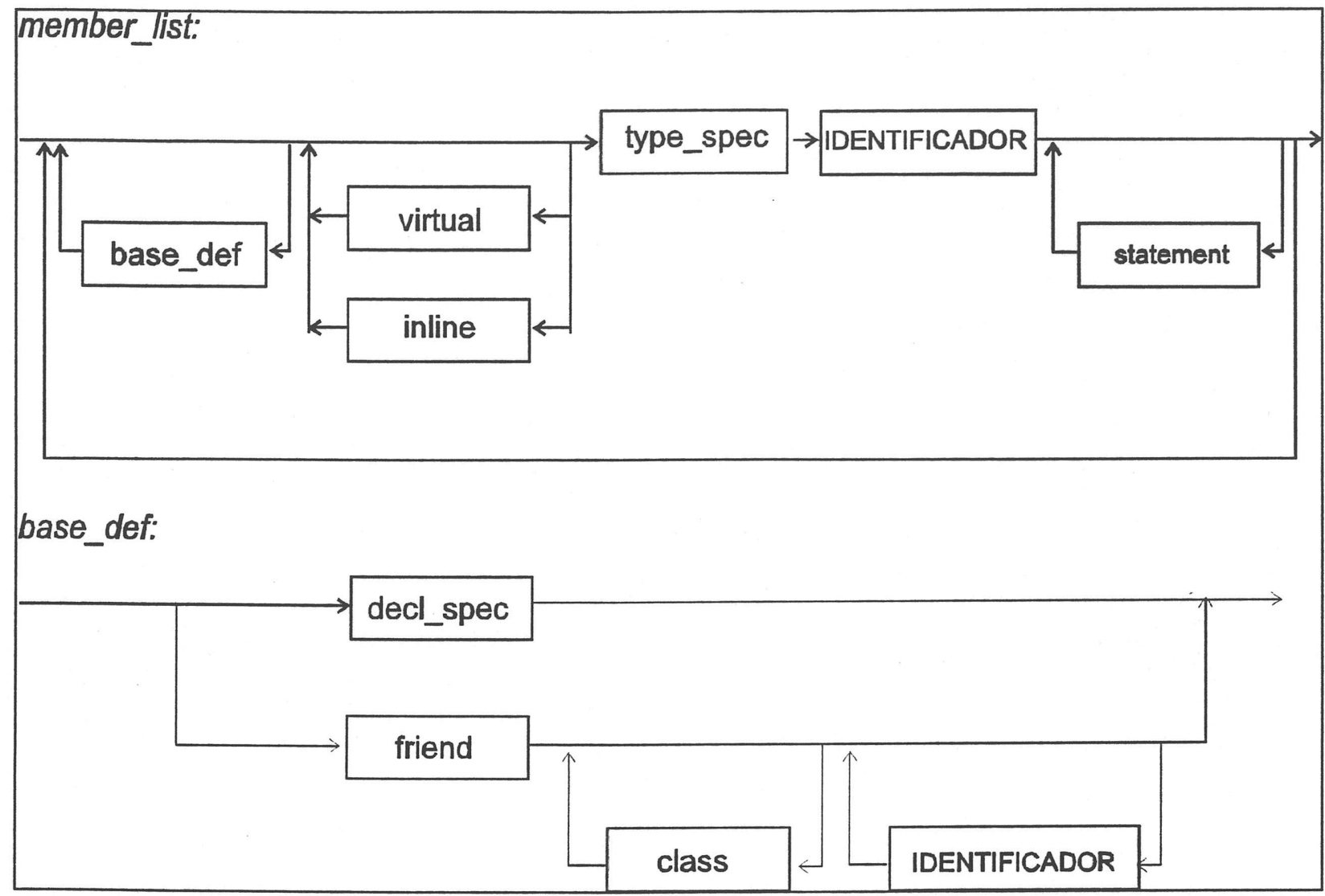

FIGURA 4.6 - TRECHO DO GRÁFICO SINTÁTICO DE C++ DESCREVENDO A DEFINIÇÃO DO CORPO DE UMA CLASSE [MOR96].

$\mathrm{O}$ grafo sintático da Linguagem $\mathrm{C}++$ encontra-se no Relatório Técnico

Analisando-se o grafo sintático de $\mathrm{C}++$ pode-se obter a tabela sintática a ser empregada no mapeamento para a LI++ (arquivo tabsin.c++). Os símbolos que são descritos no grafo sintático como opcionais deverão estar entre colchetes ([]) na tabela sintática; os que representam tipos de dados da linguagem e/ou definidos pelo usuário, identificadores e constantes deverão, respectivamente, ser representados por 'TYPEDEF', 'IDENT' e 'CONSTANT'; enquanto que as palavras-chaves de C++ (que devem estar armazenadas no arquivo tabchave.c++) deverão estar representadas entre plicas (") e escritas em letras minúsculas. As rotinas semânticas que devem ser executadas para a geração do mapeamento devem ser representadas por números, sendo que cada número irá indicar a execução de uma única rotina. 


\section{5 - Mapeamento de um Programa Exemplo}

A Tabela 4.1 mostra o programa cliente.c++ e seu respectivo mapeamento para a LI++ (arquivo cliente.li++). Este programa possui 3 classes, sendo que uma delas é classe-base (a classe customer) e as outras duas (classes loan e savings) são subclasses de customer.

A classe customer possui dois métodos públicos: info_in() e info_out(), que possuem 6 e 15 linhas de códigos respectivamente. Ainda, essa classe possui 5 variáveis definidas como privadas à classe: name, street, city, state e zip.

A classe loan (subclasse de customer) também possui 2 métodos públicos, que são loan_customer() e l_disp(). Tais métodos possuem 6 e 4 linhas de códigos. O método loan_customer() chama o método info_in() e o método l_disp() chama o método info_out(). As variáveis privadas da classe loan são loan_type e $l \_b a l$.

Finalmente, a classe savings (também subclasse de customer) possui 2 métodos: saving_customer() e s_disp(). O método saving_customer() possui 9 linhas de código, enquanto que o método $s_{-}$disp() possui apenas 3. Nessa classe são definidas duas variáveis privadas: savings_type e s_bal.

Os métodos descritos acima (pertencentes às três classes) não apresentam nenhum tipo de retorno, e portanto são descritos como void.

A função main() possui 10 linhas de código.

Nota-se na segunda coluna da Tabela 4.2 (onde está listado o arquivo cliente.li++) a existência de três átomos \$CLASS. Desses três, os dois últimos possuem respectivamente um átomo \$BASECL associado, indicando que tais classes descritas são subclasses de uma classe-base. Ainda, cada classe possui átomos \$PRIVATE e \$PUBLIC indicando que algumas variáveis e métodos descritos são privados ou públicos à classe em que foi definido.

Os métodos definidos são mapeados por seus nomes-únicos (como por exemplo o método info_in() que é mapeado por @info-in-LI++01). Neste programa não são encontrados métodos que possuam mesmo nome mas que tenham parâmetros diferentes ou que pertençam a classes diferentes - o que caracterizaria sobrecarga de métodos. No disquete anexo à tese encontram-se exemplos de programas que têm sobrecarga de métodos, além de diversas outras catacterísticas da linguagem $\mathrm{C}++$ e seus respectivos arquivos de mapeamentos para a LI++. 
Tabela 4.1 - Exemplo de Mapeamento de Programa C++ para a LI++ cliente.c++ cliente.li++

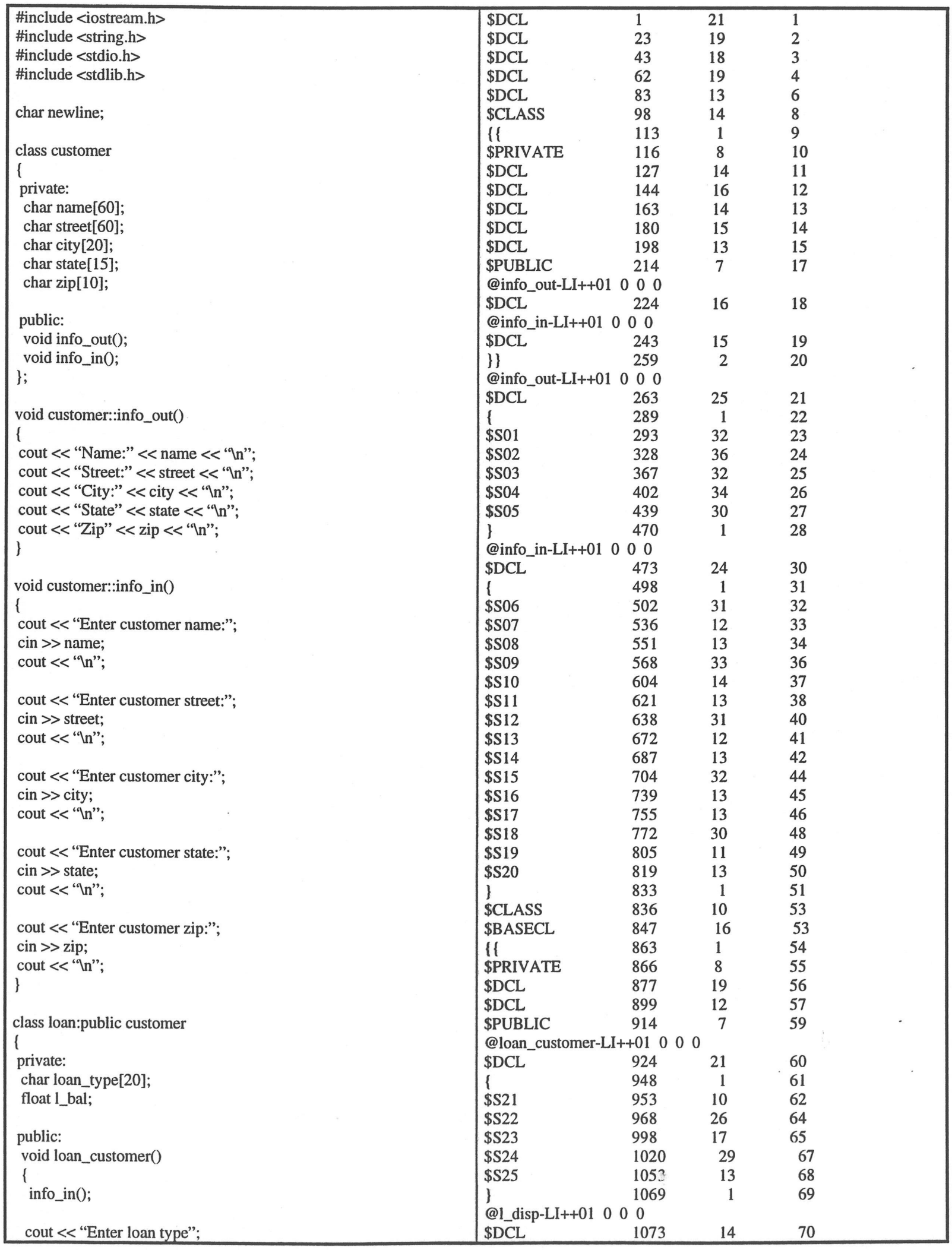




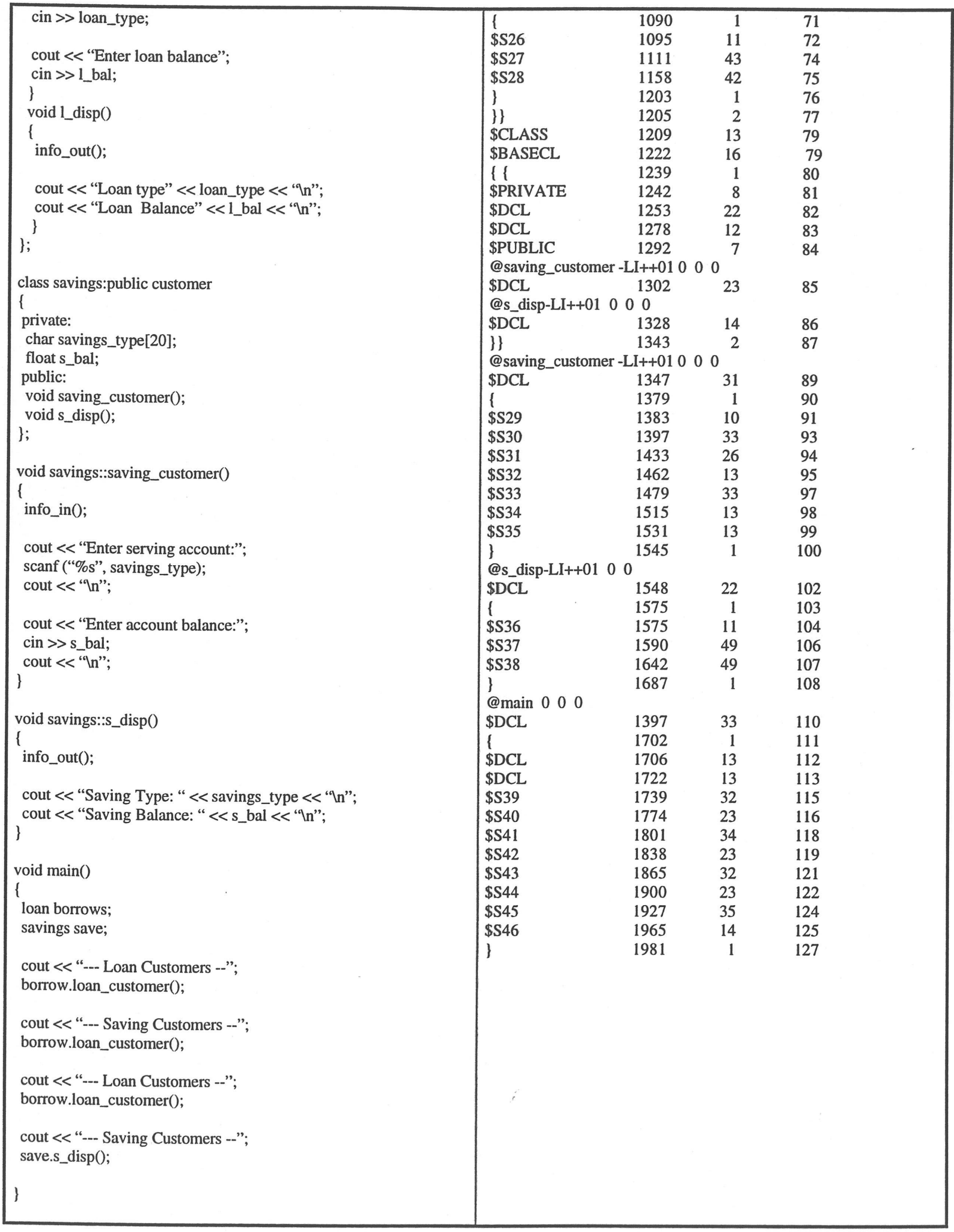




\section{6 - Avaliação de Desempenho do Mapeamento C++ / LI++}

A Tabela 4.2 mostra uma relação de alguns programas C++ utilizados para testar e validar o mapeamento $\mathrm{C}++/ \mathrm{LI}++$. Esses programas foram retirados de fontes diversas: da bibliografia, onde destacam-se [STR86], [ECK91], [HOL94], [KHO90], [SCH91], [PAP90], entre outros, com a finalidade de serem testadas construções específicas da linguagem $\mathrm{C}++$. Alguns programas foram especialmente escritos para retratar construções mais específicas da linguagem $\mathrm{C}++$. Esses programas e seus respectivos mapeamentos encontram-se no Apêndice B (disquete anexo).

Tabela 4.2 - Programas C++, suas características e respectivos tempos de mapeamento para a LI++

\begin{tabular}{|c|c|c|c|c|}
\hline programa C++ & $\begin{array}{c}\text { número de } \\
\text { classes }\end{array}$ & $\begin{array}{c}\text { número de } \\
\text { métodos }\end{array}$ & $\begin{array}{c}\text { número de } \\
\text { linha de código }\end{array}$ & $\begin{array}{c}\text { tempo de } \\
\text { execução (seg.)* }\end{array}$ \\
\hline ex03 & 01 & 00 & 12 & 0.140 \\
\hline ex01 & 02 & 01 & 27 & 0.146 \\
\hline ex07 & 03 & 02 & 31 & 0.151 \\
\hline win & 03 & 00 & 32 & 0.152 \\
\hline ex09 & 03 & 03 & 35 & 0,150 \\
\hline ex08 & 01 & 04 & 36 & 0,154 \\
\hline ex06 & 01 & 04 & 37 & 0,149 \\
\hline counter & 01 & 04 & 40 & 0,147 \\
\hline dog & 01 & 04 & 42 & 0,158 \\
\hline stack & 01 & 03 & 44 & 0,160 \\
\hline pt & 01 & 05 & 50 & 0,165 \\
\hline cadeia & 01 & 09 & 52 & 0,166 \\
\hline inner & 02 & 06 & 52 & 0,168 \\
\hline st & 01 & 06 & 52 & 0,168 \\
\hline data & 01 & 04 & 57 & 0,165 \\
\hline word & 02 & 00 & 59 & 0,170 \\
\hline
\end{tabular}




\begin{tabular}{|c|c|c|c|c|}
\hline ex02 & 05 & 07 & 63 & 0,170 \\
\hline medang & 01 & 04 & 63 & 0,168 \\
\hline tempo & 01 & 03 & 64 & 0,169 \\
\hline angulo & 01 & 03 & 65 & 0,172 \\
\hline animal & 03 & 06 & 66 & 0,170 \\
\hline dict & 02 & 01 & 68 & 0,182 \\
\hline impstack & 01 & 04 & 72 & 0,178 \\
\hline car & 01 & 03 & 73 & 0,175 \\
\hline string & 01 & 01 & 74 & 0,177 \\
\hline ex04 & 03 & 06 & 78 & 0,180 \\
\hline ration & 01 & 08 & 78 & 0,183 \\
\hline ex05 & 04 & 05 & 80 & 0,181 \\
\hline time & 01 & 04 & 82 & 0,187 \\
\hline custime & 03 & 10 & 94 & 0,190 \\
\hline mtime & 03 & 12 & 103 & 0,205 \\
\hline date & 01 & 11 & 115 & 0,215 \\
\hline vertime & 03 & 08 & 127 & 0,204 \\
\hline cliente & 03 & 06 & 128 & 0,220 \\
\hline number & 03 & 12 & 131 & 0,235 \\
\hline point & 05 & 27 & 246 & 0,370 \\
\hline vetor & 02 & 27 & 359 & 0,421 \\
\hline
\end{tabular}

* - Nesta coluna são mostradas as médias de tempo decorridos em 30 execuções de cada programa

Pode ser notado na Tabela 4.2 que os tempos de execução do mapeamento dos programas $\mathrm{C}++$, assumem valores entre 0,140 a 0,421 segundos. Os programas $\mathrm{C}++$ escolhidos para servirem de exemplos para o mapeamento $\mathrm{C}++/ \mathrm{LI}++$ possuem número médio de linhas de código aproximadamente igual a 76, número médio de classes 1,87 e número médio de métodos 7,358. Isso mostra que a execução do mapeamento de 
programas $\mathrm{C}++$ para a LI++ não acarretará baixo desempenho às ferramentas automatizadas multilinguagens de teste de softwares Orientados a Objetos. Pode-se notar ainda que o maior programa mapeado (vetor.c++) possui 359 linhas de código, 02 classes, 27 métodos o tempo médio de execuções foi de 0,368 segundos; o menor programa (ex03.c++) possui apenas 12 linhas de código, 01 classe e nenhum método. Seu tempo médio das 30 execuções foi de 0,140 segundos.

Mesmo não representando o número médio de linhas de código de programas reais normalmente empregados nas implementações acadêmicas ou comerciais, o tempo de execução do mapeamento para a LI++ deste conjunto de programas dá indícios que a execução do mapeamento de programas maiores deverá ser realizado em um intervalo de tempo que não inviabilizará a utilização desse mecanismo.

Os programas $\mathrm{C}++$ destacados na Tabela 4.2 , bem como seus respectivos mapeamentos para a LI++, encontram-se no Apêndice B (inclui disquete anexo).

\section{7 - Considerações Finais}

Implementar-se o mapeamento de uma Linguagem de Programação Orientada a Objetos para a LI++ propicia facilidades para que sejam distingüidos módulos dependentes e independentes da linguagem alvo na qual está escrito o programa que se deseja testar, além de fornecer subsídios para que sejam definidas e implementadas ferramentas de teste de software que apóiem esse paradigma e que possuam a característica de serem multi-linguagens. Dois passos básicos são importantes para a realização desse mapeamento: a Análise Léxica e a Análise Sintática. Uma maneira de se realizar as Análises Léxica e Sintática é criar-se um algoritmo genérico que se ajuste à linguagem desejada através de uma entrada externa. Por ter sido a finalidade desse trabalho a definição de uma Linguagem Intermediária para Orientação a Objetos que possa ser mapeada por programas escritos nas principais Linguagens Procedimentais e Orientadas a Objetos escolheu-se como forma de implementação a utilização de autômatos finitos definido por Setzer e Melo [SET81] para a implementação da Análise Léxica e a implementação do algoritmo de Wirth [WIR76] para a Análise Sintática. Ainda, tais algoritmos foram escolhidos por se mostrarem bastante eficazes no mapeamento de programas C para a LI [CHA91].

A realização do mapeamento de programas $\mathrm{C}++$ para a $\mathrm{LI++}$ foi baseada em um estudo preliminar da linguagem $\mathrm{C}++$. Com isso, foram definidos os arquivos de tabela sintática e de palavras-chaves para a linguagem $\mathrm{C}++$, respectivamente tabsin.c++ e tabchave.c++. A definição desses arquivos foi fortemente baseada nos arquivos tabsin.c e tabchave.c definidos por Chaim [CHA91] pois a linguagem $\mathrm{C}++$ é um superconjunto da linguagem $\mathrm{C}$. 
$\mathrm{O}$ arquivo tabsin.c++ (de tabelas sintáticas) contém números associados às rotinas semânticas que devem ser executadas após o reconhecimento de alguma sentença. Tais rotinas se encontram no arquivo rotsem.c, sendo que 38 foram mantidas inalteradas com relação ao mapeamento de programas C para a LI, 12 foram alteradas e 36 foram criadas. As rotinas criadas irão mapear os comandos Orientados a Objetos da linguagem $\mathrm{C}++$.

O próximo Capítulo apresenta as conclusões deste trabalho e aponta trabalhos que podem ser desenvolvidos no futuro a partir da definição da LI++ e do mapeamento de programas $\mathrm{C}++$ para a $\mathrm{LI}++$. 


\section{CAPÍTULO 5 - Conclusões e Trabalhos futuros}

Conforme caracterizado ao longo desse trabalho, a abordagem de desenvolvimento de software Orientado a Objetos vem se consolidando e sua utilização na produção de software é cada vez maior [BEI90][KHO90]. Outro ponto a ser destacado é a existência de várias linguagens de programação Orientadas a Objetos com ampla difusão e utilização. Entre elas podem ser citadas C++, Smalltalk, Ada, Eiffel, Smalltalk, entre outras.

Apesar da relevância atual da abordagem Orientada a Objetos e dos esforços de desenvolvimento de recursos de teste para esta abordagem, pode-se dizer que essa é uma área bastante incipiente, com poucos resultados obtidos na área de teste.

Nesse contexto, observa-se também que existe uma tendência em se utilizar os conceitos, experiências e ferramentas utilizadas no teste de programas procedimentais para o estabelecimento de estratégias de teste dentro da Orientação a Objetos [HAR92] [BER92][PER90].

O objetivo desse trabalho foi, a partir da experiência consolidada do Grupo de Engenharia de Software do ICMSC - USP - São Carlos, em colaboração com o Grupo de Engenharia de Software do DCA - FEEC - UNICAMP no estudo teórico e aplicado de critérios e no desenvolvimento de ferramentas de teste [CHA91] [DEL93] [MAL89] [MAL91][CAR91], definir uma Linguagem Intermediária para programas Orientados a Objetos (LI++) que reflita as características das principais linguagens Orientadas a Objetos, além de realizar o mapeamento de programas escritos na linguagem $\mathrm{C}++$ [STR86] para a LI++.

A proposição da LI++ propicia a definição de uma ferramenta de teste multilinguagem no contexto da Orientação a Objetos, característica relevante dada a diversa gama de linguagens de programação Orientadas a Objetos, semelhantemente à abordagem adotada no desenvolvimento das ferramentas de teste de programas procedimentais POKE-TOOL [CHA91] e PROTEUM [DEL93].

Escolheu-se a linguagem $\mathrm{C}++$ para ser a primeira a ter programas mapeados para a LI++ por ser uma linguagem que vem recebendo grande aceitação, tanto no meio acadêmico quanto no da indústria de produção de software. Ainda, por $\mathrm{C}++$ ser um superconjunto da linguagem $\mathrm{C}$, o mapeamento de programas $\mathrm{C} / \mathrm{LI}$ foi bastante útil para o mapeamento de programas $\mathrm{C}++$ / LI++, visto que a $\mathrm{LI++}$ é um superconjunto da LI .

Dois passos básicos nortearam a implementação do mapeamento de programas escritos em C++ para a LI++: a Análise Léxica e a Análise Sintática. O modo 
empregado para as realizações dessas Análises neste trabalho foi a criação de algoritmos genéricos que se ajustem à linguagem desejada através de entradas externas. Sendo a finalidade desse trabalho a definição de uma Linguagem Intermediária para Orientação a Objetos que possa ser mapeada por programas escritos nas principais Linguagens Orientadas a Objetos escolheu-se como forma de implementação a utilização de autômatos finitos para a implementação da Análise Léxica e a implementação do algoritmo de Wirth [WIR76] para a Análise Sintática.

\section{1 - Trabalhos Futuros}

Uma das motivações de se definir a LI++ e implementar seu respectivo mapeamento para a linguagem $\mathrm{C}++$ foi que utilizando-se a $\mathrm{LI}++$ pode-se separar aspectos dependentes e independentes da linguagem em que está escrito o programa, viabilizando o desenvolvimento de ferramentas multilinguagens para o teste de programas Orientados a Objetos, baseados em critérios data flow e no critério Análise de Mutantes.

A curto prazo, os mecanismos de visualização do fluxo de controle disponíveis na ViewGraph [VIL94] podem ser trazidos para esse contexto. Outro aspecto que pode ser explorado é a implementação de um módulo de métricas. Esses recursos podem facilitar as tarefas de entendimento, teste, manutenção e depuração de softwares Orientados a Objetos. 


\section{REFERÊNCIAS BIBLIOGRÁFICAS}

[ADR82] Adrion, W.R., Branstad, M.A., Cherniavski, J.C.; "Validation, Verification, and Testing of Computer Software", Computing Surveys, vol 14, Nr 2, Jun 1982.

[ARN94] Arnold, T. R., Fusom, W.; "In a Perfect World", Communications of the ACM, Nr 9, Set 1994.

[BEI90] Beizer, B.; Software Testing Techniques, 2nd edition, Van Nostrand Reinhold, New York, 1990.

[BER92] Berard, E.V.; Essays on Object-Oriented Software Engineering, Vol. I, Prentice-Hall, Englewood Cliffs, New Jersey, 1992.

[BOO86] Booch, G.; "Object-Oriented Development", IEEE Trans. on Software Eng., vol SE-12, Nr 02, Fev 1986.

[CAR91] Carnassale, M.; "GFC - Uma Ferramenta Multilinguagem para Geração de Grafo de Programa", Dissertação de Mestrado, DCA/FEEC/UNICAMP, Fev 1991.

[CHA91] Chaim, M.L.; "POKETOOL - Uma Ferramenta para Suporte ao Teste Estrutural de Programas Baseado em Análise de Fluxo de Dados", Dissertação de Mestrado, DCA/FEEC/UNICAMP, 1991.

[CHA91b] Chaim, M.L.; “Apêndices I e II", Relatório Técnico, DCA/FEEC/UNICAMP, 1991.

[CHO89] Choi, B.J., Mathur, A.P., Pattison, B.; "pMothra: Scheduling Mutants For Execution on a Hypercube", Third Symposium on Software Testing, Analysis and Verification, Key West, Dez 1989.

[COA90] Coad, P., Yourdon, E.; Object-Oriented Analysis, Prentice-Hall, 1990.

[COL94] Coleman, D.; Object-Oriented Development - The FUSION Method, Englewood Cliffs, Prentice Hall, 1994.

[DEL93] Delamaro, M. E.; "Proteum - Um Ambiente de Teste Baseado na Análise de Mutantes”, Dissertação de Mestrado, ICMSC/USP, 1993.

[DEM80] DeMillo, R.A.; "Mutation Analysis as a Tool for Software Quality Assurance", Proc. of COMPSAC, Chicago - IL, Out 1980. 
[DEM88] DeMillo, R.A., Guindi, D.S., King, K.N., McKraken, W.N., Offutt, A.J.; "An Extended Overview of the Mothra Testing Environment", Proc. of the 2nd. Workshop on Software Testing, Verification and Analysis, Banff Canada, Mai 1988.

[DOO94] Doong, R., Frankl, P.G.; "The ASTOOT - Approach to Testing ObjectOriented Programs", ACM Transactions on Software Engineering and Methodology, Vol 3, Nr 2, pp 101-130, Abr 1994.

[DUR84] Duran, J., Ntafos, S.; "An Evaluation of Random Testing", IEEE Trans. on Software Eng., Vol 10, Nr 7, pp 438-444, Jul 1984.

[ECK91] Eckel, B.; C++ - Guia do Usuário, Osborne McGraw Hill - Makron Books, 1991.

[FIE89] Fielder, S.P.; “Object-Oriented Unit Testing”, Hewlett-Packard Journal, pp 69-74, Abr 1989.

[FRA87] FRANKL, F.G., "The Use of Data Flow Information for the Selection and Evaluation of Software Test Data", PhD dissertation, New York University, New York, Out 1987.

[FRA89] Frankl, P.; "A framework for Testing Object-Oriented Programs", Technical Report - Department of Eletrical Engineering and Computer Science, Polytechnic University, New York, 1989.

[GOL83] Goldberg, A., Robson, D.; SMALLTALK-80 The Language and Its Implementation, Addison-Wesley, 1983.

[GOL84] Goldberg, A. ; SMALLTALK-80 The Interactive Programming Environment, Addison-Weseley, 1984.

[GO075] Goodenough, B., Gerhart, S.L.; "Toward a Theory of Test Data Selection", IEEE Trans. on Software Eng., Vol. SE-1, Nr 2, Jun 1975.

[GOS95] Gosling, J., McGilton, H.; "The JAVA Language Environment - A White Paper", SUN Microsystems Computer Company, Out 1995.

[HAM92] HAMLET, D.; “Are We Testing for True Reliability?”, IEEE Software, pp 21-27, Jul 1992.

[HAR92] Harrold, M.J., McGregor, J.D., Fitzpatrick, K.J.; "Incremental Testing of Object-Oriented Class Structures", Communications of the ACM, pp 68-80, Ago 1992. 
[HOL94] Holzner, S.; Programando em Visual C++, Berkeley Brasil Editora, 1994.

[HOW87] Howden, W.E.; Functional Program Testing and Analysis, Software Engineering Series, McGraw Hill, 1987.

[JOR94] Jorgesen, P., Erickson, C.; "Object Oriented Integration”, Communications of the ACM, Nr 9, Set 1994.

[KHO90] Khoshafian, S., Abnous, R.; Object Orientation - Concepts, Languages, Databases, User Interfaces, John Wiley and Sons, 1990.

[KOR90] Korson, T., McGregor, J.D.; "Understanding Object-Oriented: A Unifying Paradigm", Communications of the ACM, Vol 33, Nr 9, pp 40-60, Set 1990.

[LIN87] Linton, M.A. e Calder, P.R.; "The design and implementation of InterViews", Proceedings of USNIX C++ Workshop, pp 256-267, Abr 1987.

[LOR86] Lorensen, W.; "An Object-Oriented Graphics Animation System”, General Electric Coorporate Research \& Development - Technical Information Series Report, 1986.

[LOV85] Love, T.; "Message Object Programming: Experiences with Commercial Systems", Productivity Products International, Sandy Hook, CT, 1985.

[LUT90] Lutz, M.; “Testing Tools”, IEEE Software, Vol 7, Nr 3, Mai 1990.

[MAL89] Maldonado, J.C., Chaim, M.L., Jino, M.; “A Arquitetura de uma Ferramenta de Teste de Software de Apoio ao Critério Potenciais Usos", Proc XXII Congresso Nacional de Informática, São Paulo - SP, Set 1990.

[MAL91] Maldonado, J.C.; "Critérios Potenciais Usos: uma Contribuição ao Teste Estrutural de Software”, Tese de Doutorado, DCA/FEEC/UNICAMP, 1991.

[MEY88] Meyer, B.; Object-Oriented Software Construction, Prentice-Hall, 1988.

[MOR96] Morandini, M., Maldonado, J.C.; "Documentação do Mapeamento de programas C++ para a LI++", Relatório Técnico, ICMSC/USP, 1996, em preparação.

[MUR94] Murphy, G.C., Townsend, P., Wong, P.S.; "Experience with Cluster and Class Testing", Communications of the ACM, Nr 9, Set 1994.

[MYE79] Myers, G.J.; The Art of Software Testing, John Wiley and Sons, 1979.

[NIE96] Niemeyer, P., Peck, J.; Exploring JAVA, O’Reilly \& Associates Inc., 1996. 
[PER90] Perry, D.E., Kaiser, G.E.; "Adequate Testing and Object-Oriented Programming", Journal of Object-Oriented Programming, Vol 2, pp 13-19, Jan/Fev 1990.

[POS94] Postob, R.; "Automated Testing from Object Models”, Communications of the ACM, Nr 9, Set 1994.

[PRE92] Pressman, R.S.; Software Engineering - A Practitioner's Approach, 3rd Edition, 1992.

[PRI90] Price, A.M., Zorzo, A.; "Visualizando o Fluxo de Controle de Programas", IV Simpósio Brasileiro de Engenharia de Software, Águas de São Pedro - SP, Out 1990.

[RAP85] Rapps, S., Weyuker, E.J.; "Data Flow Analysis Techniques for Test Data Selection", IEEE Trans. on Software Eng., Vol SE-11, Abr 1985.

[RET91] Rettig, S.; "Testing Made Palatable", Communications of the ACM, Vol 34, Nr 5, Mai 1991.

[ROP93] Roper, R., Rahim, A.R.B.A.; "Software Testing Using Analysis and Design Based Techniques", Software Testing, Verification and Reliability, Vol 3, 165-179, Set 1993.

[ROS92] Rosen, J.P.; "What Orientation Should Ada Objects Take?", Communications of the ACM, Vol 35, pp 71-76, Nov 1992.

[SCH91] Schildt, H.; C - Completo e Total, MAKRON Books, 1991.

[SMI90] Smith, M. D., Rpbson, D. J.; "Object-Oriented Programming - The Problems of Validation”, IEEE Software, pp 272-281, Set 1990.

[SMI92] Smith, M. D., Robson, D. J.; "A Framework for Testing Object-oriented Programs", Journal of Object-Oriented Programming, pp 45-53, Jun 1992.

[SPA94] SPA - Sistemas e Planejamento S.A., O Ambiente TOOL - Manuais do Usuário, São Paulo - SP, 1994.

[STR86] Stroustroup, B.; The C++ Programming Language, Addison-Wesley, 1986.

[TAK90] Takahashi, T., Liesenberg K.E. H., Xavier, T. D.; "Programação Orientada a Objetos - Uma visão integrada do Paradigma de Objetos", VII Escola de Computação, São Paulo - SP, 1990. 
[VIL94] Vilela, P.R.S.; "Uma Ferramenta para Auxílio Visual ao Teste e Depuração de Programas", Dissertação de Mestrado, DCA/FEEC/UNICAMP, Campinas, 1994.

[WEB89] Webster, B.F.; The NeXT Book, Addison-Wesley, 1989.

[WEG88] Wegner, P., Zdonik, B.; "Inheritance as an Incremental Modification Mechanism or What Like Is and Isn't Like", Proceedings of ECOOP'88, pp 55-77, Springer-Verlag, 1988.

[WEY86] Weyuker, E.J.; "Axiomatizing Software Test Data Accuracy", IEEE Trans. on Software Eng., Vol SE-12, pp 227-242, Dez 1986.

[WEY88] Weyuker, E.J.; "The Evaluation of Program-Based Software Test Data Accuracy", Communications of the ACM, Vol 31, pp 668-675, Jun 1988.

[WHI80] White, L.J.; Software Testing and Verification, North-Holland Publishing Company, 1981. 


\section{APÊNDICE A - A LINGUAGEM INTERMEDIÁRIA $L I$}

Nesse Apêndice será descrita a Linguagem Intermediária LI segundo a notação de Backus-Naur, além de serem mostrados alguns exemplos de mapeamentos de trechos de programas procedimentais para a LI. A definição da LI foi extraída de [CAR91].

\section{A.1 - Tipos de Comandos e Estrutura dos Átomos da LI}

A LI tem o propósito básico de representar o fluxo de execução de um programa; assim, possui dois tipos de comandos:

- comandos seqüenciais; e

- comandos de controle de fluxo.

Os comandos seqüenciais da LI representam os comandos das linguagens procedimentais que não alteram o fluxo de execução, como por exemplo, uma declaração de variável, uma estrutura de dados, ou uma computação (comandos de atribuição ou chamadas de funções).

Os comandos de controle de fluxo da LI são equivalentes aos comandos das linguagens procedimentais que causam seleção, seleção múltipla, repetição e desvio incondicional.

Uma das características da LI é que todos os seus átomos são seguidos de números que identificam:

- o início do átomo no programa fonte (a quantos bytes da posição inicial do arquivo fonte começa o átomo);

- o comprimento do átomo (de quantos bytes é composto o átomo); e

- o número da linha do programa fonte onde se encontra o átomo.

Para a descrição da estrutura da LI é utilizada a notação de Backus-Naur [SET81], onde: os terminais serão representados em letra maiúscula; os não-terminais entre parêntesis angulares $(<>)$, e as chaves aparecerão sublinhadas quando forem parte integrante da LI. 


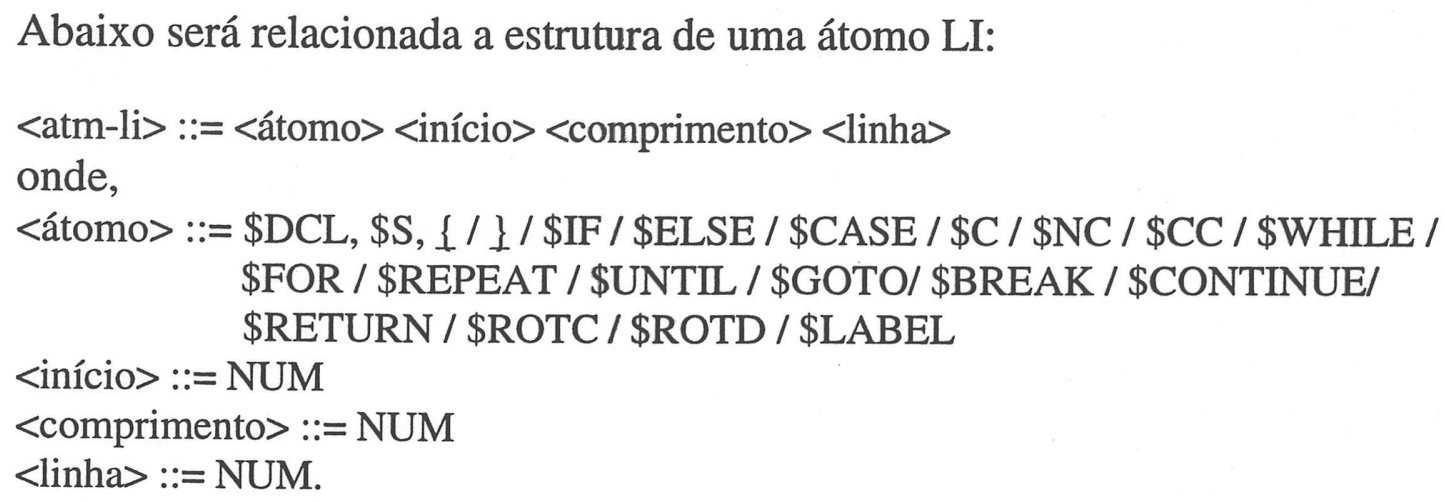

Os terminais descritos representam exatamente a mesma sequência de caracteres indicada pelos próprios terminais, com exceção de \$S, \$C, \$NC, NUM e LABEL. Estes terminais indicam:

- \$S a seqüência de caracteres $\$ S n$;

- \$C a seqüência $\$ C(n) n ;\left(" n " N^{*}\right)$

- NUM um elemento de N*;

- LABEL uma sequiência qualquer de caracteres, que é literalmente um rótulo do programa fonte.

Como ilustração, o seguinte exemplo escrito em PASCAL:

boolean $a, b, c$;

Poderia ser mapeado para a LI como:

$\begin{array}{llll}\$ D C L & 150 & 14 & 10\end{array}$

\section{A.1.1 - Comandos Seqüenciais}

Os comandos de programas fontes que não afetam o fluxo de controle são chamados de comandos sequienciais ou comandos simples. Ao serem mapeados em comandos LI, estes comandos são sintetizados produzindo uma significativa compactação do código gerado.

A descrição de um comando seqüencial é a seguinte:

$<$ dcl $>::$ \$DCL $<$ início $><$ comprimento $><$ linha $>$ e

$<\mathrm{S}>::=\$ \mathrm{~S}<$ início $><$ comprimento $><$ linha $>$

Onde $<$ dcl $>$ denota uma declaração de variável e $<$ s $>$ uma computação; sendo que uma computação pode ser uma atribuição de valor a uma variável (através de uma expressão ou chamada de função), ou então somente uma chamada de procedimento. Como exemplo pode-se ter o seguinte comando escrito em linguagem C: 
$x=$ fopen ("arquivo.c."," $r ")$;

que pode ser mapeado como:

$\$ \$ S 01 \quad 1024 \quad 27 \quad 23$

Observa-se que \$S01 representa o primeiro comando seqüencial em um programa LI, ou seja, o número que aparece após os caracteres "\$S" e antes do átomo de início do comando indica a ordem em que o comando seqüêncial aparece no programa.

\section{A.1.2 - Comandos de Seleção}

Os comandos de seleção podem ser descritos como:

$<$ if $>::=<$ if_atm $><$ cond_atm $><$ statement_1 $>$ / $<$ if_atm $><$ cond_atm $><$ statement_1 $>$ $<$ else_atm $><$ statement_2 $>$

onde,

$<$ if_atm $>::=\$$ IF $<$ início $><$ comprimento $><$ linha $>$ $<$ cond_atm $>::=\$ C<$ inicio $><$ comprimento $><$ linha $>$ $<$ else_atm $>::=\$ E L S E<$ início $><$ comprimento $><$ linha $>$ <statement_i> é o não-terminal que denota todos os possíveis comandos da LI, agrupados ou não.

Como exemplo pode ser analisado o seguinte comando escrito em MODULA-2:

if $j<>0$ then $k:=k / j$; else writeln('error: division by zero');

Mapeando este comando para a LI, pode-se ter:

\begin{tabular}{|c|c|c|}
\hline$\$ I F$ & 1031 & 2 \\
\hline$\$ C(1) 11034$ & 4 & 10 \\
\hline$\$ S 1$ & 1039 & 7 \\
\hline$\$ E L S E 1048$ & 4 & 10 \\
\hline$\$ S 2$ & 1053 & 36 \\
\hline
\end{tabular}

Os números que aparecem em \$C(1)1 indicam, respectivamente, o número de predicados que possui a condição e a ordem de aparição no programa. Os delimitadores de bloco " $\{$ " e " $\}$ " foram incorporados à LI com a intenção de acabar com as possíveis ambigüidades que poderiam existir geradas pelos encadeamentos de IFs (com e sem ELSE). 


\section{A.1.3 - Comandos de Seleção Múltipla}

Um comando de seleção múltipla pode ser representado da seguinte forma:

$<$ case $>::=$

$<$ case_atm $><$ case_cond_atm $>\{\{(<$ rotc_atm $>/<$ rotd_atm $>)\{<$ statement $>\}\}\}$

onde

$<$ case_atm $>::=\$$ CASE $<$ início $><$ comprimento $><$ linha $>$

$<$ case_cond_atm $>::=\$ C C<$ início $><$ comprimento $><$ linha $>$

$<$ rotc_atm $>::=\$$ ROTC $<$ início $><$ comprimento $><$ linha $>$

$<$ rotd_atm $>::=\$$ ROTD $<$ início $><$ comprimento $><$ linha $>$

O não-terminal <case_atm> representa o átomo que inicia o comando de seleção múltipla; <case_cond_atm> representa a condição do comando; e <rotc_atm> representa os possíveis rótulos para as sequências de comandos indicados por <statement>. O não-terminal <rotd_atm> representa o rótulo para a sequência de comandos a ser executada quando a condição não combina com nenhum rótulo $<$ rotc_atm>.

A semântica do comando acima é equivalente ao comando switch da linguagem $\mathrm{C}$, ou seja, a execução começa no rótulo que ocorreu a combinação e executa os comandos desse rótulo mais os comandos dos rótulos que o seguem, a menos que seja encontrado um comando válido de desvio incondicional. O comando break, por exemplo, causa a imediata saída do comando de seleção múltipla para o comando que o segue imediatamente. Como exemplo, podemos utilizar o trecho de programa escrito em Ada:

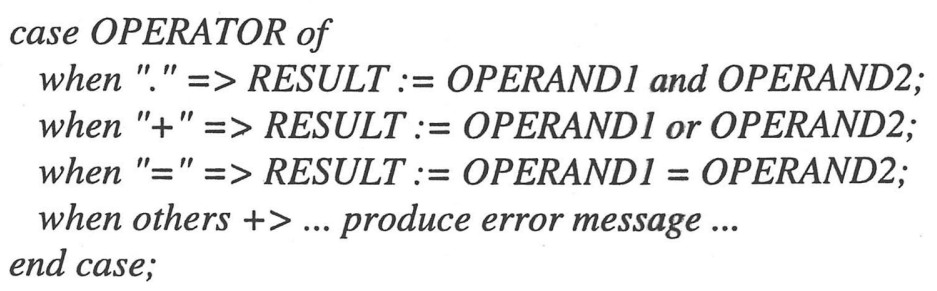

Um exemplo do mapeamento desse conjunto de comandos para a LI pode ser: 


$\begin{array}{llll}\text { \$CASE } & 1001 & 4 & 5 \\ \text { \$CC } & 1006 & 8 & 5 \\ \text { \{ } & 1015 & 2 & 5 \\ \text { \$ROTC 1020 } & 11 & 6 & \\ \text { \$S1 } & 1032 & 32 & 6 \\ \text { \$BREAK } & 0 & 0 & 0 \\ \text { \$ROTC 1067 } & 11 & 7 & \\ \text { \$S2 } & 1079 & 31 & 7 \\ \text { \$BREAK } & 0 & 0 & 0 \\ \text { \$ROTC } & 1113 & 11 & 8 \\ \text { \$S3 } & 1125 & 30 & 8 \\ \text { \$BREAK } & 0 & 0 & 0 \\ \text { \$ROTD 1158 } & 14 & 9 & \\ \text { \$S4 } & 1173 & 29 & 9 \\ \text { \} } & 1203 & 9 & 10\end{array}$

Nota-se que foram acrescentados \$BREAKs no trecho em LI para que seja mantida a mesma semântica do comando case da linguagem Ada. Os identificadores de início do átomo, comprimento e linha são iguais a 0 para identificar que não existe nenhuma correspondência direta com o código fonte.

\section{A.1.4 - Comandos de Repetição}

A LI fornece comandos de repetição tanto para um número fixo de iterações, quanto para as que dependedam de alguma condição.

Para um número fixo de repetições, a LI possui um comando semelhante ao for das linguagens estilo ALGOL. Este comando apresenta a seguinte definição:

$<$ for $>::=<$ for_atm $><$ s $1><$ cond_for_atm $><$ s $2><$ statement $>$

onde,

$<$ for_atm $>::=\$ F O R<$ início $><$ comprimento $><$ linha $>$

$<$ cond_for_atm $>::=\$ C<$ início $><$ comprimento $><$ linha $>$.

Os não-terminais <for_atm>, <s1>, <cond_for_atm> e <s2> indicam respectivamente o comando for da LI, a iniciação da variável de controle do for, a condição de parada e o comando seqüencial que altera as variáveis de controle a cada iteração do for; <statement> representa o corpo do comando. Como exemplo típico, pode ser analisado o seguinte trecho de programa escrito em linguagem $\mathrm{C}$ :

$$
\begin{gathered}
\text { for }(i=0 ; i<\text { nfiles } ; i++) \\
\text { fstat }[i]=0 ;
\end{gathered}
$$


O respectivo mapeamento para a LI pode ser feito da seguinte maneira:

\begin{tabular}{|c|c|c|}
\hline$\$ F O R$ & 110 & 3 \\
\hline$\$ S 1$ & 115 & 4 \\
\hline$\$ C(1) 1120$ & 11 & 6 \\
\hline$\$ S 2$ & 132 & 3 \\
\hline$\$ 53$ & 144 & 13 \\
\hline
\end{tabular}

Os comandos de iteração cujo número de repetições é dirigido por uma condição, são também equivalentes aos tradicionais while e repeat-until das linguagens do estilo ALGOL. O while da LI é definido como:

$<$ while $>::=<$ while_atm $><$ cond_while_atm. $<$ statement $>$

onde,

$<$ while_atm $>::=\$$ WHILE $<$ início $><$ comprimento $><$ linha $>$

$<$ while_atm $>::=\$ C<$ início $><$ comprimento $><$ linha $>$

$<$ while_atm> indica o comando while, <cond_while_atm> a condição de parada $\mathrm{e}<$ statement $>$ o corpo do while.

$\mathrm{O}$ repeat-until da LI é definido como:

$<$ repeat_until $>::=<$ repeat_atm $><$ statement $><$ until_atm $><$ cond_until_atm $>$

onde,

$<$ repeat_atm $>::=\$$ REPEAT $<$ início $><$ comprimento $><$ linha $>$

$<$ until_atm $>::=\$$ UNTIL <início $><$ comprimento $><$ linha $>$

$<$ cond_until_atm $>::=(\$ C / \$ N C)<$ início $><$ comprimento $><$ linha $>$

$<$ repeat_atm > indica o início do comando repeat-until; <statement $>$ o corpo do comando; <until_atm> indica o fim do comando; e <cond_until_atm> representa a condição de término. A semântica desse comando é equivalente aos comandos das linguagens estilo ALGOL. Nota-se que a condição de término é composta por \$C ou $\$ N C$. Isso ocorre porque na maioria das linguagens do estilo ALGOL, o corpo do repeat-until é executado até que uma dada condição seja satisfeita; porém, em algumas linguagens, como é o caso da linguagem $\mathrm{C}$, o comando repeat-until é executado enquanto a condição permanecer verdadeira. Devido a esse fato, a condição desse comando pode ser $\$ \mathrm{C}$ se for o primeiro caso (estando indicado aí um repeat-until tradicional), ou $\$ \mathrm{NC}$ se for o segundo caso (e nessa situação tem-se a repetição do laço até ser negada a condição).

Pode ser analisado o seguinte exemplo escrito em linguagem C:

$$
\begin{aligned}
& \text { do }\{ \\
& s[i++]=n \% 10+0^{\prime}{ }^{\prime} ; \\
& \text { \} while }((n /=10)>0) \text {; }
\end{aligned}
$$


Esse trecho de programa pode ser mapeado para a LI da seguinte forma:

$\begin{array}{llll}\text { \$REPEAT } & 1000 & 2 & 12 \\ \{ & 1004 & 1 & 12 \\ \text { \$S1 } & 1011 & 21 & 13 \\ \} & 1027 & 1 & 14 \\ \text { \$UNTIL } & 1029 & 5 & 14 \\ \text { \$NC(1)1 } & 1035 & 12 & 14\end{array}$

\section{A.1.5 - Comandos de Desvio Incondicional}

Os comandos de desvios incondicionais provocam a mudança de fluxo de execução em um programa. A LI possui um comando de transferência incondicional irrestrito do tipo goto e comandos de transferência incondicional controlada; estes últimos três têm utilização limitada a algumas situações e seu efeito é bem previsível.

O comando goto da LI é definido como:

$<$ goto $>::=<$ goto_atm $><$ label_atm $>$

onde,

$<$ goto_atm $>::=\$$ GOTO <início $><$ comprimento $><$ linha $>$

$<$ label_atm $>::=\$ L A B E L<$ início $><$ comprimento $><$ linha $>$

<goto_atm> representa o comando goto da LI e <label_atm> representa o rótulo para onde deve ser dirigido o fluxo de execução quando encontrado o comando goto.

Os comandos de desvio incondicional controlados da LI são:

$<$ break $>::=\$$ BREAK $<$ início $><$ comprimento $><$ linha $>$

$<$ continue $>::=\$$ CONTINUE $<$ início $><$ comprimento $><$ linha $>$

$<$ return $>::=\$$ RETURN $<$ início $><$ comprimento $><$ linha $>$

Esses comandos de transferência incondicional foram inspirados nos seus homônimos da linguagem $C$, e possuem efeitos idênticos.

\section{A.1.6 - Comandos Compostos e Programas}

Até aqui foram descritos os comandos individuais da LI, entretanto, para concluir sua definição, falta ainda descrever como se agrupam comandos na LI e como esses comandos são organizados em um programa.

O não-terminal <statement> representa um único comando da LI ou um agrupamento deles entre chaves.

Os programas em LI são definidos da seguinte maneira: 
$<$ program $>::=\{(<\mathrm{dcl}>/<\mathrm{s}>)\}<$ statement $>$.

Para exemplificar, será mostrado o resultados do mapeamento de um programa para a LI escrito em linguagem C.

Nesse mapeamento serão suprimidos os campos de início do átomo no programa fonte e tamanho do átomo, ficando apenas o campo de número da linha no programa fonte.

\section{Programa em C:}

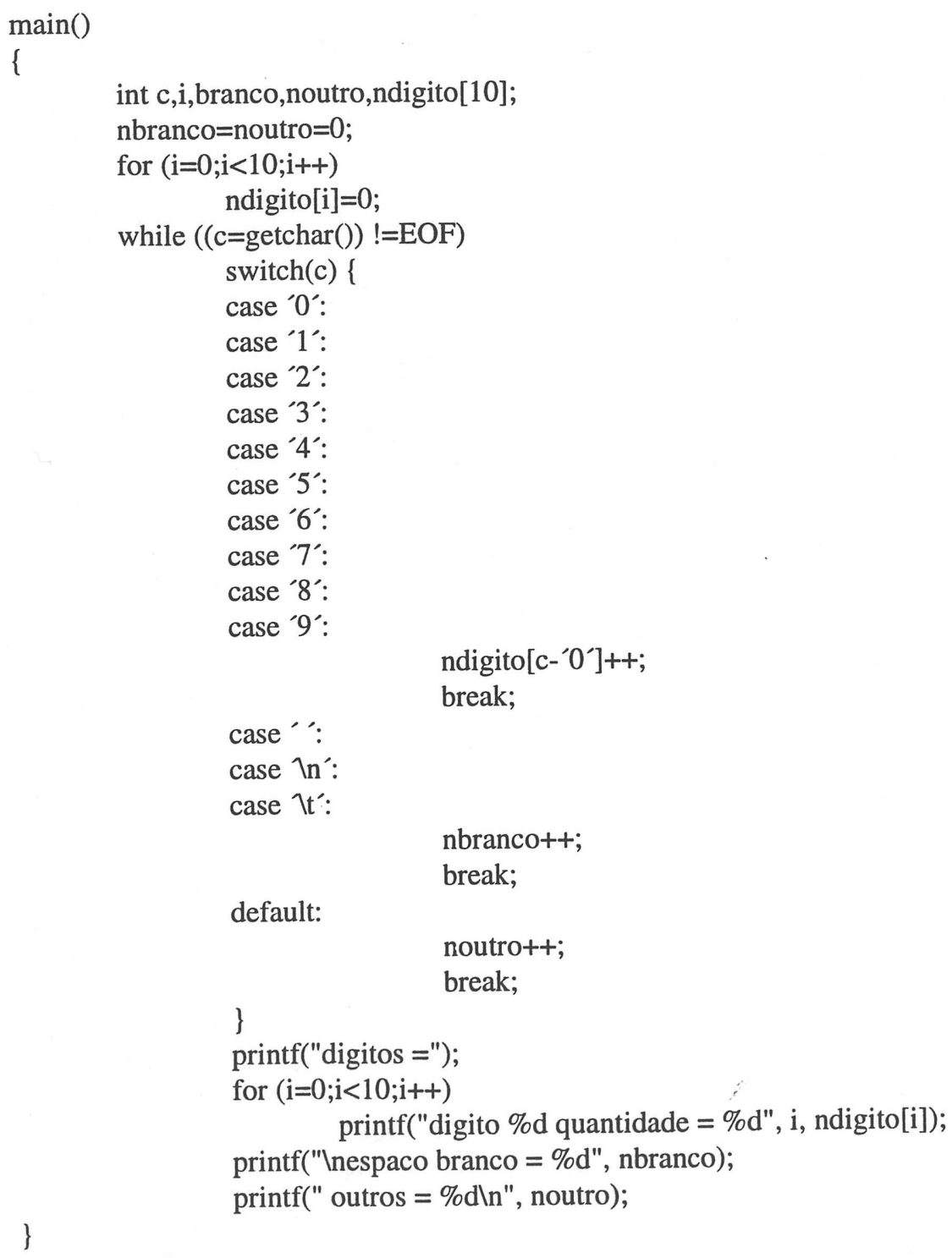


O mapeamento para a LI seria:

\begin{tabular}{|c|c|}
\hline \$DCL & 1 \\
\hline & 2 \\
\hline \$DCL & 3 \\
\hline$\$ S 1$ & 4 \\
\hline \$FOR & 5 \\
\hline$\$$ S2 & 5 \\
\hline$\$ C(01) 15$ & \\
\hline$\$$ S3 & 5 \\
\hline$\$ S 4$ & \\
\hline \$WHILE & \\
\hline$\$ \mathrm{C}(01) 2$ & \\
\hline \$CASE & 8 \\
\hline$\$ C C$ & 8 \\
\hline\{ & 8 \\
\hline \$ROTC & \\
\hline \$ROTC & 1 \\
\hline \$ROTC & 1 \\
\hline \$ROTC & 1 \\
\hline \$ROTC & 1 \\
\hline \$ROTC & 1 \\
\hline \$ROTC & 1 \\
\hline \$ROTC & 1 \\
\hline \$ROTC & 1 \\
\hline \$ROTC & 1 \\
\hline \$S5 & 1 \\
\hline \$BREAK & 2 \\
\hline \$ROTC & 2 \\
\hline \$ROTC & 2 \\
\hline \$ROTC & 2. \\
\hline \$S6 & 2 \\
\hline \$BREAK & 2 \\
\hline \$ROTD & 2 \\
\hline$\$$ \$77 & 2 \\
\hline \$BREAK & 2 \\
\hline$\}$ & 2 \\
\hline \$S8 & 3 \\
\hline$\$ F O R$ & 3 \\
\hline$\$$ S9 & 3 \\
\hline$\$ C(01) 331$ & \\
\hline$\$ S 10$ & \\
\hline$\$ S 11$ & \\
\hline$\$ S 12$ & \\
\hline l & \\
\hline
\end{tabular}

Os átomos de início e comprimento não são mostrados por motivos de praticidade. 


\section{APÊNDICE B - CÓDIGOS-FONTES DO MAPEAMENTO C++ / LI++}

Nesse Apêndice serão listados trechos dos princiapis programas escritos em linguagem $\mathrm{C}$ e as principais tabelas utilizadas para a realização do mapeamento de programas $\mathrm{C}++$ para a $\mathrm{LI}++$. Todos os programas e tabelas utilizados para a realização do mapeamento encontram-se no disquete anexo. Por se tratarem das principais tabelas empregadas no mapeamento para a LI++ serão destacadas: tabela sintática da linguagem $\mathrm{C}++$ (tabsin.c++), tabela de palavras-chaves da linguagem $\mathrm{C}++$ (tabchave.c++) e tabela de transições léxicas (tabtrans.c++). Por reportarem diversos aspectos fundamentais para a implementação do mapeamento de programas $\mathrm{C}++$ para a LI++ serão destacados trechos dos seguintes programas: rotsem.c, parserg2.c, li.c e gravali.c. Ainda, o disquete anexo contém diversos programas e trechos de programas $\mathrm{C}++$ e seus respectivos mapeamentos para a LI++.

\section{B.1 - Principais Tabelas}

O arquivo tabsin.c++ basicamente é uma carta sintática da linguagem $\mathrm{C}++$, onde cada linha representa uma construção da linguagem. Os ítens léxicos são lidos do arquivo fonte (código $\mathrm{C}++$ a ser mapeado) e devem ser "casados" com alguma estrutura definida nessa tabela; após este "casamento" uma rotina semântica associada à construção poderá ser executada. As rotinas semânticas são representadas pelos números (de 1 a 85 ) presentes neste arquivo, e cada número lido representa a execução de uma rotina. Algumas dessas rotinas irão gravar os átomos da LI++ no arquivo que contenha o mapeamento (arquivo com extensão .li++). No arquivo tabsin.c++ as separações dos símbolos por vírgulas (,) representam que seus "casamentos" são optativos, devendo haver o "casamento" com apenas um dos símbolos dentre os diversas possíveis; os símbolos colocados entre colchetes ([]) são opcionais podendo ou não serem "casados" com o item léxico lido. O ponto (.) representa o final de uma símbolo, enquanto que o caracter asterisco (*) representa que será "casado" qualquer item léxico lido. Dessa forma, o exemplo da Figura B.1 abaixo representa que esta estrutura somente será "casada" quando o item léxico "private" for lido; após este item léxico ser lido, deverá ser lido o item léxico “:” (que somente não será o item léxico lido quando o programa estiver sintaticamente incorreto, o que provocaria erro de compilação do programa C++ a ser mapeado). Após o item léxico ":" ser "casado", a rotina semântica 48 (descrita na rotina rot48_sem() do arquivo rotsem.c) será executada. 


$$
\text { E_priv = 'private' ':' } 48 \text {. }
$$

FIGURA B.1 - EXEMPLO DE CONSTRUÇÃO DE ESTRUTURA DO ARQUIVO TABSIN.C++

No arquivo tabchave.c++ está contida a lista de palavras-chaves da linguagem $\mathrm{C}++$ em ordem alfabética. Estas palavras-chaves serão "casadas" com os ítens léxicos descritos no arquivo tabsin.c++. No exemplo da Figura B.1, "private" é uma palavrachave da linguagem $\mathrm{C}++$ pois consta no arquivo tabchave.c++. Qualquer item léxico lido que não conste da tabela de palavras-chaves será considerado como um identificador um como um tipo definido pelo usuário, tal como nome de classe ou de uma estrutura de dados. Os ítens léxicos lidos que sejam tipos definidos pelo usuário em um programa $\mathrm{C}++$ são armazenados em uma tabela em memória e são casados com a estrutura 'TIPDEF' da tabela sintática. Um nome de variável será "casado" com a estrutura 'IDENT', enquanto que uma constante será "casada" com a estrutura 'CONSTANT'.

Finalmente, o arquivo tabtrans.c++ representa a tabela de transições do autômato finito descrito na Seção 4.2.2 e basicamente representa a forma como os ítens léxicos serão formados. Esses ítens léxicos, então, deverão ser "casados" com as estruturas da tabela sintática e levarão à execução das rotinas semânticas associadas.

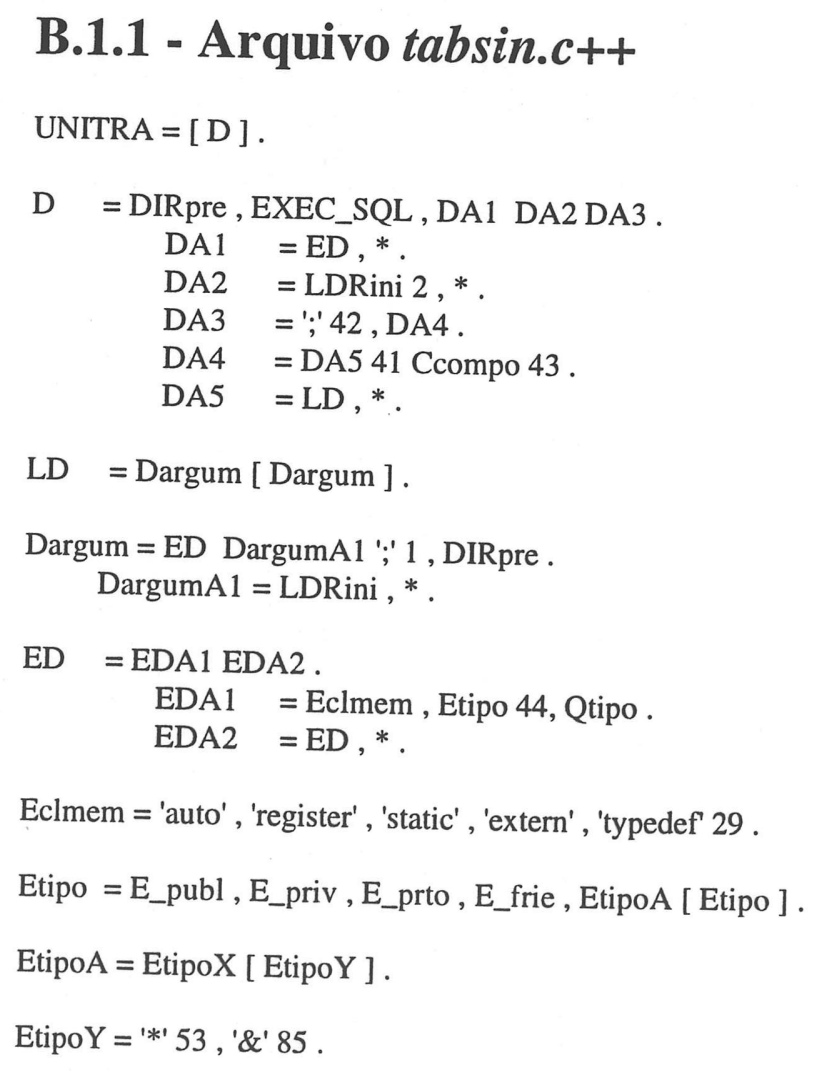


EtipoX = 'void' 51 , 'char' 51 , 'short' 51 , 'inline' , 'int' 51 , 'long' 51 , 'float' 51 , 'double' 51, 'signed' 51 , 'unsigned' 51 , 'virtual' , 'static' , E_tpdf , Ees_un, Eenume , Etempl, 'const'.

E_prto = 'protected' ':' 49 .

E_priv = 'private' ':' 48 .

E_publ = 'public' ':' 47 .

E_frie $=$ 'friend' [ E_fcla ] E_ftip .

E_fcla $=$ 'class' .

E_ftip = 'TIPDEF' 58, 'IDENT' 58 .

Etempl = 'template' ' $<$ ' 'class' Etmpx '>' 60 .

Etmpx = 'IDENT' 76, 'TIPDEF' 76 .

E_tpdf = 'TIPDEF' 57 [E_tpdy ].

E_tpdy $=$ E_tpdx, E_tpdz .

E_tpdz = 'IDENT' '(' E_tpdk ')' .

E_tpdk = 'CONSTANT' [ ',' E_tpdk ].

E_tpdx = ':' 64 ':' [ ' $\sim$ ' 62 ] E_idtp '(' 46 [ 'const' ] [ DRdireAC ] ')' 50 .

DRdire AC = DRdireAD [ ',' DRdireAC ] .

DRdire $A D=D R d i r e A F$, DRdire AE .

DRdireAF = 'TIPDEF' 51 'IDENT' .

DRdireAE = Etipo [ 'IDENT' ] .

E_idtp = 'TIPDEF' 52 , 'IDENT' 52, DRdireA9 75 .

Edest = ' $\sim 62$ 'TIPDEF' 77 '(' ')' 83 [ ';' 82 ] .

Qtipo = 'const' , 'volatile' .

Ees_un $=$ Ees_unA0, Ees_unA4 .

Ees_unA0 = Ees_unA1 Ees_unA2 Ees_unA3 .

Ees_unA1 = 'struct' 70 , 'union' , Ees_unA4 .

Ees_unA2 = 'IDENT' 69 [ ':' Ees_unA6] ]

Ees_unA6 $=$ Ees_tipx Ees_unA5 [ ',' Ees_unA6 ] .

Ees_unA5 = 'TIPDEF' , 'IDENT' .

Ees_unA3 = '\{' LDestr ' \}' ';' $63, *$.

Ees_unA4 = 'class' 'IDENT' 45 [ Ees_hera ] Ees_corp .

Ees_hera $=$ ':' Ees_tipa .

Ees_tipa $=$ [ 'virtual' $]$ [ Ees_tipx ] Ees_unA7 [ ',' Ees_tipa ].

Ees_unA7 = 'TIPDEF' 61 , 'IDENT' 61 .

Ees_tipx = 'public' , 'protected' , 'private' .

Ees_corp $=$ ' $\{$ ' 55 [ Ees_cond ] ' $\}$ ' ';' 56 .

Ees_cond = Ees_coyy , Ees_coaa , Ees_covv .

Ees_coaa $=$ Ees_coxx $[$ Ees_cond $]$.

Ees_coxx $=$ Etipo, $\mathrm{D}$.

Ees_coyy $=$ Ees_cokk [ Ees_cond ] .

Ees_cokk = 'TIPDEF' 67 ['\&'] '(' 46 [ Ees_cobb ] ')' 68 ';' 50 .

Ees_cobb $=$ Ees_cocc $[\mathrm{D}]$.

Ees_cocc = Etipo [ 'IDENT' ] [ ',' Ees_cocc ] .

Ees_covv $=$ Edest $[$ Ees_cond $]$. 
LDestr $=$ Destru $[$ Destru $]$.

LDRini = DRinic [ ',' LDRiniA1 DRinic ] .

LDRiniA1 $=\mathrm{ED}, *$.

DRinic $=$ DR DRinicA 1

DRinicA1 = '=' inicir , *.

Destru = LQE LDRest ';' .

LQE = LQEA1 LQEA2

LQEA1 = Etipo, Qtipo .

LQEA2 = LQEA1, * .

LDRest $=$ DRestr [ ',' DRestr ]

DRestr $=$ DRestrA1 DRestrA2

DRestrA1 = DR, *

DRestrA2 = ':' EXcons , *

Eenume = 'enum' EenumeA1 EenumeA2 .

EenumeA1 = 'IDENT' , * .

EenumeA2 = '\{' Lenume ' $\}$ ' , .

Lenume $=$ enumer [ ',' enumer $]$

enumer $=$ 'IDENT' enumerA1 .

enumerAl $={ }^{\prime}=$ ' EXcons , *

DR = DRA1 DRdire.

DRA1 = aponta,$*$.

DRdire = DRdireA0 [ DRdireA2 $]$.

DRdireA0 = DRdireA1 , DRdireA9

DRdireA1 = 'IDENT' 39 DRdireAA , '(' 40 DR ')' .

DRdire AA $=$ [ DRdireAB ] .

DRdireAB = ':' ':' 'IDENT" 52 '(' 46 [ DRdireAC ] ')' 50 .

DRdireA2 = '[' DRdireA3 ']' , '(' 46 DRdireA4 ')' 40 .

DRdireA3 = EXcons , *

DRdireA4 = Lparam , Lident,$*$.

DRdireA9 = 'operator' 72 DRoper 74 .

DRoper = '==' 73 , '!=' 73, '<' 73 , '>' 73, '<=' 73, '>=' 73, '<<' 73 , '>>' 73 , '=' 73.

aponta $=$ '*' apontaA1 apontaA2.

apontaA $1=$ LQtipo,$*$.

apontaA2 $=$ aponta,$*$.

LQtipo = Qtipo [ Qtipo ] .

Lparam = Dparam [ ',' LparamA1 ] .

LparamA1 = '...' , Dparam

Dparam $=$ ED DRabst.

Lident $=$ 'IDENT' LidentA1 LidentA2

LidentA1 $=[$ [', 'IDENT' $]$

LidentA2 = ';' , * . 


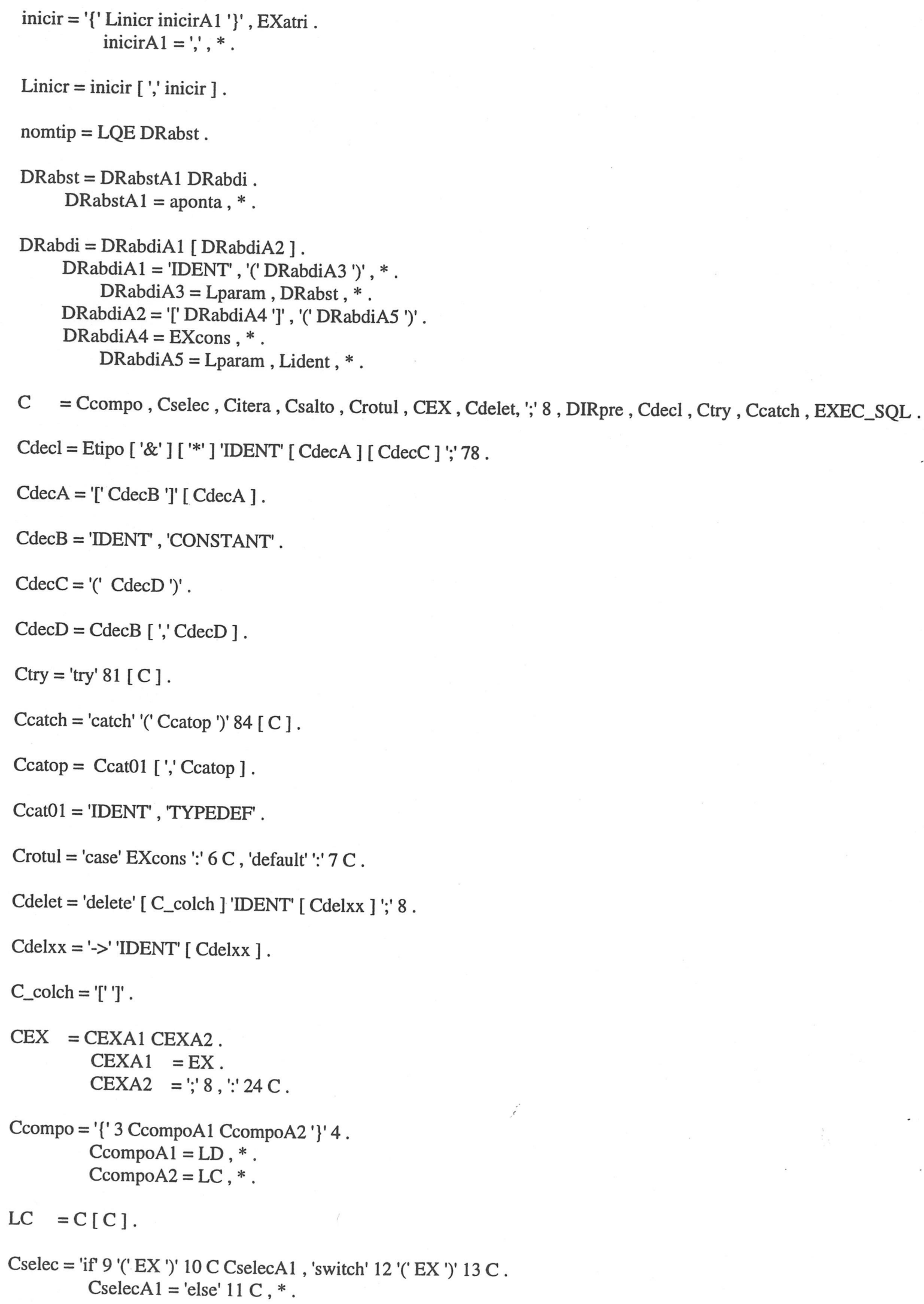




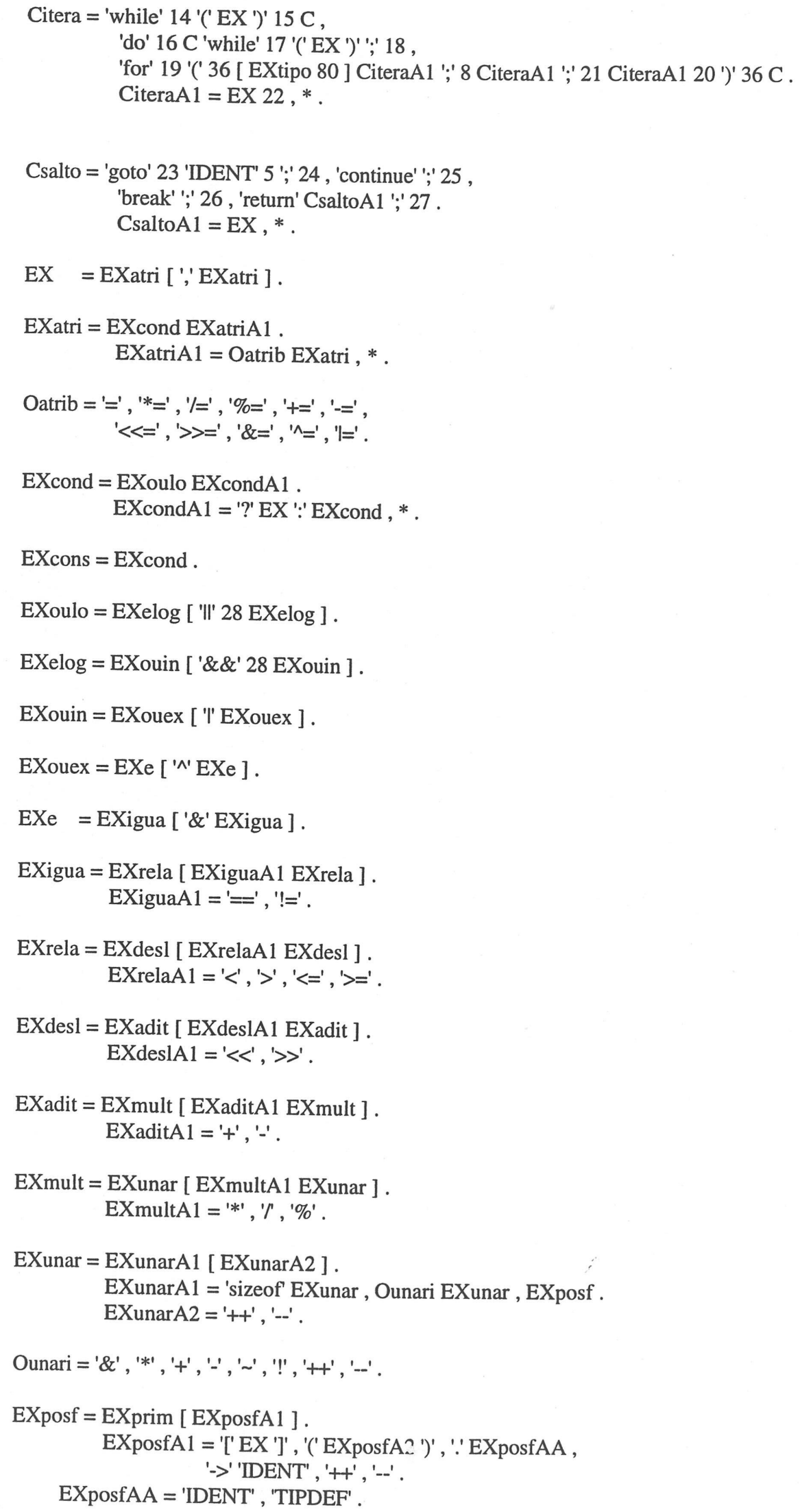




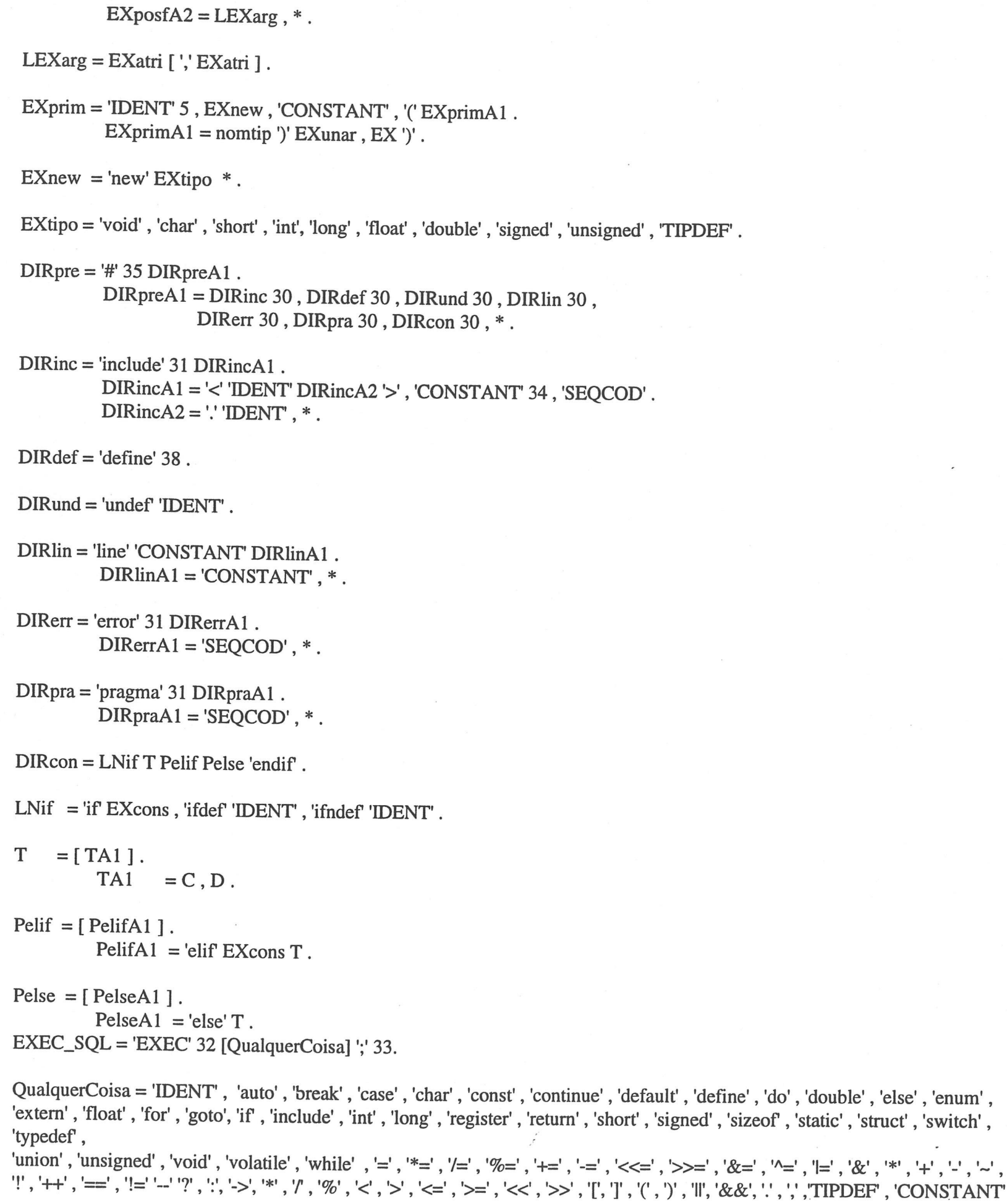

QualquerCoisa = 'IDENT', 'auto' , 'break' , 'case' , 'char' , 'const' , 'continue' , 'default' , 'define' , 'do' , 'double' , 'else' , 'enum' , 'extern' , 'float' , 'for' , 'goto', 'if' , 'include', 'int', 'long' , 'register' , 'return' , 'short' , 'signed' , 'sizeof' , 'static' , 'struct' , 'switch' , 'typedef',

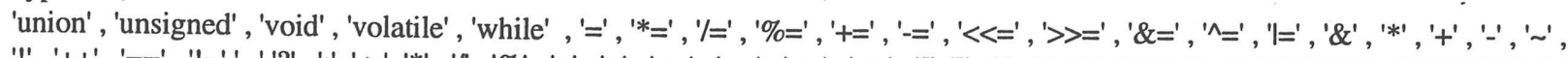

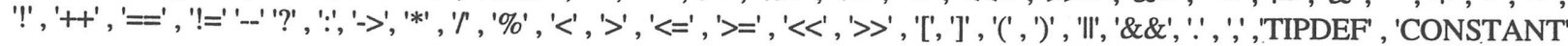




\section{B.1.2 - Arquivo tabchave.c++}

\section{EXEC 290}

auto 300

break 305

case 310

catch 313

char 315

class 317

const 320

continue 325

default 330

define 335

delete 337

do 340

double 345

else 355

enum 360

extern 370

float 375

for 380

friend 383

goto 385

if 390

include 405

inline 407

int 410

long 420

new 421

operator 422

private 423

protected 425

public 427

register 430

return 435

short 440

signed 445

sizeof 450

static 455

struct 460

switch 465

template 467

try 468

typedef 470

union 480

unsigned 485

virtual 487

void 490

volatile 495

while 500

\section{B.1.3 - Arquivo tabtrans.c++}

"i Inlttbirlf" 0000

"cd_l\&?^.।"/\%! In|t|b|r|f|'@_=|*\&+" 0100091000

"id" 011121

"i." 04131 
"il'" 05134

"il"" 08142

"il_" 011150

"i/" 015152

"i\%" 017157

"i!" 018159

"i-" 019161

"i=" 020165

"il" 021167

"i>" 028187

"i\&" 023172

"i+" 030175

"i<" 024178

"i^" 026183

"i?" 027185

"i*" 022170

"i@" 033096

"id" 11221

"il" 12225

"cdl." 1100061000

"i." 13229

"il+-" 22225

"i." 23229

"id" 21221

"cdl" 2100061000

"il" 32225

"id" 31221

"id" 41221

"i." 432295

"cd." 4100081000

"cl'll" 55234

"il'" 5100051000

"ill" 56237

"il'" 65234

"cl'" 67239

"ill" 76237

"clll'" 77239

"il'" 7100051000

"cl"II" 88242

"ill" 89245

"il"" 8100051000

"il"" 98242

"cl"" 910247

"ill" 109245

"il"" 10100051000

"cl"II" 1010247

"ild_" 1111250

"cdl_" 11100031000

"c*=" 15100081000

"i*" 1516055

"i=" 15100071000

"c*" 1616055

"i*" 1631092

"c=" 17100081000

"i=" 17100071000

"c=" 18100081000

"i=" 18100071000

"i=" 19100071000 
"i-" 19100071000 "i>" 19100071000 "c-=" 19100081000 "i=" 20100071000 "c=" 20100081000 "il" 2121267 "i=" 21100071000 "cl=" 21100081000 "c=" 22100081000 "i=" 22100071000 "c=\&" 23100081000 "i=" 23100071000 "i\&" 23100071000 "c+=" 30100081000 "i=" 30100071000 "i+" 30100071000 "i=" 24100071000 "c<=" 24100081000 "i<" 2425281

"c=" 25100081000 "i=" 25100071000 "i=" 26100071000 "c=" 26100081000 "i:" 27100071000 "c:" 27100081000 "i=" 28100071000 "c>=" 28100081000 "i>" 2829290 "i=" 29100071000 "c=" 29100081000 "c/*" 3116055 "i/" 31000 "i*" 3131092 "i." 32100071000 "i \t" 3333096 "il"" 338142

"ilr" 33000 "i<" 33100091000 "il"' 335134 "id" 331121

"c |t|r|"l'd<" 33341103 "clrIV" 34342103 "ilr" 341000101000 "i/" 34362109 "ill" 34352107

"i \t" 35352107

"c \t" 35342103 "c*" 36342103 "i*" 361000111000 "cdl" 3100061000 


\section{B.2 - Trechos de Códigos-Fontes}

O arquivo rotsem.c descreve todas as rotinas semânticas que deverão ser executadas para formarem o arquivo que contenha o mapeamento para a LI++ (tal arquivo terá o mesmo nome do programa $\mathrm{C}++$, porém sua extensão será .lì++). Algumas rotinas semânticas são mantidas inalteradas com relação ao mapeamento de programas C para a LI [CHA91], outras foram alteradas ou criadas. Um exemplo de rotina semântica encontra-se na Figura B.2 e mostra a rotina semântica 48 que faz a gravação do átomo \$PRIVATE. Esta gravação é feita chamando-se a rotina grava_li() descrita no arquivo gravali.c.

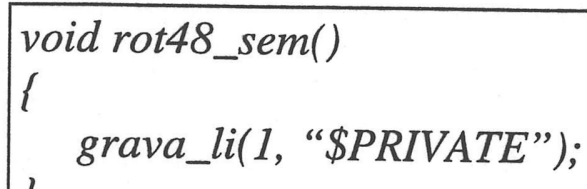

FIGURA B.2 - ROTINA SEMÂNTICA 48

No arquivo parserg2.c encontra-se a rotina responsável pela realização do parser. Esta rotina é a responsável pela realização da análise sintática do programa fonte, pela leitura do número da rotina semântica a ser executada (leitura feita do arquivo tabsin.c++) e pela chamada à rotina semântica através da rotina rotsem(rsem), onde rsem armazena o número da rotina semântica a ser executada.

Finalmente, o arquivo li.c é o responsável pela definição dos principais arquivos a serem utilizados no mapeamento, como por exemplo o arquivo de tabela de sobrecarga de métodos, o arquivo que conterá o mapeamento para a LI++, além das principais estruturas de dados a serem utilizadas na realização do mapeamento $\mathrm{C}++$ / $\mathrm{LI++}$.

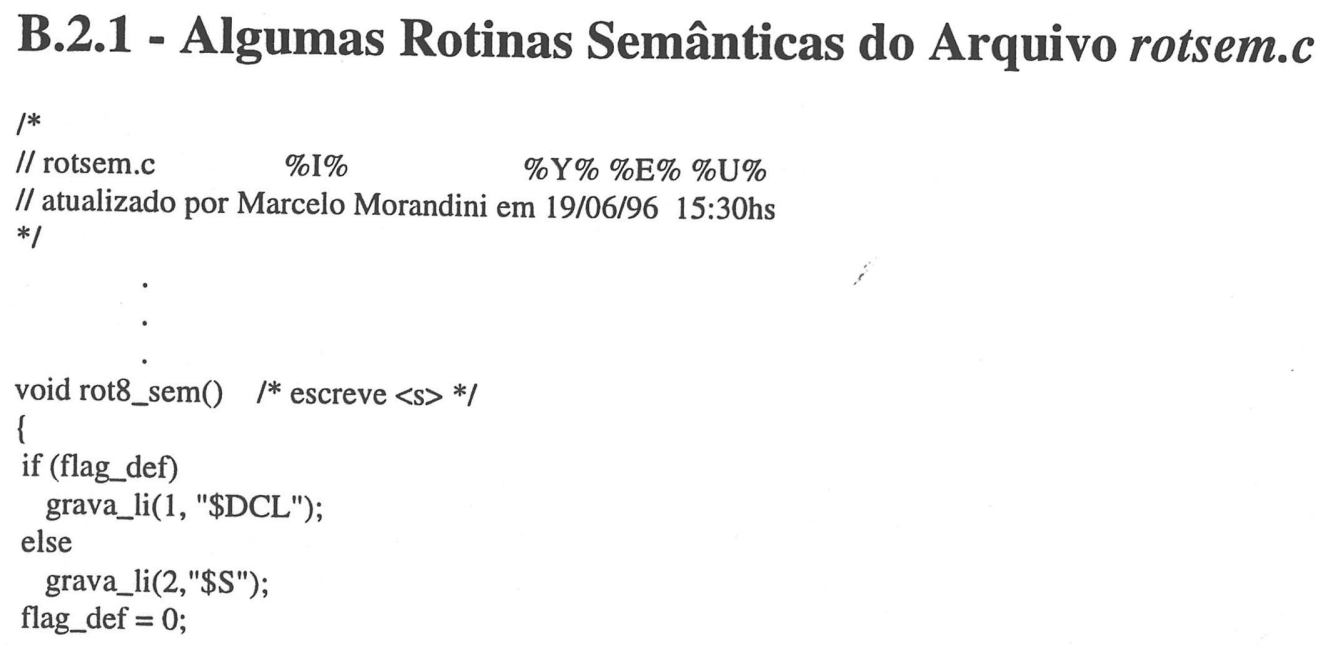




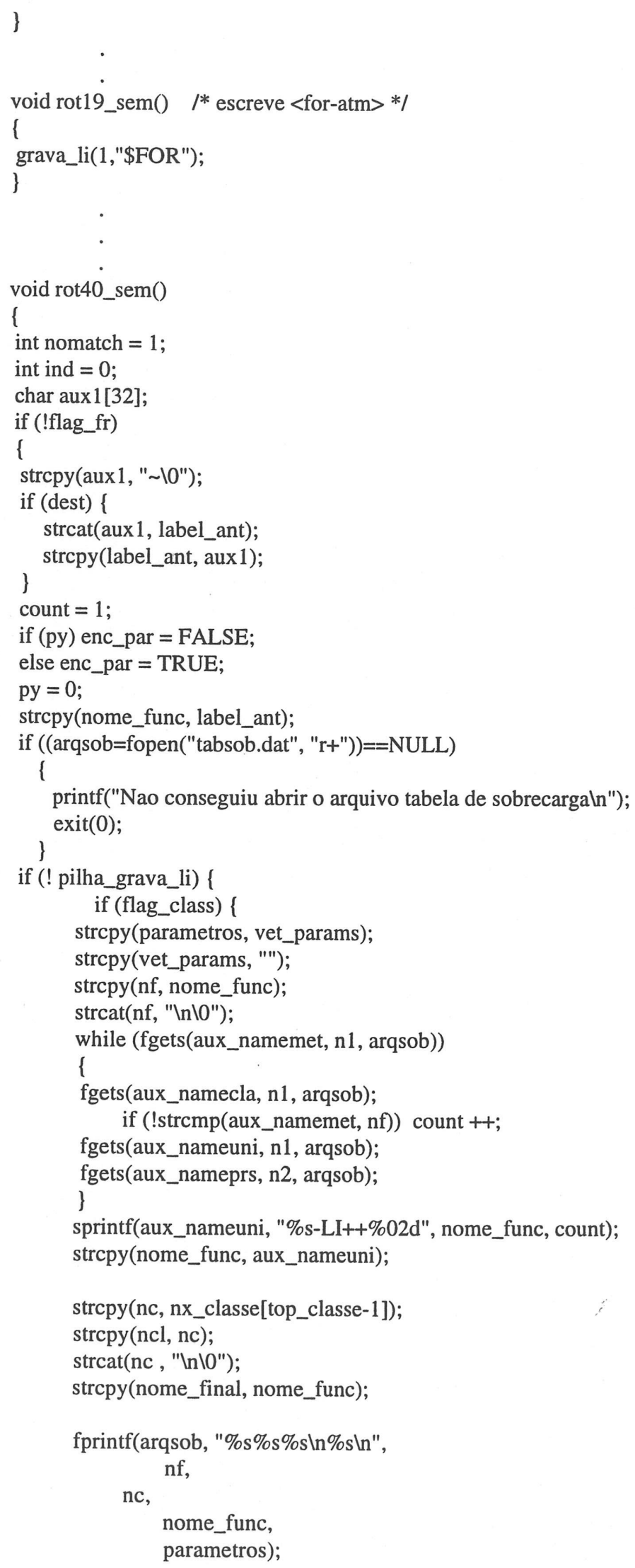


strcpy(vet_params, "'");

if $(! \mathrm{pk})\{\mathrm{pk}=1$;

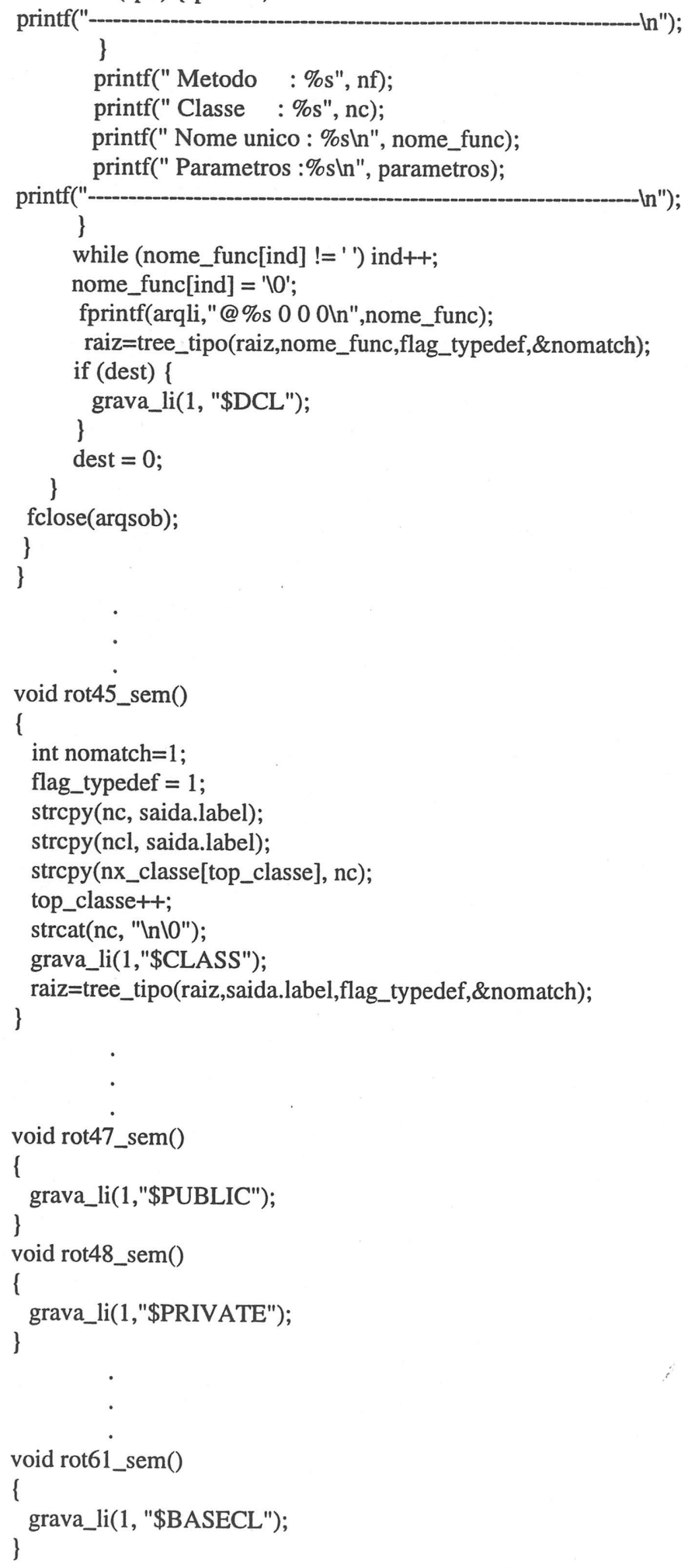




\section{B.2.2 - Rotina gravali()}

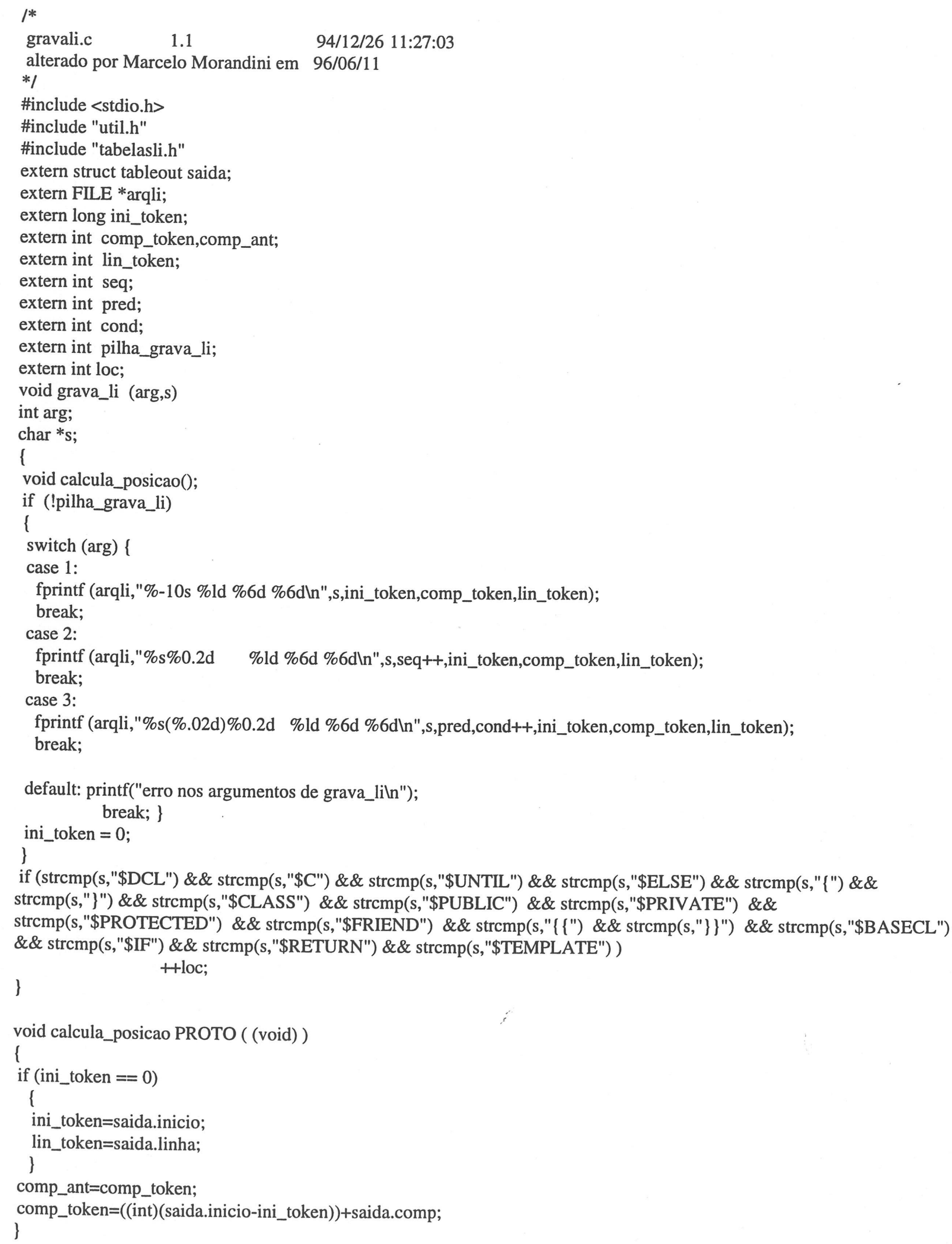




\section{B.2.3 - Rotinas parser() e rotsem()}

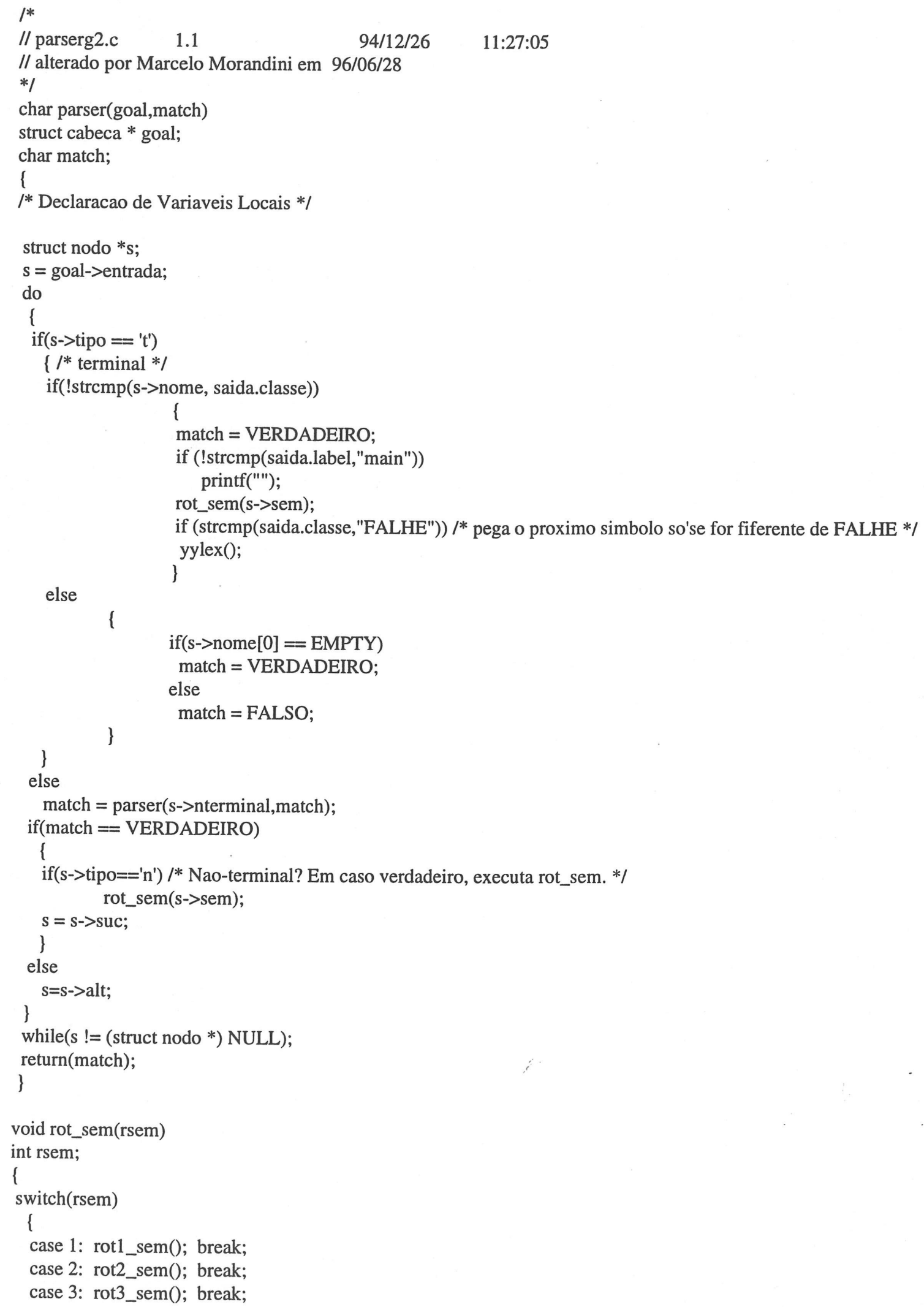


case 4: rot4_sem(); break; case 5: rot5_sem(); break; case 6: rot6_sem(); break; case 7: rot7_sem(); break; case 8: rot8_sem(); break; case 9: rot9_sem(); break; case 10: rot10_sem(); break; case 11: rot11_sem(); break; case 12: rot12_sem(); break; case 13: rot13_sem(); break; case 14: rot14_sem(); break; case 15: rot15_sem(); break; case 16: rot16_sem(); break; case 17: rot17_sem(); break; case 18: rot18_sem(); break; case 19: rot19_sem(); break; case 20: rot20_sem(); break; case 21: rot21_sem(); break; case 22: rot22_sem(); break; case 23: rot23_sem(); break; case 24: rot24_sem(); break; case 25: rot25_sem(); break; case 26: rot26_sem(); break; case 27: rot27_sem(); break; case 28: rot28_sem(); break; case 29: rot29_sem(); break; case 30: rot30_sem(); break; case 31: rot31_sem(); break; case 32: rot32_sem(); break; case 33: rot33_sem(); break; case 34: rot34_sem(); break; case 35: rot35_sem(); break; case 36: rot36_sem(); break; case 37: rot37_sem(); break; case 38: rot38_sem(); break; case 39: rot39_sem(); break; case 40: rot40_sem(); break; case 41: rot41_sem(); break; case 42: rot42_sem(); break; case 43: rot43_sem(); break; case 44: rot44_sem(); break; case 45: rot45_sem(); break; case 46: rot46_sem(); break; case 47: rot47_sem(); break; case 48: rot48_sem(); break; case 49: rot49_sem(); break; case 50: rot50_sem(); break; case 51: rot51_sem(); break; case 52: rot52_sem(); break; case 53: rot53_sem(); break; case 55: rot55_sem(); break; case 56: rot56_sem(); break; case 57: rot57_sem(); break; case 58: rot58_sem(); break; case 59: rot59_sem(); break; case 60: rot60_sem(); break; case 61: rot61_sem(); break; case 62: rot62_sem(); break; 
case 63: rot63_sem(); break; case 64: rot64_sem(); break; case 66: rot66_sem(); break; case 67: rot67_sem(); break; case 68: rot68_sem(); break case 69: rot69_sem(); break; case 70: rot70_sem(); break; case 71: rot71_sem(); break; case 72: rot72_sem(); break; case 73: rot73_sem(); break; case 74: rot74_sem(); break; case 75: rot75_sem(); break; case 76: rot76_sem(); break; case 77: rot77_sem(); break; case 78: rot73_sem(); break; case 79: rot74_sem(); break; case 80: rot75_sem(); break; case 81: rot76_sem(); break; case 82: rot77_sem(); break; case 83: rot76_sem(); break; case 84: rot84_sem(); break; case 85: rot85_sem(); break; default: ;

\} return

\}

\title{
B.2.4 - Trecho do Arquivo li.c
}

\author{
/* \\ // li.c $\quad \% \mathrm{I} \% \quad \% \mathrm{Y} \% \quad \% \mathrm{E} \% \% \mathrm{U} \%$ \\ alterado por Marcelo Morandini em 96/07/02 \\ $*$ / \\ \#include "util.h" \\ \#include $<$ stdio.h $>$ \\ \#include $<$ stdlib.h> \\ \#include <string.h> \\ \#include "util.h" \\ \#include "tabelasli.h" /* definicoes de tipo para o A.L. (analisador lexico) */ \\ \#include "hparserg.h" /* definicoes de tipos para o parser (analisador sinta- \\ tico */ \\ \#include "hli.h" $\quad$ /* Declaracoes e definicoes de tipos e funcoes do pro- \\ grama "li" */ \\ /* DECLARACAO DE VARIAVEIS GLOBAIS */ \\ /* Variavel utilizada para controle da depuracao */ \\ /* debug_level $=0 ; * /$ \\ /* Variaveis globais utilizadas para armazenar as tabelas do analisador \\ lexico e contrlar o A.L. */ \\ int linha $=1 ; \quad / *$ linha do caracter lido pelo A.L. $* /$ \\ long offset $=0 ; \quad / *$ posicao do caracter lido pelo A.L. */ \\ FILE *arqli; $\quad / *$ arquivo que contem programa LI */ \\ FILE *arqsob; $\quad / *$ arquivo que contem a tabela de sobrecarga $* /$ \\ int pred $=1 ; \quad / *$ numero de predicados de uma expressao condicional $* /$ \\ int seq $=1 ; \quad / *$ numero do comando sequencial $* /$ \\ int cond $=1 ; \quad / *$ numero da expressao condicional $* /$ \\ int flag_vazio $=1 ; \quad / *$ indica ausencia de expressao no comando if $* /$ \\ long ini_token $=0 ; \quad / *$ posicao do 10. token do item sintatico $* /$
}


int comp_token $=0 ; \quad / *$ comprimento do item sintatico $* /$

int comp_ant; $\quad / *$ comprimento do item sintatico anterior */

int lin_token $=0 ; \quad / *$ linha do 1o.token do item sintatico $* /$

char label[TAMLEX]; /* contem label de tranf.incondicional */

struct no_tipdef *raiz; /* raiz da arvore binaria de tipos definidos */

int flag_typedef $=0 ; \quad / *$ indica ocorrencia de definicao de tipo */

int pilha_grava_li $=0 ; / *$ indica a nao gravacao do comando $\mathrm{LI} * /$

int flag_dirpre $=0 ; \quad / *$ indica diretiva de pre-processamento $* /$

int tamanho; $\quad / *$ contem tamanho do identificador *l

char ch; $\quad / *$ ultimo caracter lido */

struct tableout saida; $/ *$ ultimo token lido */

int n_chaves; $\quad / *$ contem o numero de palavras chaves $* /$

int ntablex; $\quad / *$ contem o numero de trasicoes do A.L. */

struct table *tab_trans[NLEX]; /* armazena a tabela de transicao */

struct chave *tab_chave[NCHAVE]; /* armazena tabela de palavras chaves */

/* Variaveis Globais utilizadas para criacao do grafo sintatico na

memoria *I

struct cabeca * list, * hdeclaration,

struct cabeca * sentinel;

* hstatement, * hexpression;

struct cabeca $*$ h;

struct nodo *p;

struct nter sym;

struct tableout saida;

/* Variaveis Globais que apontam para Arqivos */

FILE * arqfonte;

FILE * arqparser;

FILE * arqsob;

/* Variavel com o caminho das tabelas */

char * lipath;

/* Variavel com o caminho dos arquivos de include */

char *includes[MAXINC];

/* numero de linhas de codigo sem comentario */

int last_loc $=0,10 c=0$;

I* lista de resultados $* /$

GOTOLABEL * lista_resul=(GOTOLABEL *) NULL ; 